\title{
Organization and composition of apicomplexan kinetochores reveal plasticity in chromosome segregation across parasite modes of division
}

Lorenzo Brusini ${ }^{*}$, Nicolas Dos Santos Pacheco, Dominique Soldati-Favre \& Mathieu Brochet*

5 Department of Microbiology and Molecular Medicine, Faculty of Medicine, University of Geneva, Switzerland

*Correspondence: lorenzo.brusini@unige.ch and mathieu.brochet@unige.ch

\section{Summary}

Kinetochores are multiprotein assemblies directing mitotic spindle attachment and chromosome

10 segregation. In apicomplexan parasites, most known kinetochore components and associated regulators are apparently missing, suggesting a minimal structure with limited control over chromosome segregation. In this study, we use interactomics combined with deep homology searches to identify six divergent eukaryotic components, in addition to a set of eight apicomplexan kinetochore proteins (AKiTs) that bear no detectable sequence similarity to known proteins. The nanoscale organization of the

15 apicomplexan kinetochore includes four subdomains, each displaying different evolutionary rates across the phylum. Functional analyses confirm AKiTs are essential for mitosis and reveal architectures parallel to biorientation at metaphase. Furthermore, we identify a homolog of MAD1 at the apicomplexan kinetochore, suggesting conserved spindle assembly checkpoint signaling. Finally, we show unexpected plasticity in kinetochore composition and segregation throughout the parasite lifecycle, indicating diverse requirements to maintain fidelity of chromosome segregation across apicomplexan modes of division.

Keywords: kinetochore, mitosis, spindle assembly checkpoint, Apicomplexa, Plasmodium, Toxoplasma, evolutionary cell biology 


\section{Introduction}

25 Eukaryotic chromosome segregation occurs along a spindle formed of microtubules. In order to segregate DNA into daughter cells, the spindle must interact with chromosomes. Most organisms achieve specificity in this interaction by binding to chromosomal sites called centromeres, distinguished by the histone H3 variant centromere protein A (CENP-A) (Fukagawa \& Earnshaw, 2014; Westhorpe \& Straight, 2013). Onto the centromere assembles the kinetochore, a hierarchical assembly and molecular

30 machine that links chromosomes to the spindle (Cheeseman \& Desai, 2008). The kinetochore is formed of multiple compartments, each composed of different protein complexes. In animals and fungi, the constitutive centromere-associated network (CCAN) forms the inner kinetochore (Foltz et al., 2006), whilst at the onset of mitosis the outer kinetochore KMN network is recruited, formed of KNL1, MIS12 and NDC80/NUF2 complexes (Cheeseman et al., 2006). It is the KMN network that serves as both the

35 microtubule-binding component of the kinetochore and a landing pad for either SKA or DASH complexes that strengthen microtubule attachment in animals and fungi (Helgeson et al., 2018; Lampert et al., 2010, 2013), respectively, in addition to the Spindle Assembly Checkpoint (SAC), a surveillance system that ensures faithful chromosome segregation (Varma \& Salmon, 2012). Fidelity requires that sister chromatids are bi-oriented at metaphase, kinetochores bound by microtubules emanating from opposing

40 spindle poles (Lampson \& Cheeseman, 2011). Bi-orientation is achieved through an error-correction process mediated by a "wait" signal from the Mitotic Checkpoint Complex (MCC) (Musacchio \& Salmon, 2007). This diffusable inhibitor prevents precocious activation of the anaphase-promoting complex/cyclosome (APC/C). Upon bi-orientation, the APC/C is liberated and initiates the cascade that culminates in cleavage of cohesin and segregation of sister chromatids into daughter cells.

45 The conservation of kinetochore proteins varies greatly across organisms (Tromer et al., 2019; van Hooff et al., 2017). Whilst components of the KMN network have been detected in all studied eukaryotes (D'Archivio \& Wickstead, 2017), most components of the CCAN are not readily identified (Przewloka et al., 2007; Westermann \& Schleiffer, 2013). In particular, members of the phylum Apicomplexa lack almost all clearly identifiable components of the CCAN and SAC as described in animals and fungi, in

50 addition to the majority of the KMN network (D'Archivio \& Wickstead, 2017; van Hooff et al., 2017). This phylum groups a large number of obligate intracellular parasites of considerable medical and veterinary relevance, including the malaria parasite Plasmodium and Toxoplasma, causative agent for toxoplasmosis. In addition to a widespread lack of "canonical" kinetochore components, apicomplexan parasites appear to divide quite differently to most of the cells of their hosts (Francia \& Striepen, 2014;

55 Gerald et al., 2011; Striepen et al., 2007). Flexibility in the scale of amplification and modes of division, often adapting to the size and environment of different host cells and tissues, suggests division checkpoints in these parasites may be very different to those described in animals (Alvarez \& Suvorova, 2017; D. E. Arnot \& Gull, 1998). Asexual forms of $T$. gondii divide in tissues of the mammalian intermediate host by a mechanism termed endodyogeny, producing two daughter cells from a single 60 round of fission within the mother cell, which is consumed as the offspring mature. Uncoupling nuclear 
divisions from the cell cycle allows certain apicomplexan parasites to successively replicate their genome in the absence of cytokinesis. In red blood cells, Plasmodium species divide by schizogony to produce multi-nucleated coenocytes. Similar division modes occur in liver hepatocytes and beneath the mosquito midgut basal lamina (Aly et al., 2009). Karyokinesis is asynchronous, resulting in non-

65 geometric expansion. Following the last round of division, daughter cells either bud internally or from the surface of the mother plasmalemma (David E Arnot et al., 2011; Speer \& Dubey, 2001). During host-tovector transmission, a mosquito blood meal induces capacitated male gametocytes (microgametocytes) to produce a polyploid nucleus that then divides to form 8 haploid gametes. Microgametes fertilize female gametes (macrogametes), shortly followed by meiosis and differentiation producing characteristic banana-shaped ookinetes.

Three organelles contain DNA in apicomplexan parasites. In addition to the mitochondrion, the nucleus and a remnant of secondary symbiosis called the apicoplast each have their own distinct segregation cycle. The nucleus undergoes a largely closed mitosis, an intranuclear spindle nucleates from spindle poles and links centromeres to kinetochore-like structures maintained close to the nuclear periphery

75 (David E Arnot et al., 2011; Dubremetz, 1973; Farrell \& Gubbels, 2014; Zeeshan et al., 2020). Current evidence suggests apicomplexan parasites segregate their chromosomes with fidelity (Iwanaga et al., 2010, 2012). However, in light of the apparent absence of most kinetochore and checkpoint proteins, how these organisms maintain faithful chromosome segregation remains unknown.

Here, we identify the repertoires of four biochemically stable compartments of apicomplexan

80 kinetochores that include at least six divergent eukaryotic components, in addition to a set of eight for which we did not detect similarity with known proteins. Despite sequence disparity, these apicomplexan kinetochore proteins (AKiTs) display modes of chromosome segregation parallel to metaphase to anaphase transition and include a homolog of the spindle assembly checkpoint protein MAD1, that we show also localizes to apicomplexan kinetochores. Furthermore, we show plasticity in kinetochore

85 composition and segregation between lifecycle stages, suggestive of unique requirements and regulation between modes of division. Finally, AKiTs are required for proper parasite proliferation, identifying the apicomplexan kinetochore as an excellent therapeutic candidate for selective inhibition. 


\section{Results}

\section{NUF2 and SKA2 assemble at the nuclear periphery in the malaria parasite}

90 Whilst the majority of kinetochore components are not clearly detectable in apicomplexan parasites (van Hooff et al., 2017), centromeric proteins (CENPs) A, C and E, the SKA component SKA2 and the NDC80/NUF2 complex are present (Fig. S1A), and NDC80/HEC1 has recently been described as a bona fide kinetochore marker in the rodent malarial parasite Plasmodium berghei (Zeeshan et al., 2020). To understand whether apicomplexan kinetochore proteins bear similarities to their animal and fungal cousins, we took a pan-localization approach by tagging $P$. berghei components related to different animal kinetochore sub-complexes. Candidate proteins were localized throughout asexual blood-stages and during sexual development that occurs upon host-to-mosquito transmission. Immunoblotting confirmed expression of fusion proteins with the expected mobility (Fig. S1B \& C) corresponding to the integration of the coding sequence for $\mathrm{mScarlet}-\mathrm{I}(\mathrm{mSc})$ or $\mathrm{mNeonGreen}$ fused with triple hemagglutinin-

100 epitope tag (mNG-3xHA) at the C-terminus of endogenous NUF2 (PBANKA_0414300) and SKA2 (PBANKA_0405800), respectively.

In agreement with previously localized Plasmodium centromeres (Perrin et al., 2021; Verma \& Surolia, 2014) and kinetochores (Zeeshan et al., 2020), location and movement of NUF2 and SKA2 fusion proteins was restricted to the nuclear periphery during progression of asexual blood-stage divisions

105 (Fig. 1A). Protein levels were undetectable in $\mathrm{G} 1$ phase in intraerythrocytic ring stages and first seen in the nucleus at the onset of DNA replication during trophozoite development, then accumulating as punctate foci concomitant with chromosome segregation and formation of daughter nuclei. Signal for both NUF2 and SKA2 fusions reduced to below detectability in fully budded schizonts.

Unexpectedly, SKA2 and NUF2 fusion proteins showed very different localizations during Plasmodium 110 sexual development (Fig. 1B). Whilst "rod-like bridges", as previously described for components of the NDC80/NUF2 complex (Zeeshan et al., 2020), were visible for NUF2 during the three rounds of DNA replication and mitosis that occur at microgametogenesis - SKA2 signal at kinetochore foci was not clearly detectable. A similar dichotomy was seen post-activation of the macrogametocyte, NUF2 spreading sparingly across the cytoplasm compared to SKA2 residing primarily in the nucleus. However,

115 24-hours post-fertilization and meiosis, both fusion proteins united as four distinct nuclear foci in fully developed banana-shaped ookinetes. Time-course fluorescence microscopy further revealed a hierarchical assembly for SKA2 and NUF2 throughout ookinete development (Fig. 1C). SKA2 first accumulated as a single focus at the nuclear periphery between $1-2$ hours post-fertilization, which duplicated and migrated to opposing nuclear poles between 2 - 4 hours. On the other hand, NUF2 foci

120 were first seen between 4-6 hours of development, at which point SKA2 signal stretched along a spindlelike structure connecting opposing poles. Signal from both fusion proteins stretched along the central spindle by $8-10$ hours. Two successive rounds of asynchronous duplication and migration ultimately formed four puncta at the nuclear periphery by 12 hours of development. 
bioRxiv preprint doi: https://doi.org/10.1101/2021.11.03.466924; this version posted November 3, 2021. The copyright holder for this preprint (which was not certified by peer review) is the author/funder, who has granted bioRxiv a license to display the preprint in perpetuity. It is made available under aCC-BY-NC 4.0 International license.

125 we applied Ultrastructure Expansion Microscopy (U-ExM) during ookinete development to increase resolution (Bertiaux et al., 2021; Gambarotto et al., 2019). Pan-proteomic (NHS-ester), subpellicular/spindle microtubule and nuclear stainings identified parasite shape and ultrastructure were well preserved following expansion of between $4.5-4.6 \mathrm{x}$, and, alongside the localizations of tagged SKA2 and NUF2, resolved kinetochores along the Plasmodium meiotic spindle (Fig. 1D). SKA2 130 accumulated primarily at three locations during meiosis in ookinetes. Consistent with our live fluorescence microscopy, the majority of SKA2 localized to spindle poles, closely associated to $\mathrm{y}$-tubulin. However, upon formation of a diamond shaped bipolar spindle, additional foci were obvious both along the spindle and at the spindle equator, co-localizing with NUF2 at kinetochores.

These observations indicate that SKA2 localizes to both the spindle and kinetochores in the malaria

135 parasite, similarly to SKA components in animals (Hanisch et al., 2006).

\section{NUF2 and SKA2 form distinct biochemically stable complexes in Plasmodium}

In models, the NDC80 complex is formed of two heterodimers: NDC80 with NUF2, and SPC24 with SPC25. The metazoan SKA complex forms an independent three component complex: SKA1 - 3 (Hanisch et al., 2006; Welburn et al., 2009). In P. berghei, a divergent SPC24 ortholog was recently

140 identified as the final missing component of the NDC80/NUF2 complex, copurifying with NDC80 following affinity purification from chemically cross-linked cells (Zeeshan et al., 2020). To identify interacting proteins for NUF2 and SKA2, we used affinity purification of 3xHA tagged proteins from synchronized mitotic gametocytes under non cross-linking conditions and combined label-free semiquantitative mass spectrometry (Trudgian et al., 2011) to estimate enrichment of interacting 145 proteins. We compared samples by integrated spectral intensities (Fig. 1E), reasoning that if NDC80 and SKA2 assemble independent kinetochore complexes in Plasmodium, stable interactors would be evident in each pull down relative to one another. Supporting the notion of a biochemically stable NDC80/NUF2 complex, NDC80, SPC25 and recently described SPC24 were the most abundant proteins co-purifying with NUF2 relative to SKA2. Similarly, the abundance of two hypothetical proteins of unknown function

150 (Gene IDs: PBANKA_0812300 and PBANKA_1362400) strongly suggests the presence of a three SKA component complex in the malaria parasite. To validate our biochemical approach, we tagged each SKA2 interacting protein with mNG-3xHA, alongside the marker for the outer kinetochore NUF2-mSc (Supp. Fig. S1D \& E). Both tagged PBANKA_0812300 and PBANKA_1362400 proteins showed localization patterns highly similar to that of SKA2 in the malaria parasite (Fig. $1 F \& S 1 F \& G$ ),

155 colocalizing with NUF2 during asexual blood stage divisions, not detected during microgametogenesis and present as four nuclear foci in fully developed ookinetes.

\section{SKA components are required for timely kinetochore segregation in Toxoplasma}

The SKA complex has been identified in all 5 - 6 eukaryotic supergroups (He et al., 2014; van Hooff et al., 2017). Despite this broad distribution, the complex is not ubiquitously detected in functionally 160 characterized kinetochores, such as in fungi and kinetoplastids. Missing individual SKA components 
occurs more sporadically, suggesting spurious absences may result from lack of detection due to sequence divergence rather than genuine gene loss. Consistent with the notion of rapidly changing kinetochore protein sequences in apicomplexan parasites, BlastP of PBANKA_0812300 and PBANKA_1362400 in the "closely related" apicomplexan parasite, Toxoplasma gondii, yielded no

165 significant hits (e-value $\geq 0.1$ ). In an attempt to more sensitively identify SKA2-interacting proteins, we employed a similar iterative Hidden Markov Model (HMM) profiling strategy to as described (Koreny et al., 2021). Briefly, HMMs constructed from clear homologs of PBANKA_0812300 and PBANKA_1362400 were used as search queries across an in-house database of HMMs generated from homologous groups of alveolate protein sequences (Table S1), however with the addition of manually curated HMMs 170 generated from previously classified eukaryotic kinetochore sequences (van Hooff et al., 2017). Significant hits were concatenated iteratively to generate pan-apicomplexan-kinetochore HMMs (Supplementary HMM files). In contrast to BlastP, reciprocal HMM profile-profile comparisons identified significant similarity in both SKA2-interacting proteins, with pan-SKA HMMs as highest scoring hits (Fig. S2A \& B). In particular, we reunited PBANKA_0812300 with SKA1 and PBANKA_1362400 with

175 SKA3, and detected corresponding putative homologs in T. gondii TGME49_264960 and TGME49_289790, respectively.

To validate our bioinformatic approach and investigate the conservation of SKA proteins across the Apicomplexa, TgSKA1 and TgSKA2 were fused at the endogenous locus with a mini auxin-induced degron (mAID) including triple hemagglutinin (3xHA)-epitope tag, to localize and deplete protein upon 180 addition of auxin (IAA) (Fig. S2F \& G). Supporting identification of divergent apicomplexan SKA components, tagged TgSKA1 and TgSKA2 showed clear kinetochore localization during T. gondii tachyzoite division (Fig. 2A). Co-staining DNA and the mitotic spindle revealed SKA proteins were undetectable in $\mathrm{G} 1$ phase, but accumulated centrally upon a bipolar spindle during mitosis. Foci segregated at anaphase into budding daughter cells, returning to below detectability at cytokinesis. Co185 expression with the kinetochore component NUF2 fused to a double Ty epitope tag (NUF2-2xTy), in addition to co-staining with antibodies directed to various intracellular organelles, revealed T. gondii SKA proteins are substantially displaced distal to the apicoplast and centrosome compared to kinetochores (Fig. S2E).

U-ExM further resolved TgSKA2 at the tachyzoite mitotic spindle (Fig. 2B). In tachyzoites, the spindle 190 nucleates from a region closely associated to a centriolar microtubule organizing center. A short prometaphase spindle elongates to form a bipolar opposing diamond at metaphase, prior to collapse into a tight central bundle and segregation into budding daughter caps. In contrast to NUF2, which localized to the spindle at prometaphase, SKA2 signal was only detected upon diamond-spindle formation. As in the malaria parasite, the majority of SKA2 signal localized to the spindle poles, along the spindle and at

195 the midzone.

Depletion of either TgSKA1 or TgSKA2 by IAA treatment led to a rapid and severe reduction of cell growth (Fig. S2F). Consistent with a role in nuclear chromosome segregation, vacuoles contained 
bioRxiv preprint doi: https://doi.org/10.1101/2021.11.03.466924; this version posted November 3, 2021. The copyright holder for this preprint (which was not certified by peer review) is the author/funder, who has granted bioRxiv a license to display the preprint in perpetuity. It is made available under aCC-BY-NC 4.0 International license.

accumulations of DNA with no associated daughter cell body 18 hours post-depletion (Fig. S2G). This defect was evident within the first round of mitosis 6 hours post-depletion, with an accumulation of parasites with monopolar and bipolar spindles and budding daughter caps (Fig. 2C). U-ExM revealed cells stalled during mitosis, with elongated mitotic spindles and misaligned and lagging kinetochores, not seen in non-induced and normal cells (Fig. 2D).

To investigate the hierarchy of outer kinetochore components in $T$. gondii, we looked at the recruitment and co-dependency of the NDC80/NUF2 complex component NUF2 relative to SKA1 or SKA2, in cells depleted for either protein (Fig. 2E \& F). Whilst neither SKA component was required for recruitment of NUF2 onto kinetochore foci (instead a surprising increase of NUF2 signal was seen post-SKA depletion), kinetochore assembly of SKA1 and SKA2 was abolished in mitotic tachyzoites depleted for NUF2.

Taken together, apicomplexan kinetochores require SKA components for proper mitosis and furthermore suggest that maintenance of the SKA complex at kinetochores is dependent on, and possibly downstream to, assembly of the NDC80/NUF2 complex.

\section{Apicomplexan Kinetochore protein 1 (AKiT1) is a component of the Plasmodium kinetochore}

The apparent absence of CCAN components outside of CENP-C, in addition to Mis12/KNL1 of the KMN network, questions what bridges the outer kinetochore to the centromere in apicomplexan parasites? NDC80 and SKA complexes appear to be biochemically distinct sets and affinity purification of NUF2 and

215 SKA2 from $P$. berghei gametocytes did not clearly enrich for additional candidates. To investigate the possibility of less stable inter-complex associations, we employed a proximity-based approach of affinity purification under conditions of formaldehyde cross-linking and compared spectral intensities to controls without cross-linking (Fig. 3A). In addition to components of the minichromosome maintenance (MCM) complex; MCM3 and MCM6, two proteins were most enriched upon crosslinking (green). One of these

220 proteins is a homolog of STU2 (PBANKA_1337500; Fig. S3A), a protein required for the correction of kinetochore-spindle attachment errors and bipolar spindle stability during chromosome bi-orientation (Miller et al., 2016, 2019). In contrast, a hypothetical protein of unknown function (PBANKA_0621300) bore no clear sequence similarity to known animal or fungal proteins, whilst orthologs were identified across apicomplexan genomes (Fig. S3B). In agreement with biochemical interaction, the tagged protein showed clear co-localization with NUF2 throughout asexual blood-stage divisions (Fig. 3B). However, in contrast to previously localized SKA components, foci were also seen across spindle bundles during microgametogenesis (Fig. $3 C \& S 3 C$ ). Furthermore, the identified protein accumulated as foci in the nuclei of female gametes prior to fertilization, suggesting kinetochore recruitment prior to outer kinetochore NDC80/NUF2 complex assembly. Given biochemical affinities, kinetochore localization and

230 conservation across apicomplexan organisms, we named the protein Apicomplexan Kinetochore protein 1 (AKiT1).

U-ExM of PbAKiT1 alongside spindle pole and kinetochore markers in asexual blood-stage cells revealed that centrosome migration and spindle elongation were accompanied by alignment of kinetochores at the spindle midzone (Fig. 3D), forming a structure reminiscent of the metaphase plate as 
235 described in animal cells. Interestingly, spindle length changed drastically between asexual and sexualstage cells (Fig. 3D - E \& S3D). During the first round of microgametocyte mitosis, PbAKiT1 localized along the spindle as pairs of kinetochore foci (Fig. 3F; mean distance apart $139 \mathrm{~nm} \pm 4 \mathrm{~nm}$ ). Kinetochores then fired asynchronously to spindle poles (Fig. 3F \& S3D) - which may go some way to explaining the "rod-bridge" phenotype described in cells imaged at lower resolutions (Zeeshan et al.,

240 2020; and this study). Two additional rounds of mitosis ultimately produced kinetochore foci arranged into 6 - 8 cone-shaped clusters at the nuclear periphery. Crucially, additional staining of NUF2 identified sub-kinetochore localizations and a clear bipartite architecture in segregated kinetochore clusters, with the distinction of PbAKiT1 at the inner kinetochore relative to PbNUF2 at the outer kinetochore and centrin at the centrosome (Fig. 3G; mean distances of $103 \mathrm{~nm} \pm 3 \mathrm{~nm}$ and $422 \mathrm{~nm} \pm 7 \mathrm{~nm}$, respectively).

\section{AKiT1 is essential for kinetochore segregation and spindle function in Toxoplasma}

Previous genome-wide screenings have indicated that AKiT1 is essential for blood-stage proliferation in both human and rodent malaria parasites (Zhang et al., 2018). Furthermore, despite several attempts, we were unable to interrogate AKiT1 function using conditional approaches available in $P$. berghei, including no clear depletion of protein levels upon introduction of an auxin-inducible degradation motif

250 and no recovery of parasites following attempts to integrate blood-stage specific promoters. We therefore interrogated the AKiT1 ortholog in T. gondii by fusion with an auxin-inducible degron, speculating that kinetochore architectures with respect to AKiT1 may bear similarities across apicomplexan organisms. Supporting the notion of a conserved role for AKiT1 across the Apicomplexa, tagged protein showed kinetochore-like localizations during T. gondii asexual tachyzoite divisions (Fig. 4A), with clearer

255 association of foci with respect to TgNUF2 at kinetochores compared to the centrosome or apicoplast (Fig. S4A).

In contrast to the localization of TgSKA2, U-ExM revealed TgAKiT1 foci forming a cone around the tachyzoite prometaphase spindle (Fig. 4B). Little overlap was seen between TgAKiT1 and the majority of TgNUF2 signal at the spindle. This distinction exaggerated upon formation of the diamond spindle with

260 TgAKiT1 forming a striking metaphase pate, comparable to that seen during Plasmodium asexual bloodstage division, prior to segregation of foci at anaphase.

As with depletion of TgSKA components, reducing levels of TgAKiT1 (Fig. S4B \& C) led to a rapid and severe reduction of intracellular growth (Fig. S4D), producing vacuoles with abnormal accumulations of DNA 18 hours post-depletion (Fig. S4E). TgAKiT1 depletion primarily stalled cells progressing through

265 anaphase, with a greater increase in the number of cells with bipolar spindles (Fig. 4C), resulting in elongated mitotic spindles and aberrant kinetochore segregation (Fig. 4D).

Surprisingly, despite the striking centromere proximal localization of TgAKiT1 relative to TgNUF2, no clear reduction in TgNUF2 levels at the spindle were seen in tachyzoites depleted for TgAKiT1 relative to parental and non-induced controls (Fig. 4E). Similarly, levels of TgAKiT1 at kinetochores was not clearly

270 affected by depletion of TgNUF2 (Fig. 4F), suggesting neither protein is dependent on one another for assembly onto kinetochores. 
bioRxiv preprint doi: https://doi.org/10.1101/2021.11.03.466924; this version posted November 3, 2021. The copyright holder for this preprint (which was not certified by peer review) is the author/funder, who has granted bioRxiv a license to display the preprint in perpetuity. It is made available under aCC-BY-NC 4.0 International license.

\section{An AKiT complex bridges the outer kinetochore to the centromere}

In animals and fungi, kinetochores are composed of hierarchical assemblies totaling 50 - 100 proteins. Whilst exciting, the addition of AKiT1 increases our repertoire of validated apicomplexan kinetochore components to a mere order of magnitude less than in animal or fungal systems. Streamlining of redundant kinetochore composition is not uncommon in eukaryotes (Przewloka et al., 2007; Westermann \& Schleiffer, 2013). Furthermore, the frequency of gene loss compared to gain has been associated with transition to parasitism in the Apicomplexa (Mathur et al., 2019). It's quite possible few apicomplexan kinetochore proteins manage the roles of many in other organisms. However, neither the centromeric histone variant CENH3 nor SEA1 (a previously reported homolog of CENP-C (Perrin et al., 2021; Verma \& Surolia, 2014)) were identified in immunoprecipitates of NUF2 or SKA2, suggesting additional components may bridge the outer kinetochore to the centromere. To test whether PbAKiT1 interacts with centromeric proteins, we employed a similar proximity based approach and affinity purified protein, however with an additional limited cross-linking condition (D'Archivio \& Wickstead, 2017). Given that at least in animals the SPC24:SPC25 heterodimer forms a direct interaction with the CCAN, we additionally immunopurified PbSPC24 under the same conditions, to compare interactors (Fig. 5A). Further supporting the identification of a biochemically stable outer kinetochore complex, a clear reciprocal enrichment was seen for each component of NDC80/NUF2 across all immunoprecipitates of SPC24. Additionally, PbAKiT1 was enriched - albeit marginally - upon cross-linking, reinforcing a less stable

290 interaction between SPC24 and PbAKiT1 compared to SPC24 and other NDC80/NUF2 components. Two additional proteins of unknown function (Gene IDs: PBANKA_1243900, PBANKA_0522000) were enriched to comparable levels. Proteins belonging to the pre-replicative complex MCM6, ORC1 and CDC6 were enriched upon higher cross-linking conditions and this set also contained components of the SKA complex and STU2, along with six additional hypothetical proteins of unknown function. SEA1 was identified upon high cross-linking alone.

Along with AKiT1, 5 proteins of unknown function were most abundant across PbAKiT1 immunoprecipitates (Fig. 5B), 4 of which (Gene IDs: PBANKA_0612200, PBANKA_1310500, PBANKA_1243900 and PBANKA_0522000) were also enriched in purifications of SPC24 upon crosslinking. In addition to components of the pre-replicative complex, MCM2 - 7, and STU2, proteins previously reported to be at the apicomplexan centromere SMC1, Exportin 1 and Exportin 7 (Francia et al., 2020) in addition to SEA1 were enriched upon low cross-linking conditions, and this threshold showed reciprocal enrichment for all components of the NDC80/NUF2 complex.

Together, these data suggest the existence of biochemically stable complex that includes PbAKiT1 that deposits between NDC80/NUF2 complex at the spindle and proteins at the centromere. Each tagged305 hypothetical protein showed PbAKiT1-like localization patterns (Fig. S5A \& C), colocalizing with NUF2 during blood-stage and microgametocyte mitosis, also present as foci in activated female macrogametes and accumulating as four puncta in fully developed ookinetes. We therefore named these proteins AKiT2 - 6. 
bioRxiv preprint doi: https://doi.org/10.1101/2021.11.03.466924; this version posted November 3, 2021. The copyright holder for this preprint (which was not certified by peer review) is the author/funder, who has granted bioRxiv a license to display the preprint in perpetuity. It is made available under aCC-BY-NC 4.0 International license.

Interestingly, three proteins of unknown function (Gene IDs: PBANKA_0612300, PBANKA_0213200 and PBANKA_1307000) formed a distinct enrichment profile compared to AKiTs $1-6$ across immunoprecipitations (Fig. 5A \& B). Each tagged protein showed characteristic kinetochore localizations (Fig. S5B \& C), with that encoded by PBANKA_0612300 displaying an additional localization reminiscent of the nuclear membrane during sexual development. We named these proteins AKiT7 - 9, respectively. To test the extent and composition of additional complexes at the malaria parasite kinetochore, we 315 similarly affinity purified tagged protein. The relative abundances of co-purifying proteins identified in immunoprecipitations of $P$. berghei kinetochore proteins (without cross-linking) were then assessed by principal component analysis (Fig. 5C) (Brusini et al., 2021), including NUF2, SPC24, SKA2, AKiT1, AKIT7, AKiT8 and AKIT9, alongside controls previously shown to localize in the vicinity of the Plasmodium spindle, KIN8X and NEK1 (Dorin-Semblat et al., 2011; Zeeshan et al., 2019). Principal

320 components 1 and 3 encompass $69 \%$ of the total variance in the data and show distinct clustering of NDC80/NUF2 and SKA components relative to all AKiTs. Principle components 2 and 3 further resolved AKiT clustering, with the distinction of AKiTs $1-6$ relative to AKiT9, itself clustering with histones $\mathrm{H} 3$ and $\mathrm{H} 4$, the histone modifier SPT16, and two additional proteins of unknown function (Gene IDs: PBANKA_0406000 and PBANKA_0803900) that we named AKiT10 and AKiT11, respectively.

325 Taken together, our immuno-affinity purification strategy has identified 4 biochemically stable compartments at the Plasmodium kinetochore (Table S4). Between compartments, more labile interactions were also detected between the outer kinetochore NDC80/NUF2 complex and PbAKiT1, itself closely associated with 5 additional AKiT proteins. AKiT1 - 6 also interact with AKiT9 - 11, which, given their association with proteins known to interact with DNA, likely form the most centromere proximal kinetochore sub-domain identified in this study.

\section{Plasmodium kinetochores include distant relatives of CENP-C and the SAC}

AKiTs 1 - 11 have not previously been annotated with protein function. Furthermore, sequence analysis of AKiT proteins revealed no clearly predicted Pfam domains (Fig. 6A), excepting an unusual allancoitase domain in AKiT8, not previously identified in any kinetochore protein, and an AT-hook within

335 AKiT10. Iterative HMM profile-profile comparisons failed to find any evidence that AKiTs 1- 6, 8 or 11 are similar to known eukaryotic kinetochore components (Fig. S6A-G). In contrast, we detected strong similarity between AKiT7 and the spindle assembly checkpoint protein MAD1 (Fig. 6B \& C \& S6H). Similarly, scores for AKiT9 and AKiT10, in addition to the previously described SEA1 (Perrin et al., 2021), suggest these genes are homologous to the conserved CCAN component CENP-C (Fig. 6D \& E).

340 Similar phylogenetic profiles have previously been shown to reflect and predict functional interactions between eukaryotic kinetochore proteins (van Hooff et al., 2017). To investigate the evolutionary relationships and predict interactions between newly identified AKiT proteins, we assessed profile-profile scores for all kinetochore HMMs by principal components analysis $(n=90$, Fig. $6 F)$. In agreement with previously reported homology and functional interaction, we found intracomplex clustering between the SKA (SKA1 - 3), DASH (DUO, DAM, DAD and ASK), CENP-O (CENP-OUPQ), CENP-T (CENP-TWSX), 
in addition to components of the spindle assembly checkpoint (SAC) with nuclear pore proteins (NUPs) and the KMN network. A cluster of profiles for AKiT9, AKiT10, SEA1 and CENP-C further supports evidence these genes are homologous. AKiT7 clustered within the KMN network, and we predict this protein's function to be more tightly linked with that of the outer kinetochore and AKiT1 - 6 compartments compared to the CCAN in the malaria parasite (Fig. 6G). We did not find clustering of AKiT proteins, but instead found AKiT4 within KMN and AKIT5 - 6 within SAC clusters, respectively.

Overall, our data indicates that the CCAN in malaria parasites includes at least two distant relatives of CENP-C. Between the CCAN and the outer kinetochore deposits an AKiT1 - 6 compartment, comprised of proteins bearing very little detectable similarity to known kinetochore proteins and patterns of

355 phylogenetic profiles suggest only AKiT4 remotely within the outer kinetochore cluster. AKiT7 is the MAD1 component of the SAC and its function is most likely linked with that of the KMN network.

\section{AKiT1 requires CENP-C for kinetochore localization in Toxoplasma}

Identification of CENP-C within the Plasmodium CCAN certainly suggests homologous structures drive assembly of very different kinetochores in these parasites. Interestingly, we identified only a single

CENP-C gene in T. gondii (Fig. 7A). To investigate whether assembly of the NDC80/NUF2 complex or AKiT1 onto kinetochores relies upon CENP-C in Toxoplasma, we similarly tagged protein with the auxininducible degron fused to 3xHA, alongside tagged TgAKiT1 and TgNUF2 kinetochore markers. Consistent with a conserved localization to eukaryotic kinetochores, the majority of tagged TgCENP-C localized to the mitotic spindle, closely associated with TgAKiT1 at kinetochores throughout tachyzoite 365 divisions (Fig. 7B \& S7B). Furthermore, U-ExM revealed TgCENP-C foci were present on the centromeric side of the metaphase plate relative to TgAKiT1 at the tachyzoite mitotic spindle (Fig. 7C \& S7B), maintaining this bipartite localization following anaphase. Supporting the notion that CENP-C forms a platform for kinetochore assembly, recruitment of TgAKiT1 to kinetochore foci was abolished upon depletion of TgCENP-C (Fig. 7D \& S7C). Surprisingly however, levels of TgNUF2 at kinetochore foci were unaffected upon depletion of TgCENP-C (Fig. 7E), despite the severe phenotype on parasite proliferation and spindle assembly at both 6 hours and 18 hours post-depletion (Fig. S7D \& E). 


\section{Discussion}

\section{Apicomplexan models to study eukaryotic kinetochores}

375 In this study, we have looked into the composition and function of kinetochores in the Apicomplexa, a group of parasites belonging to a lineage that diverged early in eukaryotic evolution from animals and fungi and an obvious niche in kinetochore research. In addition to eukaryotic placement, apicomplexan parasites appear to divide differently to most of the cells of their hosts. A longstanding question remains as to how these parasites maintain fidelity of genome segregation following multiple rounds of DNA

380 replication without concomitant karyokinesis, in spite of an apparent absence of canonical kinetochore and checkpoint proteins. To address these largely unexplored questions we have used two model apicomplexan parasites to gain insights into the conservation of kinetochore proteins and compare protein behavior between lifecycle stages. SKA2 is a highly conserved kinetochore protein that we show localizes to $P$. berghei kinetochores during blood-stage mitosis. However, SKA2 foci were not clearly detected by live fluorescence microscopy during mitosis that occurs at male sexual development and furthermore first appeared at spindle poles before kinetochores during meiosis in the ookinete. Depletion of SKA2 in T. gondii asexual tachyzoites led to a strong increase in mitotic index, in particular in cells with bipolar spindles and a metaphase-like arrested state, reminiscent of siRNA-mediated depletion of Ska components in HeLa cells (Hanisch et al., 2006). The significance of differing SKA behavior remains

390 to be explored, however, given the strong requirement for Ska components to enhance spindle attachment in animal cells, it is quite possible kinetochores bind to the spindle with different strengths between apicomplexan lifecycle stages (Helgeson et al., 2018). Low levels of SKA were present at the prometaphase tachyzoite spindle, increasing upon formation of the diamond spindle at metaphase, when kinetochore-microtubule attachments are most likely under greatest tension.

395 Kinetochore components evolve relatively rapidly compared to most eukaryotic protein sets and become highly specialized along with centromere architectures (Meraldi et al., 2006). Within kinetochores of Toxoplasma and Plasmodium we have identified a single CENP-C in Toxoplasma that is required for assembly of AKiT1 onto kinetochores, whilst Plasmodium AKiT9, AKiT10 and SEA1 have been shown to be essential for parasite proliferation in rodent and human malaria parasite models (Table S4) (Bushell et 400 al., 2017; Perrin et al., 2021; Zhang et al., 2018). Notably, centromeres of P. falciparum and P. berghei are extremely AT-rich compared to T. gondii (Brooks et al., 2011; Verma \& Surolia, 2018) and AKiT10 encodes an AT-hook found in many DNA-binding proteins (Aravind \& Landsman, 1998), including the budding yeast CENP-C homolog, Mif2 (Xiao et al., 2017). Given the diverse modes of division there are likely to be many unique features of the apicomplexan chromosome segregation machinery and further comparative studies across the phylum will be needed to confirm whether any AKiT repertoire is truly specific to any organism. 
bioRxiv preprint doi: https://doi.org/10.1101/2021.11.03.466924; this version posted November 3, 2021. The copyright holder for this preprint (which was not certified by peer review) is the author/funder, who has granted bioRxiv a license to display the preprint in perpetuity. It is made available under aCC-BY-NC 4.0 International license.

\section{The molecular architecture of the apicomplexan kinetochore}

By combining quantitative proteomics with U-ExM we have identified 4 biochemically stable and distal compartments of the Plasmodium kinetochore, including; a three component SKA complex that

410 accumulates at spindle poles and kinetochores; a 6 component AKiT compartment that deposits between the NDC80/NUF2 complex at the outer kinetochore; and the most centromere proximal complex identified formed of AKiT9 - 11. AKiT7, AKiT8 and STU2 also interact with Plasmodium kinetochores, however their spatial characterization currently remains elusive. Taken together the findings presented here have provided the first model composition of protein complexes at an apicomplexan kinetochore

415 displayed in Fig. 7G.

How does our model of the apicomplexan kinetochore compare to those in other eukaryotes? All monocentric eukaryotic kinetochores investigated so far are partite, hierarchical assemblies deposited onto specific chromatin environments, themselves often demarked by centromeric nucleosomes (Akiyoshi \& Gull, 2014; Cheeseman, 2014; Cortes-Silva et al., 2020; D'Archivio \& Wickstead, 2017; 420 Kozgunova et al., 2019). In animals, CENP-C binds directly to CENP-A nucleosomes (Carroll et al., 2010) and interacts with the four-subunit Mis12 complex (Przewloka et al., 2011; Screpanti et al., 2011), itself interacting with KNL1 and the NDC80/NUF2 complex at the spindle (Petrovic et al., 2010). An alternative pathway utilizes the CENP-TWSX complex that bridges DNA to the NDC80/NUF2 complex (Gascoigne et al., 2011). The above design principle is conserved in the Apicomplexa, whose

425 kinetochores we show are also partite hierarchical assemblies. AKiTs $9-11$ join two identifiable homologs of CENP-C in forming a centromere proximal compartment and likely part of the apicomplexan CCAN. AKiT1 localizes to a midpoint between the CCAN and NDC80/NUF2 complex at the spindle and is dependent upon CENP-C for kinetochore assembly in T. gondii, reminiscent of CENP-C binding to Mis12 - KNL-1. However, neither depletion of CENP-C nor AKiT1 in T. gondii reduced levels of NUF2 at

430 the spindle and similarly endogenous NUF2 levels were not required for kinetochore recruitment of AKiT1. Recently, a highly elongated Plasmodium SPC24 component of the NDC80/NUF2 complex was identified and suggested to bridge the $>100 \mathrm{~nm}$ distance separating the outer kinetochore from the centromere (Zeeshan et al., 2020). However, this "long form" is poorly conserved across the Apicomplexa. Whilst present in coccidians, it is lacking in Theileria and Babesia, meaning any direct

435 centromere binding potential would have converged or else been lost by most-closely related hematozoan SPC24 proteins. How the NDC80/NUF2 complex is maintained at the spindle in apicomplexan parasites currently remains unknown, however it is quite possible a pathway similar to CENP-T kinetochore assembly exists or that re-purposing of NDC80/NUF2 function has facilitated binding to microtubules independently of kinetochores.

440 In human cells, 16 CCAN subunits, forming four sub-complexes are critical for kinetochore assembly and function (Cheeseman, 2014; Guse et al., 2011; Weir et al., 2016). In Plasmodium, only three CCAN components, AKiT9 - 11, have been identified. Importantly however, the conserved centromeric histone variant CENP-A that associates with centromeres in P. falciparum (Hoeijmakers et al., 2012; Miao et al., 
bioRxiv preprint doi: https://doi.org/10.1101/2021.11.03.466924; this version posted November 3, 2021. The copyright holder for this preprint (which was not certified by peer review) is the author/funder, who has granted bioRxiv a license to display the preprint in perpetuity. It is made available under aCC-BY-NC 4.0 International license.

2006; Trelle et al., 2009; Volz et al., 2010) was not found in immunoprecipitates, suggesting the presence of additional as yet unidentified CCAN components in the malaria parasites.

\section{Origins of the apicomplexan kinetochore}

By HMM profile-profile comparisons, we have re-united 6 apicomplexan components identified in this study to a common set, including STU2, SKA2-interacting proteins SKA1 and SKA3, AKiT7, AKiT9 and AKiT10. We did not detect significant similarity between any of AKiTs $1-6$, which deposit between the 450 CCAN and outer kinetochore, with known eukaryotic kinetochore components. So why is it difficult to identify homology at the apicomplexan kinetochore? Unconventional kinetochores bearing no detectable similarity and arising from a unique origin have been reported in eukaryotic parasites (Akiyoshi \& Gull, 2014). Similarly, it is possible AKiTs 1 - 6 are not directly descended from the kinetochores of the last alveolate common ancestor, and in light of the secondary endosymbiosis that forms an integral part of their origins, this scenario is more likely for the Apicomplexa compared to the overall relatively low frequency of horizontal gene transfer in eukaryotes. However, homologs identified in at least some components favors the notion of a common origin for the apicomplexan kinetochore with those in animals and fungi. Gene duplications can be traced in the presence of two INCENP genes (Berry et al., 2018), one of which has been shown to be required for proper mitosis, and we show AKiT9 and AKiT10

460 are homologous to the conserved kinetochore protein CENP-C. Cupin domains at the C-termini of CENP-C are known to homodimerize (Cohen et al., 2008), and it is tempting to speculate a similar interaction was maintained following duplication that led to formation of a heterodimer. AKiTs $1-6$ may be more susceptible to change compared to other apicomplexan kinetochore components and this may go some way to explain the lack of similarity detected between this set and all other known eukaryotic kinetochore proteins. Furthermore, identification of AKiT7 as a homolog of the MAD1 component of the spindle assembly checkpoint, further suggests divergence of a KNL1 complex and landing pad for the SAC that we and others have so far been unable to identify (D'Archivio \& Wickstead, 2017; Kops et al., 2020; van Hooff et al., 2017). We anticipate that with the ongoing development of greater sensitivity in searches, divergent homologs will be exposed within most kinetochore sets (D'Archivio \& Wickstead, 2017; Tromer et al., 2021; Zeeshan et al., 2020).

\section{Diverse requirements and regulation across apicomplexan modes of division}

Fidelity of metazoan chromosome segregation requires the SAC, a surveillance system mediated by the MCC that inhibits CDC20 and activation of the APC/C until proper chromosome bi-orientation. Plasmids containing centromeric sequences are stably maintained throughout the Plasmodium lifecycle (Iwanaga et al., 2010, 2012), however the apparent absence of most MCC proteins and the inability to delay cell cycle progression in response to microtubule destabilizing agents has suggested apicomplexan parasites are incapable of a generating a comparable SAC response (Kops et al., 2020; Morrissette \& Sibley, 2002). In this study, we reveal alignment of kinetochores during mitosis that occurs during asexual divisions in both Plasmodium and Toxoplasma, and additionally during meiosis in the ookinete form of the malaria parasite. These architectures are reminiscent of chromosome bi-orientation at the 
metaphase plate and suggestive of a "hold signal" that prevents precocious entry into anaphase (displayed in Fig. 7H). Furthermore, identification of STU2 at the Plasmodium kinetochore hints towards an intrinsic tension-sensing and error-correction mechanism required for establishing bioriented attachments (Miller et al., 2016, 2019). So far, we have been unable to identify a similar metaphase architecture during microgametogenesis. However, kinetochore architecture with respect to tagged-SKA protein localization differs between asexual and sexual stages of division and we speculate this may correlate with requirements to satisfy specific metaphase checkpoints.

Identification of AKiT7 as a homolog of MAD1 and enrichment of protein at kinetochores during nuclear divisions suggest at least a partial SAC response in Plasmodium species, and depletion of CDC20 and

$490 \mathrm{APC} / \mathrm{C}$ components has been shown to prevent proper chromosome condensation during microgametogenesis (Guttery et al., 2012; Wall et al., 2018). Suggestion of any SAC response in the Apicomplexa raises some important questions regarding the existence of a $\mathrm{MCC}$, its recruitment to kinetochores and whether it enables a checkpoint comparable to that in other organisms. Kinases resembling Monopolar Spindle 1 and Polo-Like that are required for MCC assembly onto unattached

495 kinetochores in animal and fungal models have not been detected in the Apicomplexa. Instead, a number of kinases distantly related to Aurora and Cyclin-dependent kinase families have been shown to be implicated in cell cycle control, in particular DNA synthesis and mitosis in both Plasmodium and Toxoplasma (Balestra et al., 2020; Morahan et al., 2020). Whether phosphoregulation has been repurposed at apicomplexan kinetochores and the effects such divergences have on chromosome segregation will likely broaden our views on the malleability of eukaryotic mitotic checkpoint control. 
bioRxiv preprint doi: https://doi.org/10.1101/2021.11.03.466924; this version posted November 3, 2021. The copyright holder for this preprint (which was not certified by peer review) is the author/funder, who has granted bioRxiv a license to display the preprint in perpetuity. It is made available under aCC-BY-NC 4.0 International license.

\section{Figures}

Figure 1

A

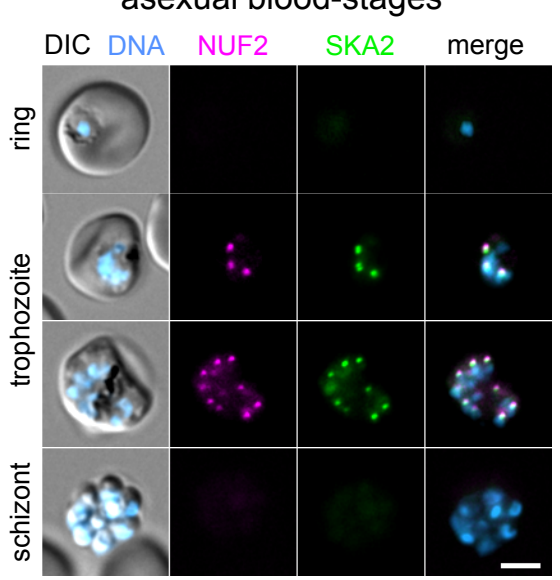

B

sexual mosquito-stages

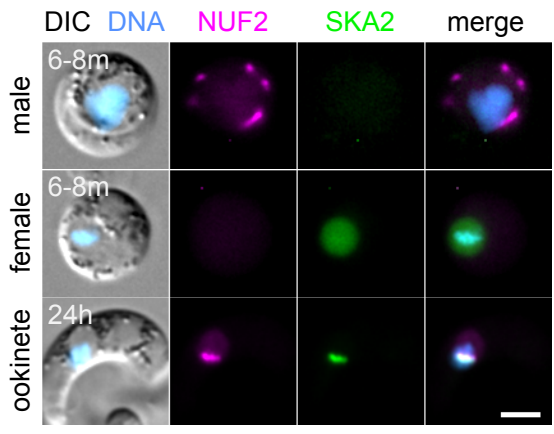

D

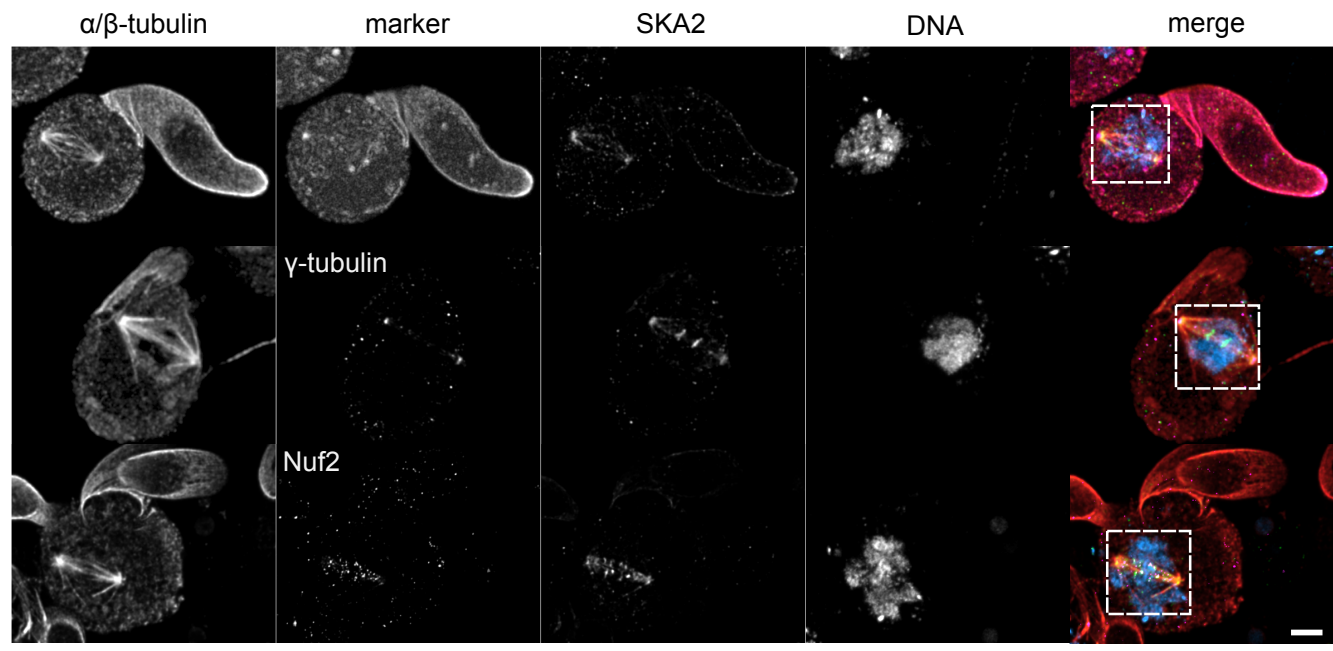

C

ookinete development
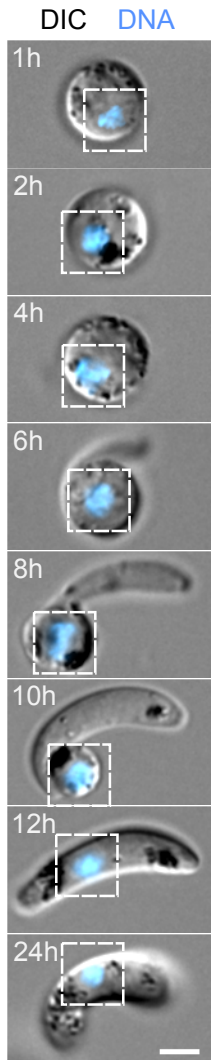

NUF2

SKA2
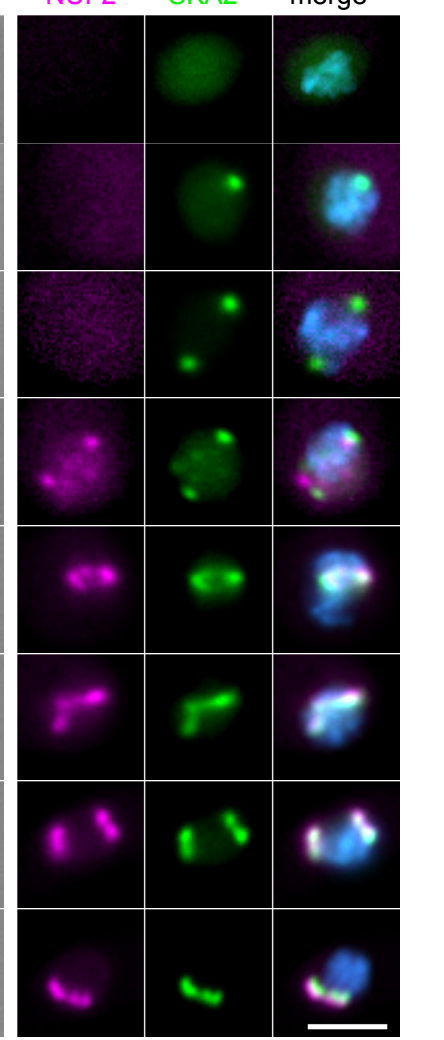

F
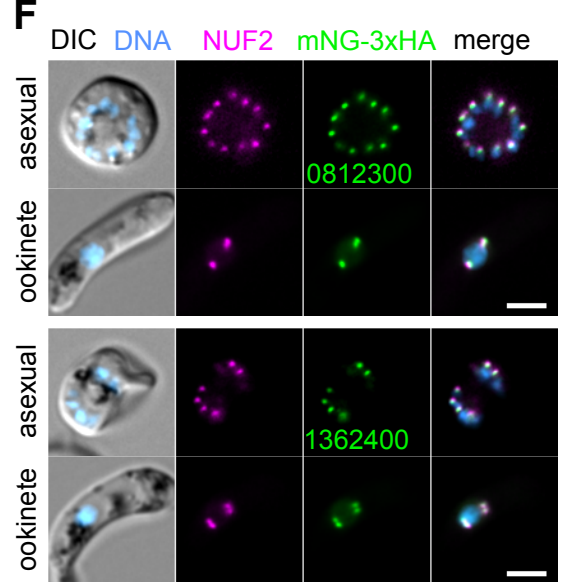

a/ß-tubulin SKA2 marker SKA2

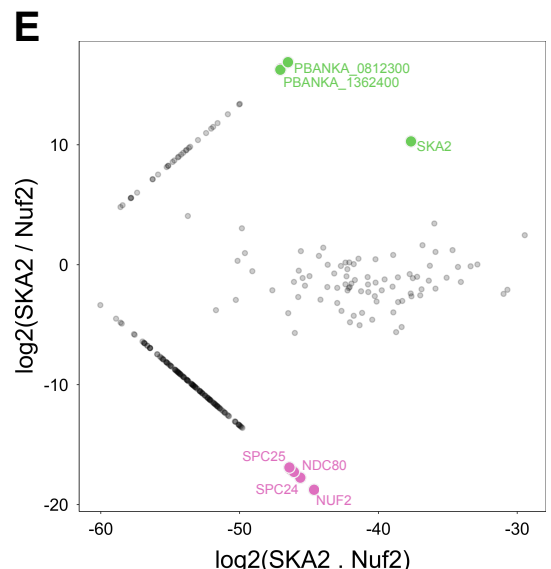

DIC DNA NUF2 mNG-3XHA merge

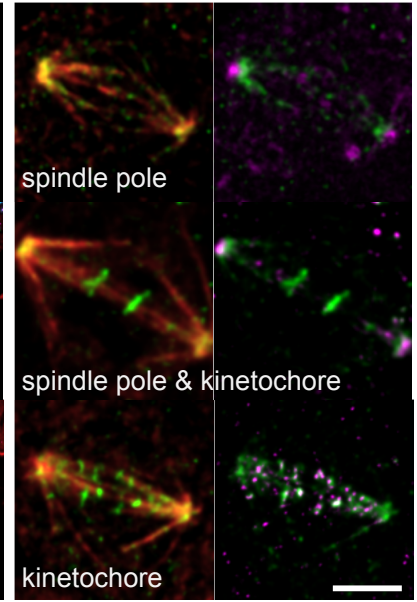


Figure 1. Plasmodium species encode a biochemically stable SKA complex. Micrographs of live native fluorescence in malaria parasites expressing tagged kinetochore components NUF2-mScarlet-I (magenta) and SKA2-mNeonGreen fused to triple hemagglutinin-epitope tag (green) during asexual blood-stage proliferation (A), sexual mosquito-stages $(B)$, and throughout meiosis and differentiation in

505 developing ookinetes (C). Counter-staining of DNA with Hoechst 33342 (cyan) and differential interference contrast images (DIC) are also shown. Bar: $2 \mu \mathrm{m}$. (D) Ultrastructure Expansion Microscopy revealed that tagged-SKA2 localizes to spindle poles (identified by $\mathrm{y}$-tubulin and pan-proteomic NHSester counter-stainings), along the spindle ( $\alpha / \beta$-tubulin) and at kinetochores (NUF2) during meiosis. Counter-staining of DNA with Hoechst 33342 (cyan) also shown. Bar: $1 \mu \mathrm{m}$. (E) Label-free

510 semiquantitative mass spectrometry showing relative enrichment of proteins identified following immunoprecipitations of tagged kinetochore components NUF2-3xHA (magenta) and SKA2-3xHA (green). Signals from the NDC80 complex and two novel SKA2-interacting proteins are highlighted. Intensities of proteins not detected for a specific immunoprecipitation are set to an arbitrary minimum value. (F) Live native fluorescence validated SKA2-interacting proteins tagged with mNG-3xHA localize 515 to kinetochore foci during asexual blood stages and ookinete development. 
bioRxiv preprint doi: https://doi.org/10.1101/2021.11.03.466924; this version posted November 3, 2021. The copyright holder for this preprint (which was not certified by peer review) is the author/funder, who has granted bioRxiv a license to display the preprint in perpetuity. It is made available under aCC-BY-NC 4.0 International license.

Figure 2

A asexual tachyzoite-stages
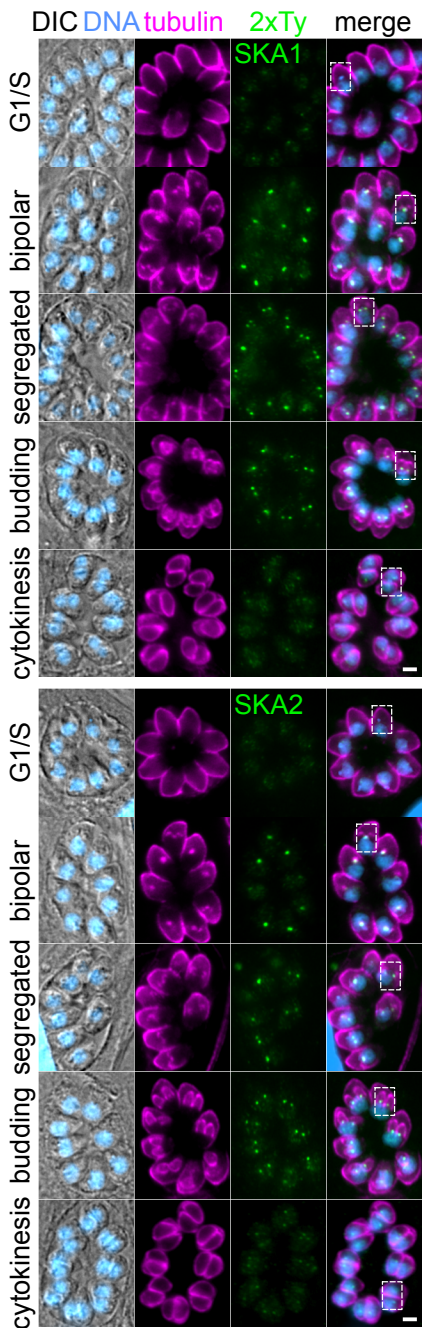

C

parental SKA1-mAID SKA2-mAID $\mathrm{n}=298370430333 \quad 342448392$

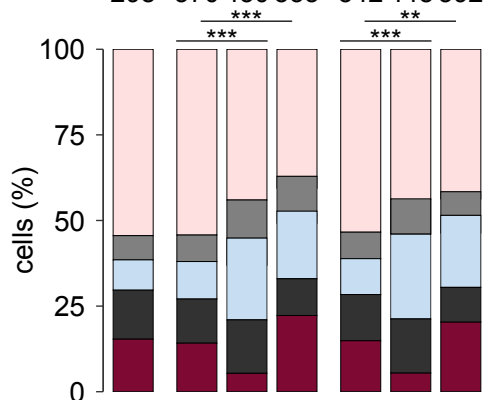

IAA: $0 \begin{array}{lllllll}0 & 0 & 6 & 18 & 0 & 6 & 18\end{array}$ time $(\mathrm{h})$

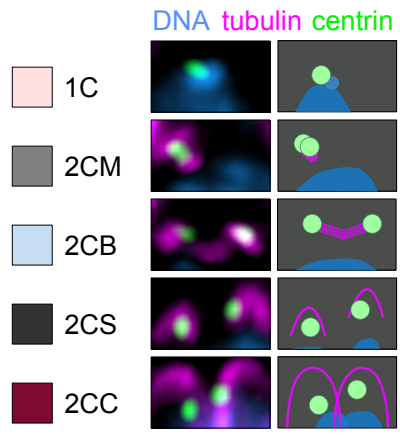

B

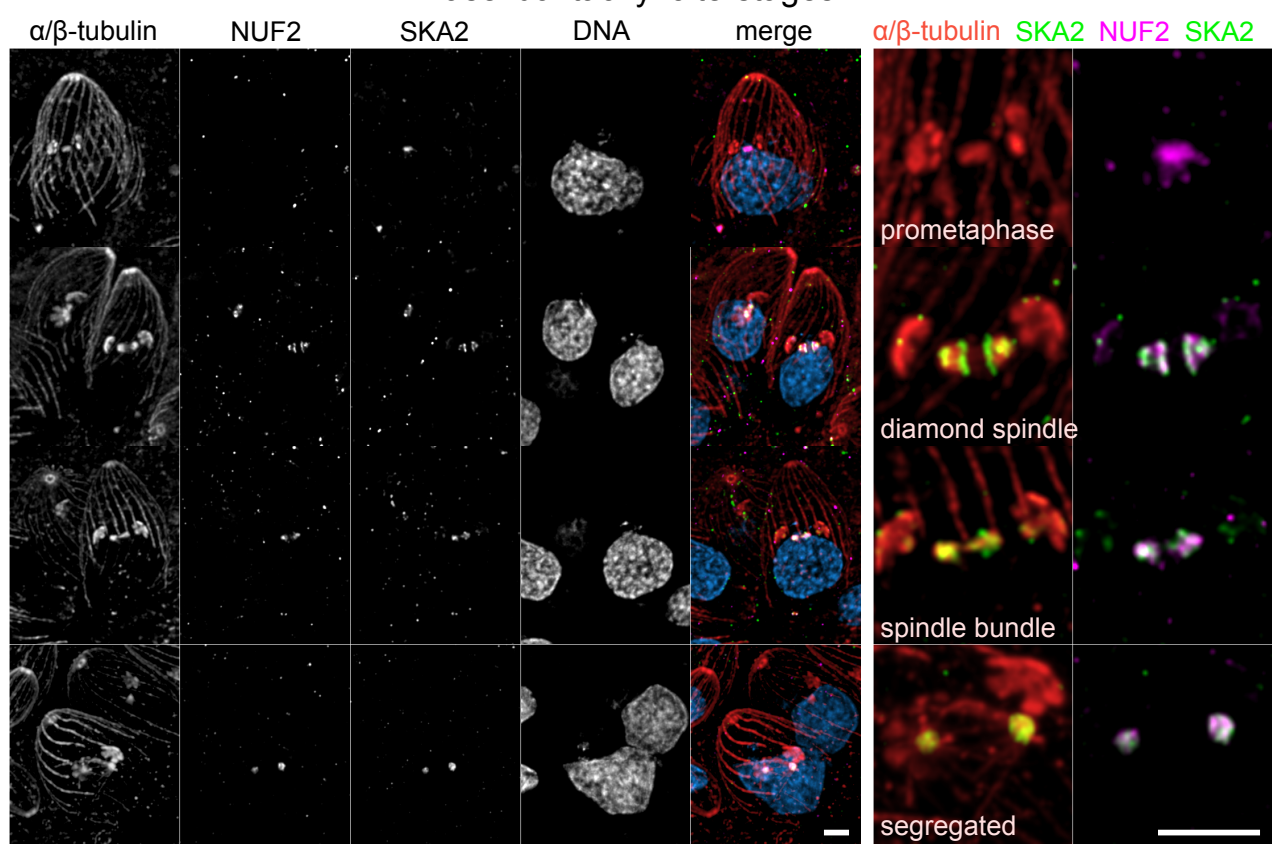

TgSKA2-mAID-3xHA tachyzoite mitotic spindles

D
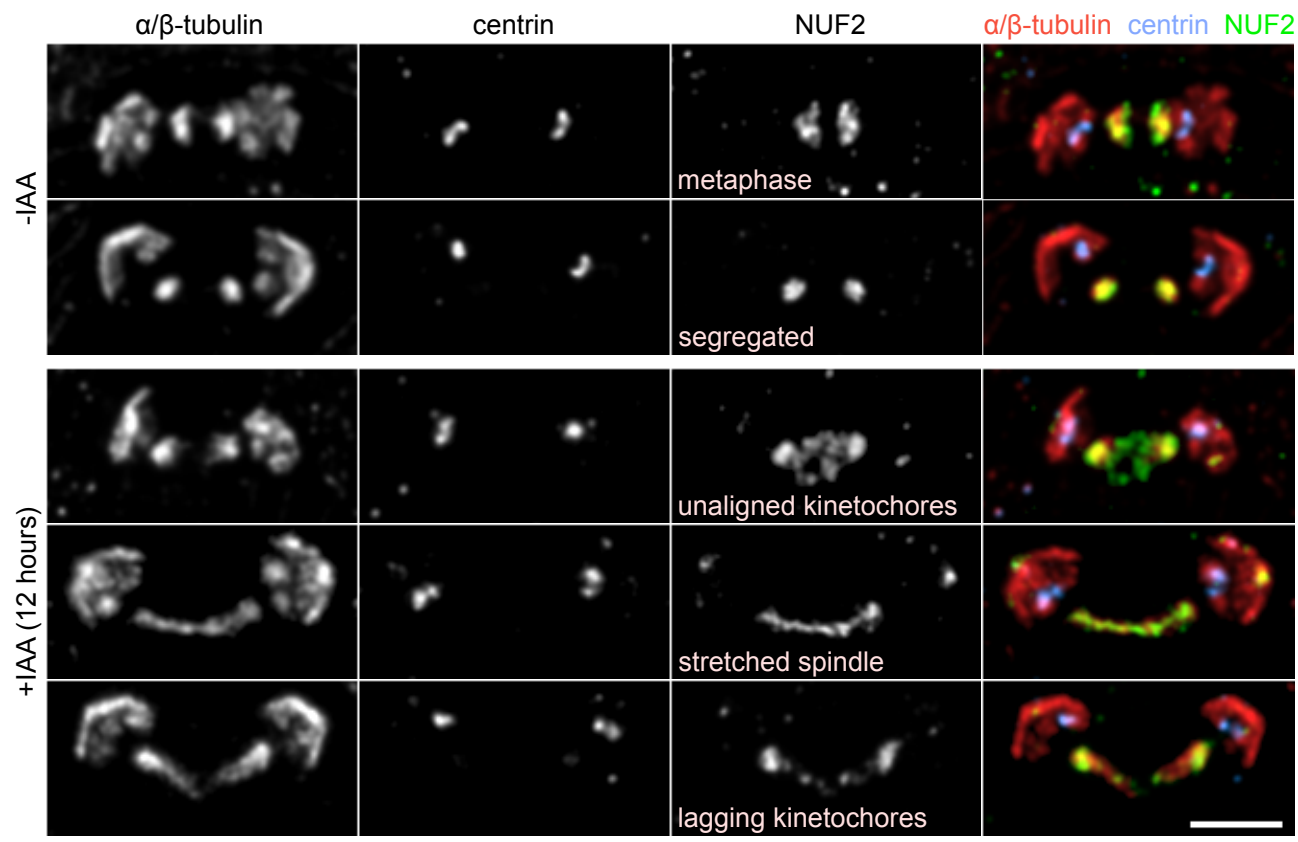

E

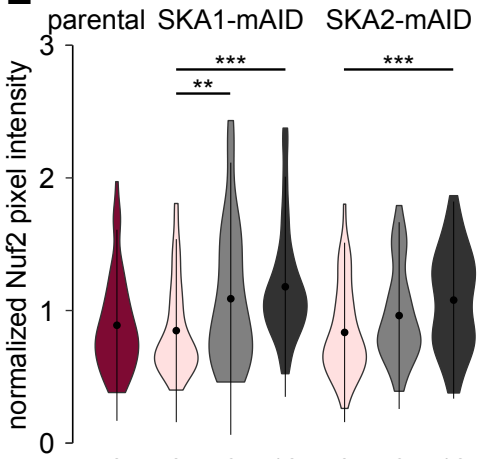

IAA:

Centrin

DNA

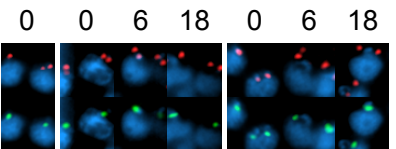

$\mathbf{F}$
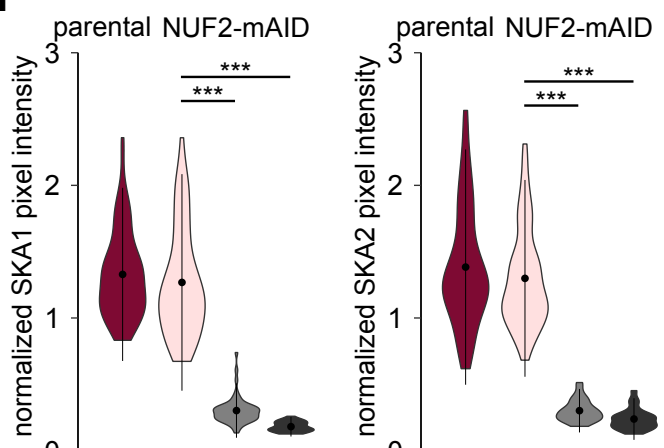

IAA: $0 \quad 0 \quad 0 \quad 6 \quad 18$

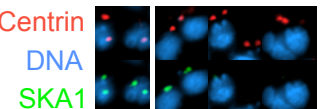

IAA: $\begin{array}{llll}0 & 0 & 6 & 18\end{array}$

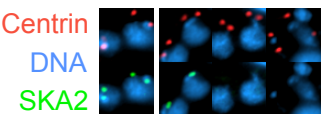


Figure 2. SKA components are required for kinetochore segregation in Toxoplasma. (A) Micrographs of fixed immunofluorescence in Toxoplasma gondii tachyzoites expressing kinetochore components SKA1 and SKA2 fused to a double Ty epitope (2xTy) throughout intracellular divisions. Counter-staining of DNA with DAPI (cyan), tubulin (magenta) and DIC images are also shown.

520 Bar: $5 \mu \mathrm{m}$. (B) U-ExM revealed SKA2 is recruited to the tachyzoite mitotic spindle primarily at metaphase, to spindle poles (identified by $\alpha / \beta$-tubulin counter-stain) and kinetochores (NUF2). Counterstaining of DNA with DAPI (cyan) also shown. Bar: $2 \mu \mathrm{m}$. (C) Morphological analysis of cells depleted for SKA1 or SKA2 tagged with mAID-3xHA shows a buildup of cells with duplicated centrosomes and bipolar spindles (2CB) compared to monopolar spindles (2CM), segregated centrosomes into daughter 525 cell caps (2CS) and cells in cytokinesis (2CC). Assessed by immunofluorescence against Toxoplasma Centrin1 (green) and tubulin (magenta) ${ }^{* *}, \mathrm{P}<0.01 ;{ }^{* * *}, \mathrm{P}<0.001 ; \mathrm{Chi}^{2}$ test). (D) U-ExM further characterized phenotypic changes post-depletion, revealing tachyzoites with stretched mitotic spindles and unaligned and lagging kinetochores during mitosis. Bar: $1 \mu \mathrm{m}$. Levels and localization of NUF2 (E) and SKA components $(F)$ in cells at 0,6 and 18 hours post-depletion of SKA and NUF2 components,

530 respectively, assessed by immunofluorescence against Centrin1 and 2xTy tagged protein. Representative images shown below. DNA stain DAPI. 
bioRxiv preprint doi: https://doi.org/10.1101/2021.11.03.466924; this version posted November 3, 2021. The copyright holder for this preprint (which was not certified by peer review) is the author/funder, who has granted bioRxiv a license to display the preprint in perpetuity. It is made available under aCC-BY-NC 4.0 International license.

\section{Figure 3}

A

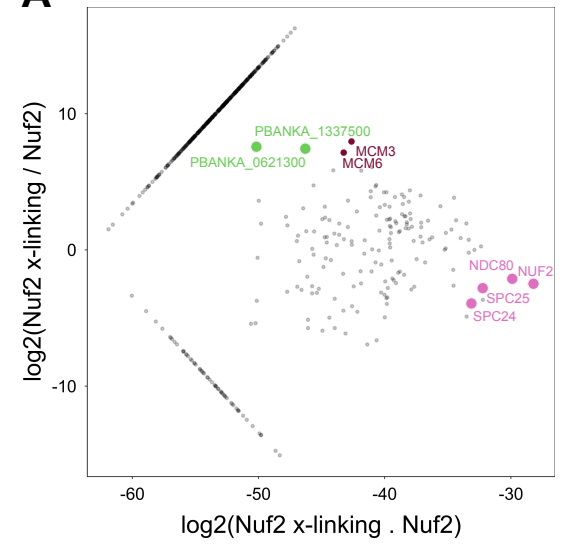

D

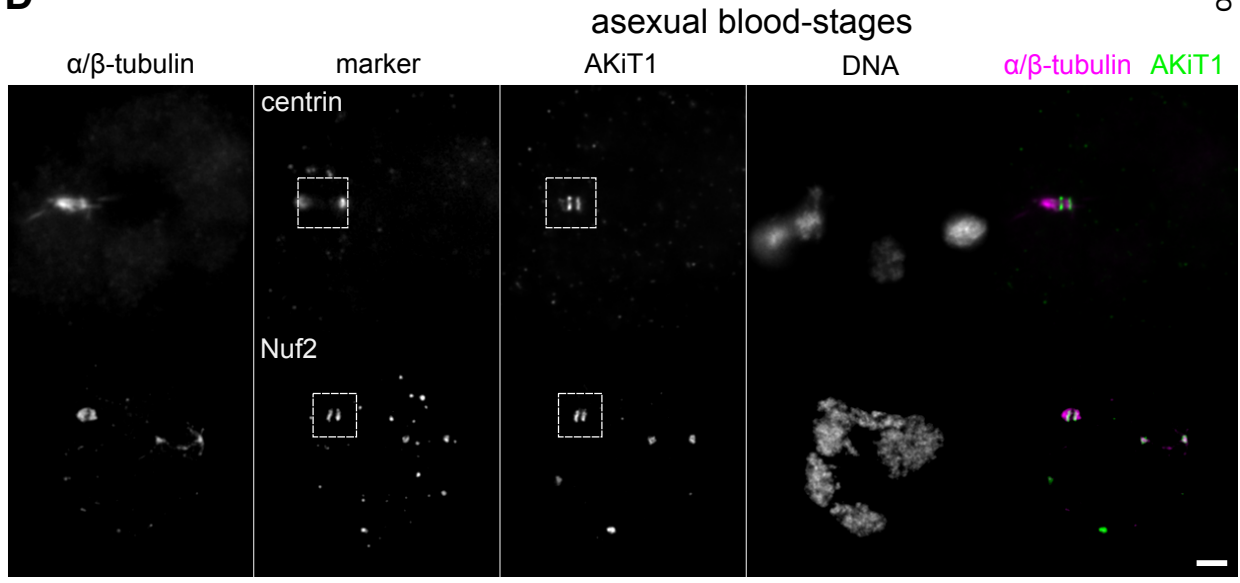

\section{E}
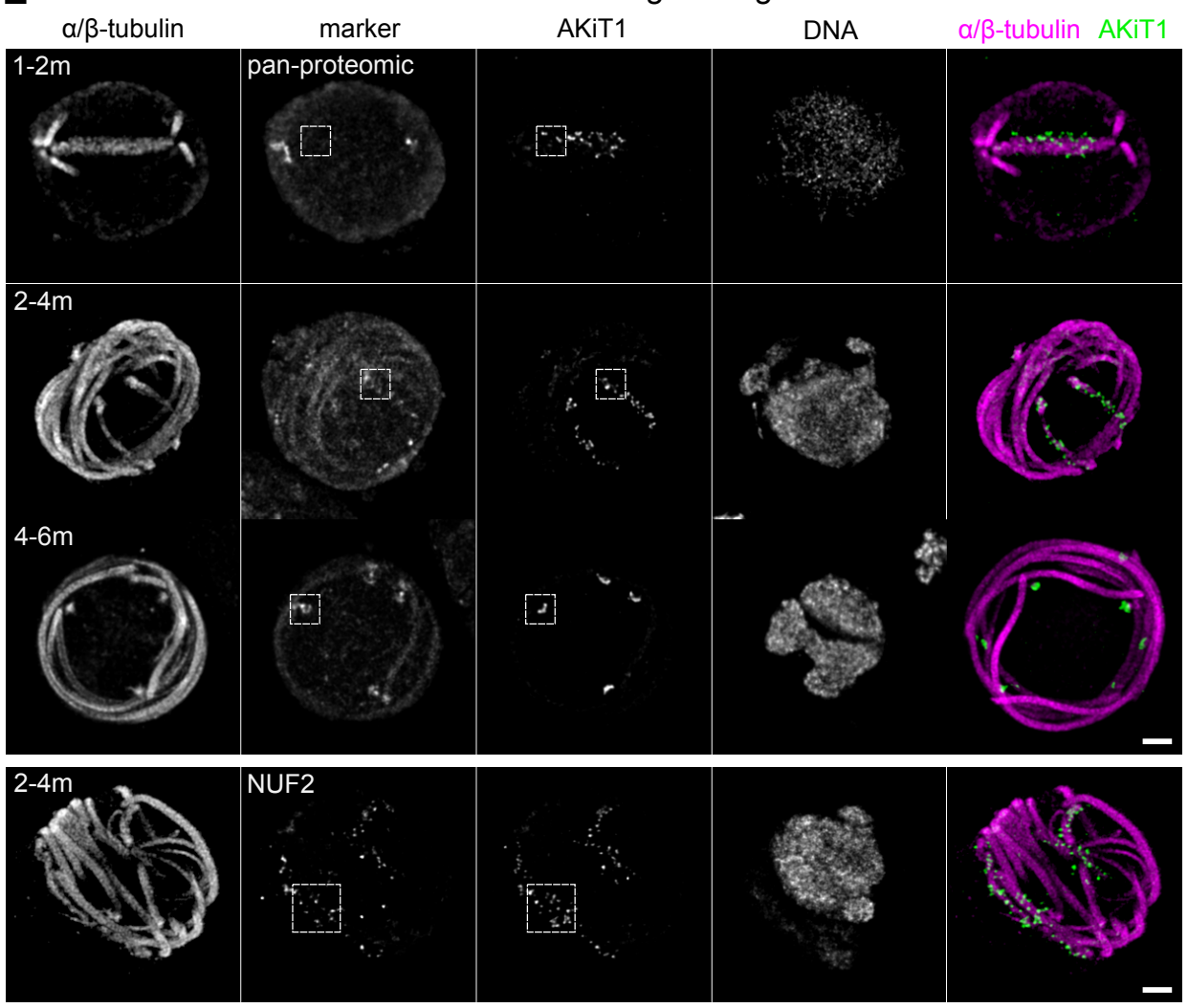

C sexual mosquito-stages

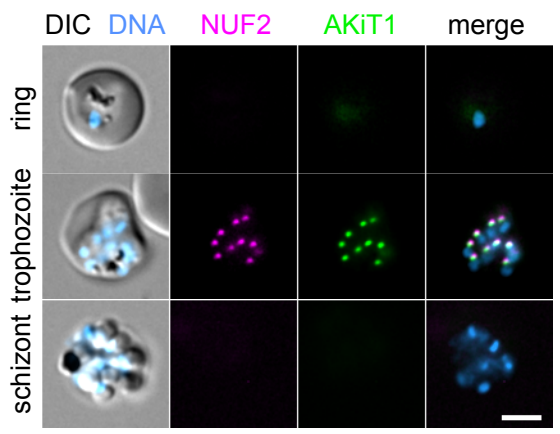

DIC DNA NUF2 AKIT1 merge

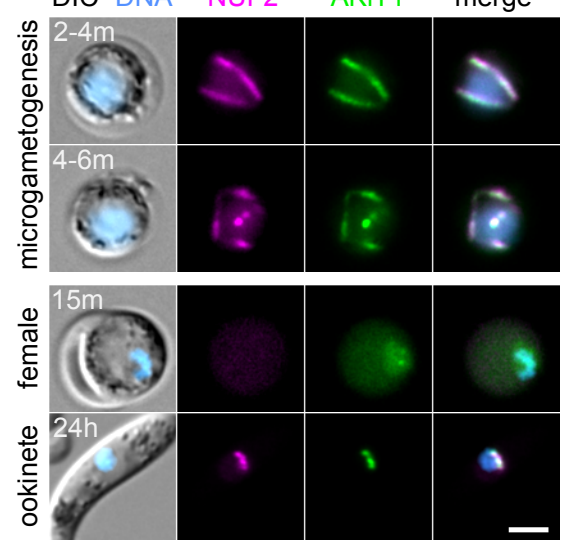

marker AKiT1

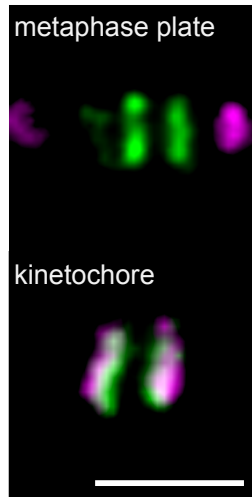

marker AKiT1
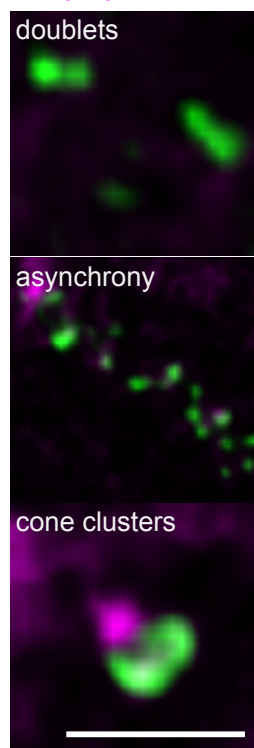

kinetochore

*

8

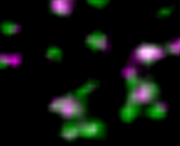

F

closest centroid

$\varangle \mathrm{n}=46$

$\sum_{1} 100$

产

远 50

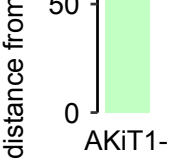

$\mathrm{mNG}-3 \times \mathrm{HA}$

\section{G}

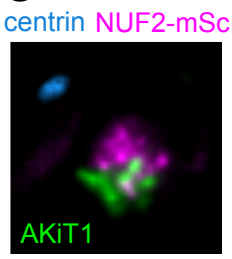

closest centroid

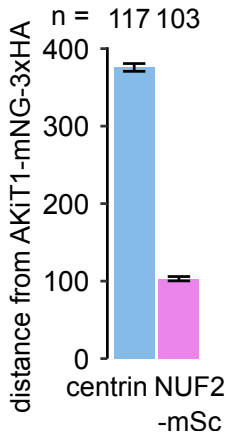

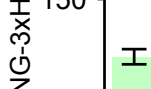


Figure 3. AKiT1 belongs to a newly identified compartment of the Plasmodium kinetochore. (A) Relative enrichment of proteins following immunoprecipitation of NUF2-3xHA under conditions of formaldehyde cross-linking compared to non cross-linked cells. Signals from NDC80 complex

535 components and most enriched proteins are highlighted. Live fluorescence in malaria parasites expressing tagged kinetochore components NUF2-mScarlet-I (magenta) and AKiT1-mNeonGreen-3xHA (green) during asexual blood-stage proliferation (B) and microgametogenesis (C). Bar: $2 \mu \mathrm{m}$. U-ExM revealed alignment of AKiT1 foci at kinetochores (identified by NUF2 counter-stain) during asexual blood-stage divisions (D), whilst dispersed along the mitotic spindle (tubulin) prior to segregation during

540 microgametogenesis (E). DNA, centrin and pan-proteomic stainings are also shown. Bar: $1 \mu \mathrm{m}$. Distance between closest centroids of AKiT1 along the microgametocyte spindle (F), and of NUF2 and centrin relative to AKiT1 (G). Numbers indicate total number of foci. Bars show S.E.M. 
bioRxiv preprint doi: https://doi.org/10.1101/2021.11.03.466924; this version posted November 3, 2021. The copyright holder for this preprint (which was not certified by peer review) is the author/funder, who has granted bioRxiv a license to display the preprint in perpetuity. It is made available under aCC-BY-NC 4.0 International license.

Figure 4

A

asexual tachyzoite-stages

DIC DNAtubulin AKiT1 merge

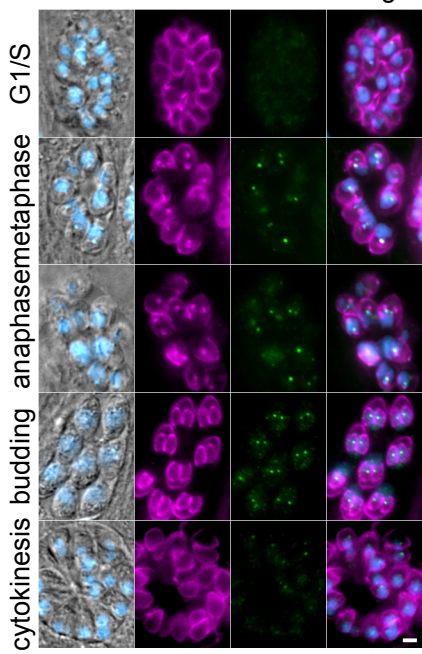

C

parental AKiT1-mAID

$\mathrm{n}=575691801522$
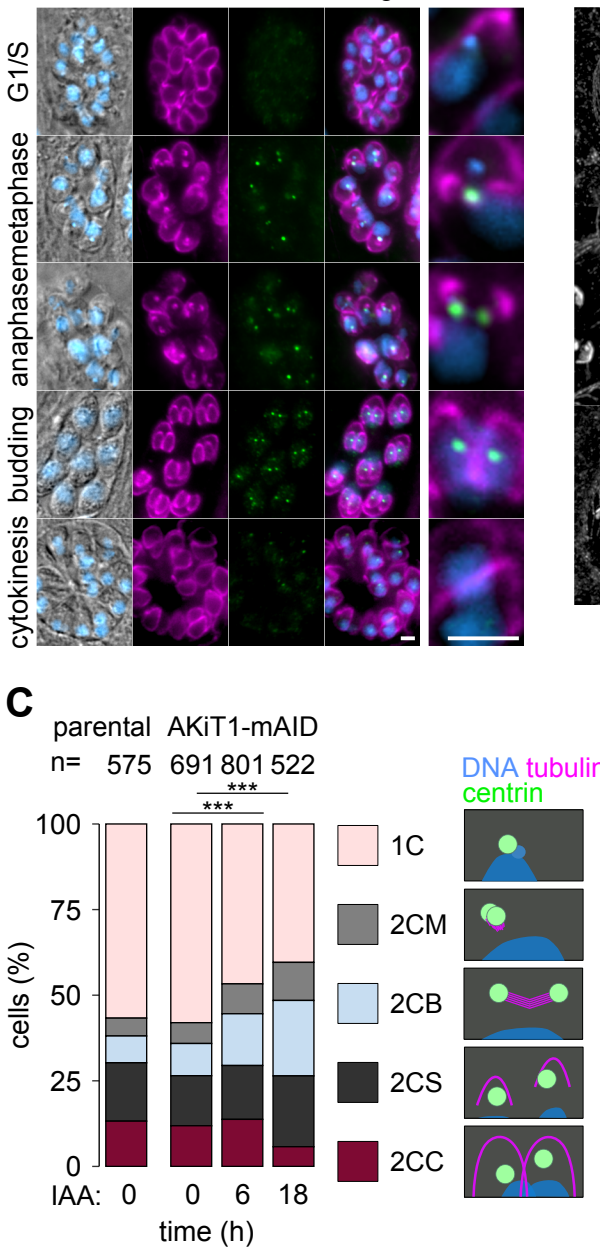

B

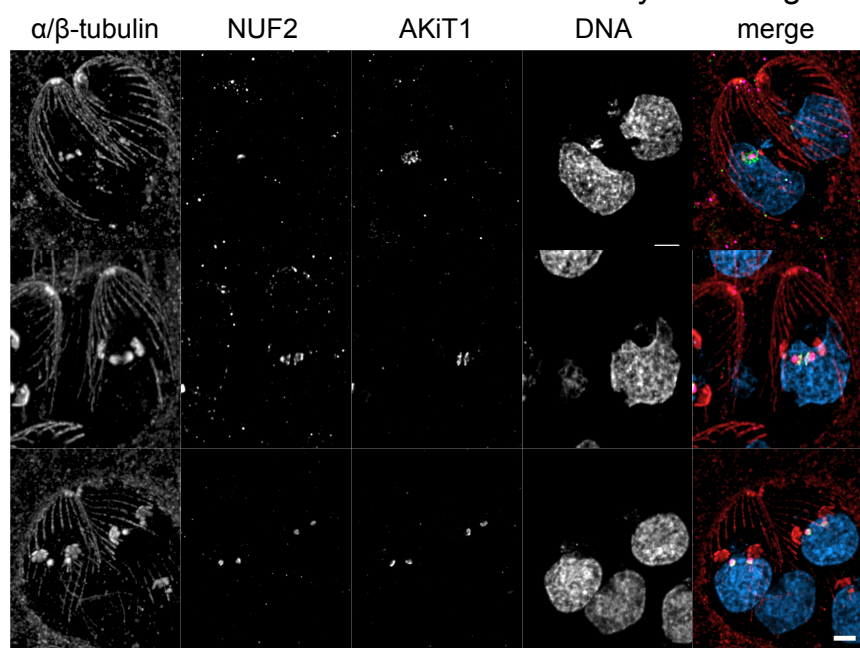

E

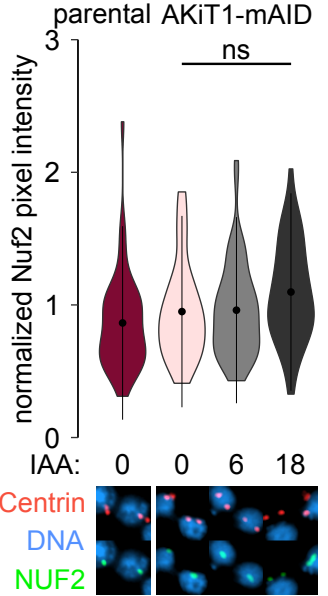

$\mathbf{F}$
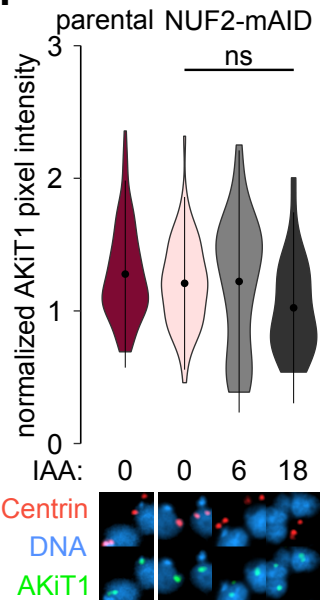

D

TgAKiT1-mAID-3xHA tachyzoite mitotic spindles
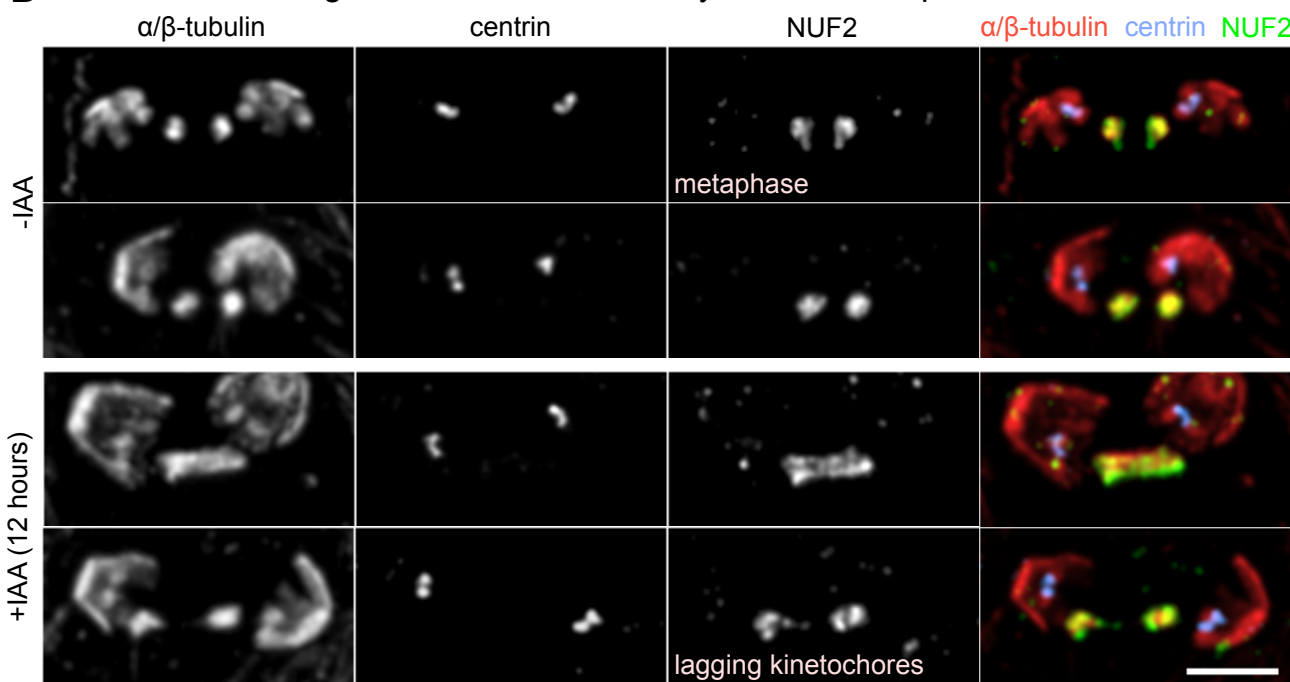
Figure 4. AKiT1 is an essential component of the Toxoplasma kinetochore. (A) Micrographs of $T$. gondii tachyzoites expressing AKiT1-2xTy throughout intracellular divisions. Counter-staining of DNA

545 with DAPI (cyan), tubulin (magenta) and DIC images are also shown. Bar: $5 \mu \mathrm{m}$. (B) U-ExM revealed AKiT1 at the tachyzoite mitotic spindle (identified by $\alpha / \beta$-tubulin counter-stain) and kinetochores (NUF2) throughout mitosis. Counter-staining of DNA with DAPI (cyan) also shown. Bar: $2 \mu \mathrm{m}$. (C) Depletion of AKiT1-mAID-3xHA prevented proper mitotic progression due to a buildup of cells with duplicated centrosomes and bipolar spindles $(2 \mathrm{CB})\left({ }^{* *}, \mathrm{P}<0.01\right.$; ${ }^{* * *}, \mathrm{P}<0.001$; Chi $^{2}$ test). (D) U-ExM further

550 characterized phenotypic changes post-depletion, revealing tachyzoites with stretched mitotic spindles and lagging kinetochores. Bar: $1 \mu \mathrm{m}$. (E\& F) Levels and localization of NUF2 and AKiT1 kinetochore components in cells at 0,6 and 18 hours post-depletion of either component. Representative images shown below. 
bioRxiv preprint doi: https://doi.org/10.1101/2021.11.03.466924; this version posted November 3, 2021. The copyright holder for this preprint (which was not certified by peer review) is the author/funder, who has granted bioRxiv a license to display the preprint in perpetuity. It is made available under aCC-BY-NC 4.0 International license.

Figure 5

A
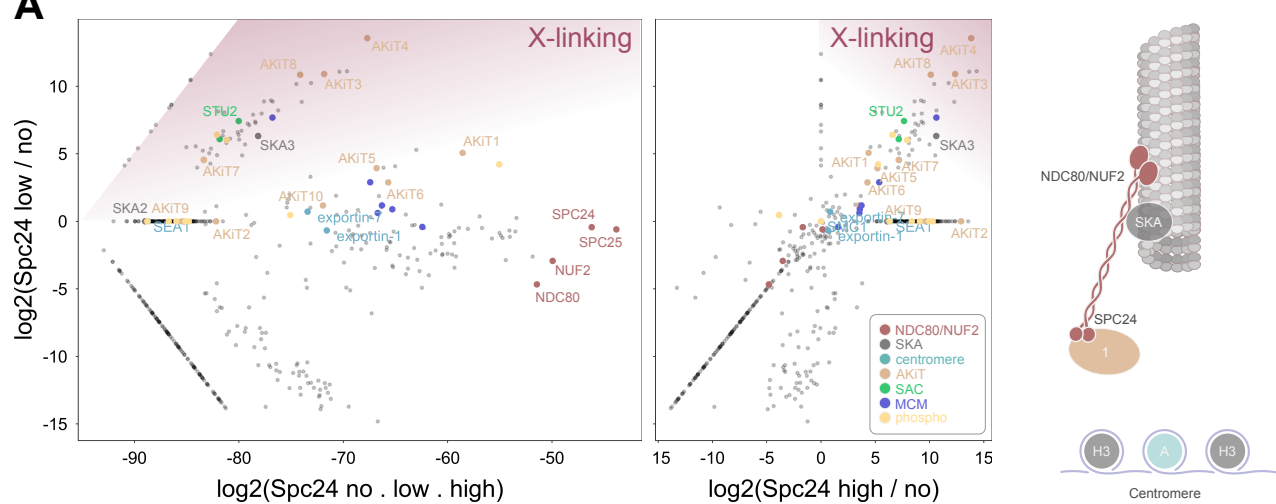

B
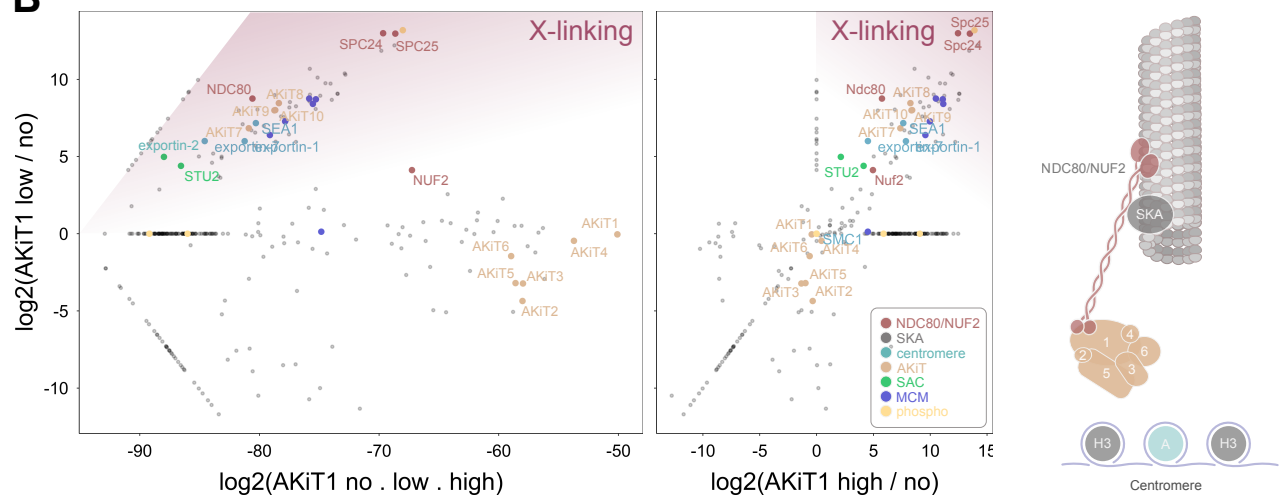

C

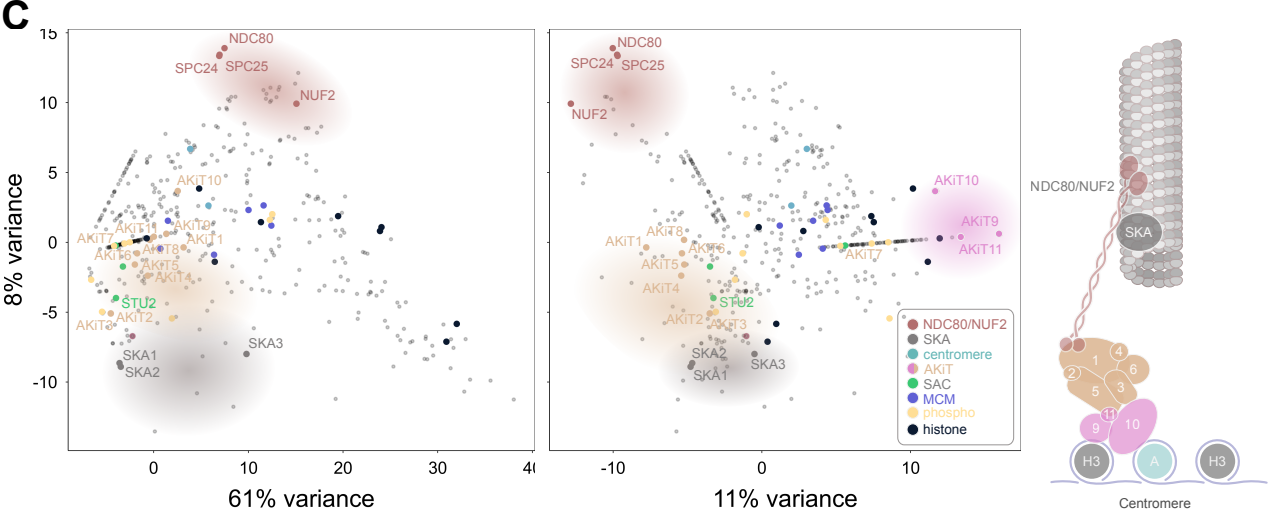


Figure 5. The Plasmodium kinetochore is composed of at least four biochemically stable

555 compartments. Relative enrichment of proteins immuno-purified with SPC24-3xHA (A) and AKiT1-3xHA (B) under conditions of "low" compared to "high" and "no" cross-linking conditions (left), or "low" compared to "high" cross-linking (right). (C) Relative enrichment of proteins immuno-purified (without cross-linking) with NUF2, SPC24, AKiT1, AKiT8, AKiT9, SKA2 and PBANKA_1343200, in addition to spindle controls; NEK1 and KIN8X, displayed in principal components 1 and 3 (left) and 2 and 3 (right).

560 Schematic interpretations are shown on the far right. Intensities for all 780 proteins detected across experiments are presented in Table S3. 
bioRxiv preprint doi: https://doi.org/10.1101/2021.11.03.466924; this version posted November 3, 2021. The copyright holder for this preprint (which was not certified by peer review) is the author/funder, who has granted bioRxiv a license to display the preprint in perpetuity. It is made available under aCC-BY-NC 4.0 International license.

Figure 6

A AKIT1 (PBANKA_0621300) AKiT2 (PBANKA_1202800)

AKIT3 (PBANKA 0612200)

AKIT4 (PBANKA_1310500)

AKIT5 (PBANKA_1243900)

AKIT6 (PBANKA 0522000)

AKIT7 (PBANKA_0612300)

AKIT8 (PBANKA 0213200)

AKIT9 (PBANKA_1307000)

AKIT10 (PBANKA_0406000)

AKIT11 (PBANKA 0803900)

SEA1 (PBANKA_0506000)

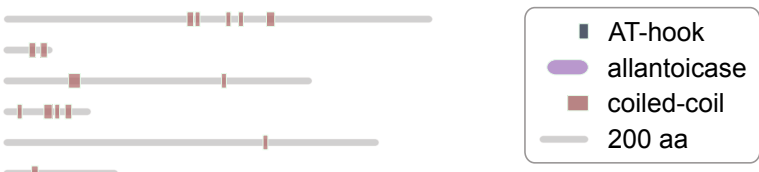

B

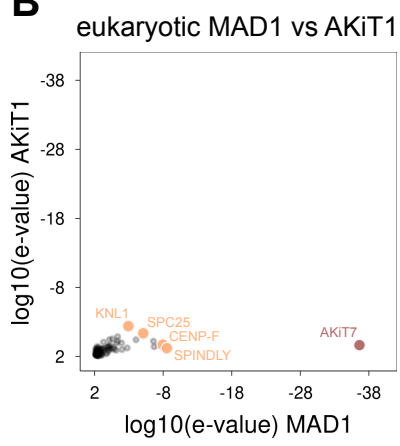

D

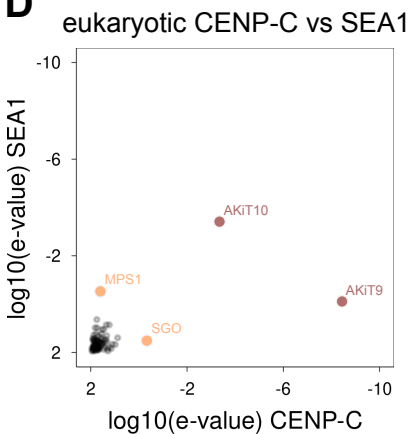

C

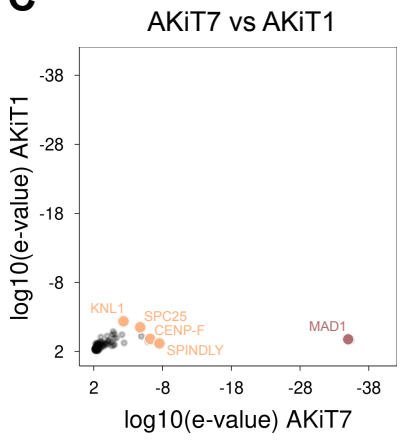

E

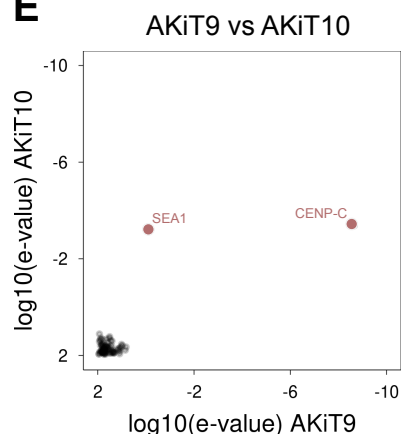

$\mathbf{F}$

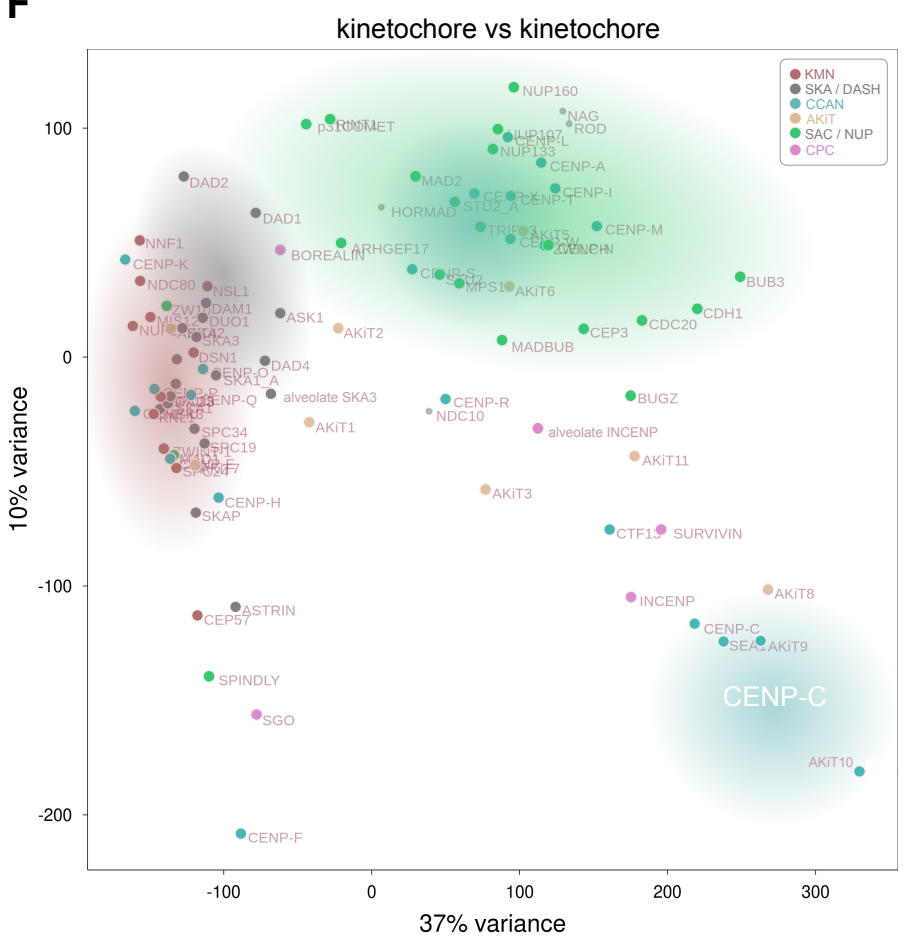

\section{G}

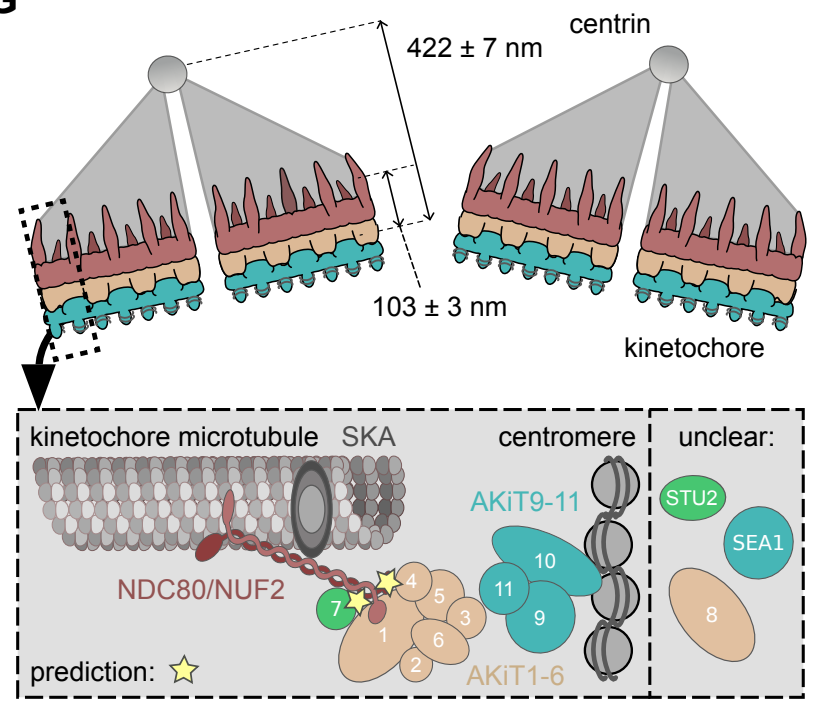

H
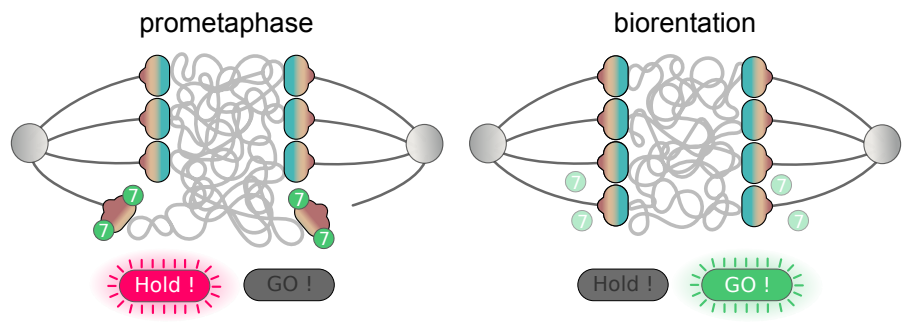
Figure 6. AKiT7, AKiT9 and AKiT10 are related to known eukaryotic kinetochore and spindle assembly checkpoint proteins. (A) Protein architectures, including Pfam domains and coiled-coils, for $P$. berghei homologs of AKiTs 1-11 and SEA1, predicted using HMMer tools (hmmscan). (B-E) Reciprocal

565 HMM profile-profile comparisons using kinetochore HMMs that include alveolate homologs of AKiT7 (PBANKA_0612300), AKiT9 (PBANKA_1307000), AKiT10 (PBANKA_0406000) and SEA1 (PBANKA_0506000) and pan-eukaryotic HMMs identify similarity with MAD1 and CENP-C as highest scoring hits. In red are high confidence/scoring HMMs and in orange low confidence hits. (F) Scores of all kinetochore HMM profile-profile comparisons displayed in principal components of largest variance.

570 Clusters are colored according to previously demonstrated functional (biochemically purified complexes) and/or phylogenetic (sequence similarity) interactions. (G) Schematic model representation of the Plasmodium kinetochore. Overall organization based on electron microscopy images, presented previously (Guttery et al., 2012), and molecular architectures combine biochemically purified complexes and localization data presented in this study. $(\mathrm{H})$ Proposed metaphase kinetochore organization with the

575 inclusion of AKiT7/MAD1 as a spindle assembly checkpoint component, based on biochemical and localization data presented in this study. 
bioRxiv preprint doi: https://doi org/10.1101/2021.11.03.466924 t this version posted November 3, 2021. The copyright holder for this preprint (which was not certified by peer review) is the author/funder, who has granted bioRxiv a license to display the preprint in perpetuity. It is made available under aCC-BY-NC 4.0 International license.

Figure 7

A

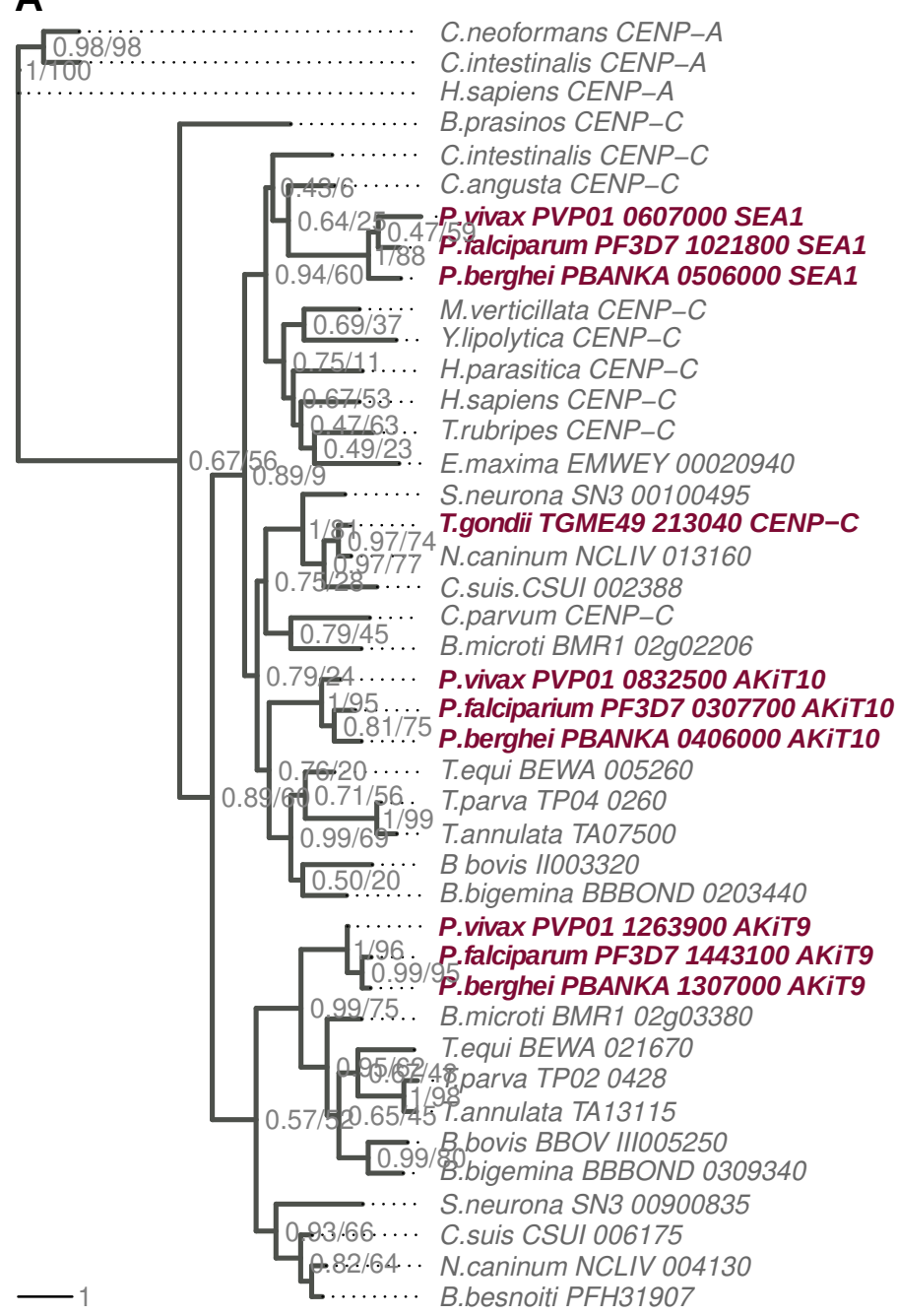

C

tachyzoite mitotic spindles

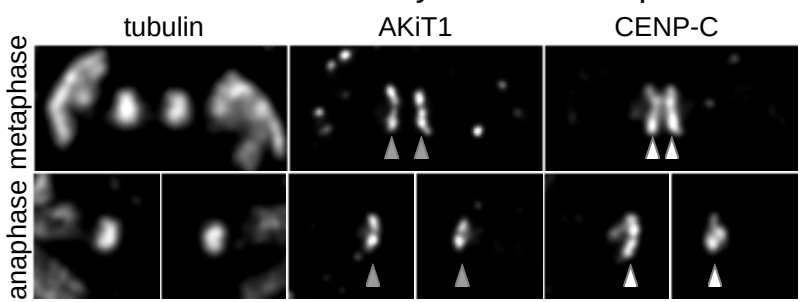

B

asexual tachyzoite-stages

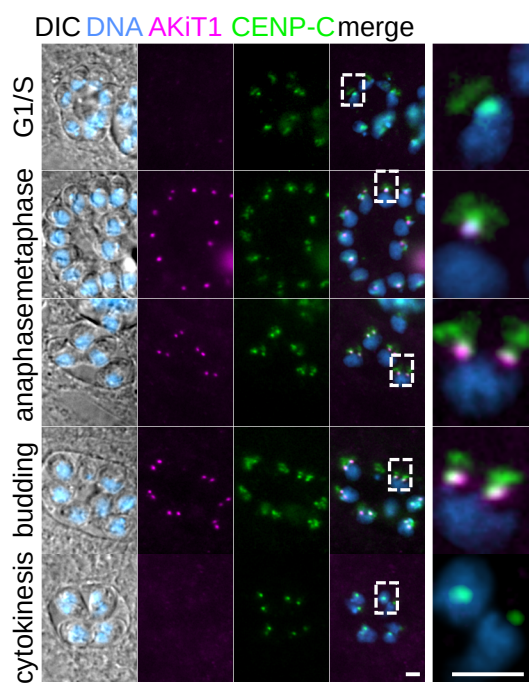

D

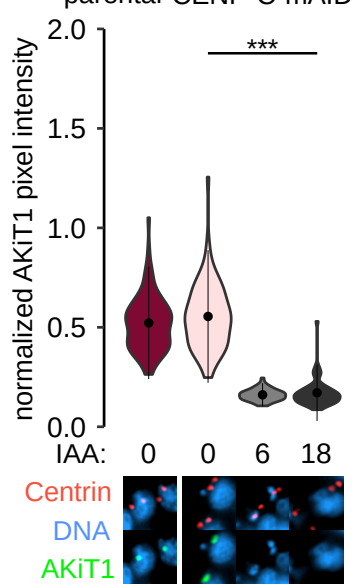

E

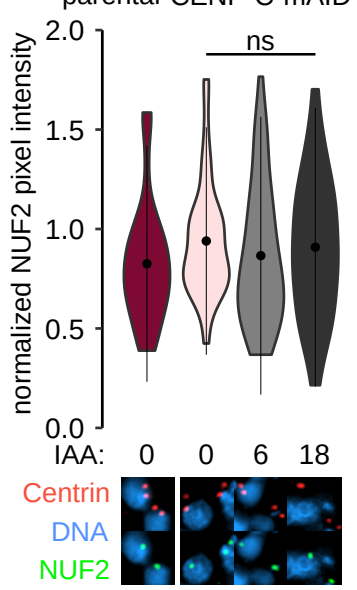
AKIT1 CENP-C

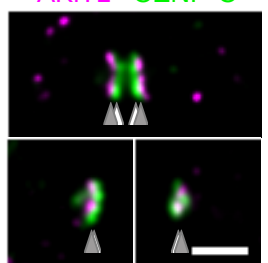


Figure 7. AKiT1 localization to kinetochores is dependent upon CENP-C in Toxoplasma. (A) Result of a maximum likelihood inference based on an alignment of sequences retrieved following iterative HMM scans for homologs of Plasmodium AKiT9 (PBANKA_1307000), AKiT10 (PBANKA_0406000) and

580 SEA1 (PBANKA_0506000). Numbers beside nodes indicate support from Bayesian posterior probabilities / maximum likelihood-bootstrap values (100 replicates). (B) Micrographs of Toxoplasma gondii tachyzoites expressing TgCENP-C fused to mAID-3xHA (green) and AKiT1-2xTy (magenta) throughout intracellular divisions. Counter-staining of DNA with DAPI (cyan) and DIC images are also shown. Bar: $5 \mu \mathrm{m}$. (C) U-ExM revealed CENP-C (green) localizes to the centromeric side of the

585 metaphase plate relative to AKiT1 (magenta). Bar: $1 \mu \mathrm{m}$. (D \& E) Levels and localization of NUF2 and AKiT1 kinetochore components in cells at 0,6 and $18 \mathrm{~h}$ post-depletion of CENP-C, assessed by immunofluorescence against Centrin1 and 2xTy tagged protein. Representative images shown below. DNA stain DAPI. 
bioRxiv preprint doi: https://doi.org/10.1101/2021.11.03.466924 this version posted November 3, 2021. The copyright holder for this preprint (which was not certified by peer review) is the author/funder, who has granted bioRxiv a license to display the preprint in perpetuity. It is made available under aCC-BY-NC 4.0 International license.

\section{Supplementary figures}

\section{Figure S1}

A

S. cerevisiae

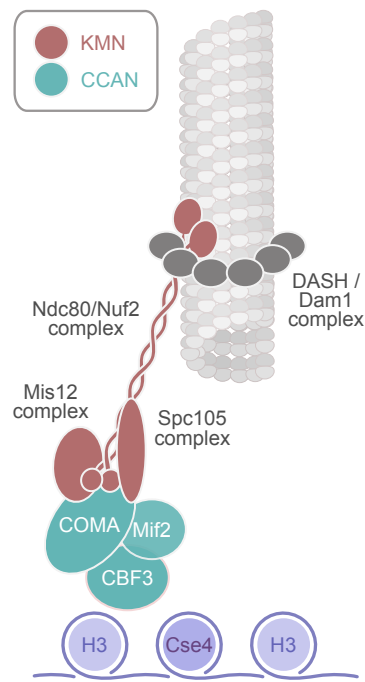

Centromere
H. sapiens

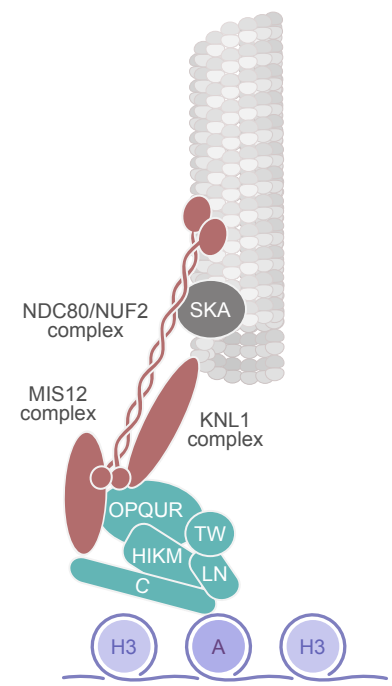

Centromere
P. berghei

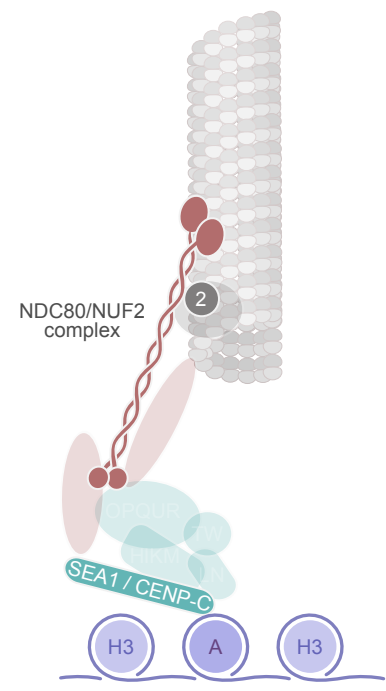

Centromere
T. gondii

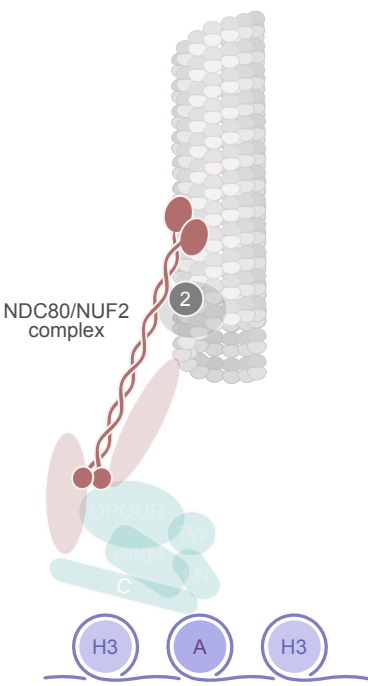

Centromere
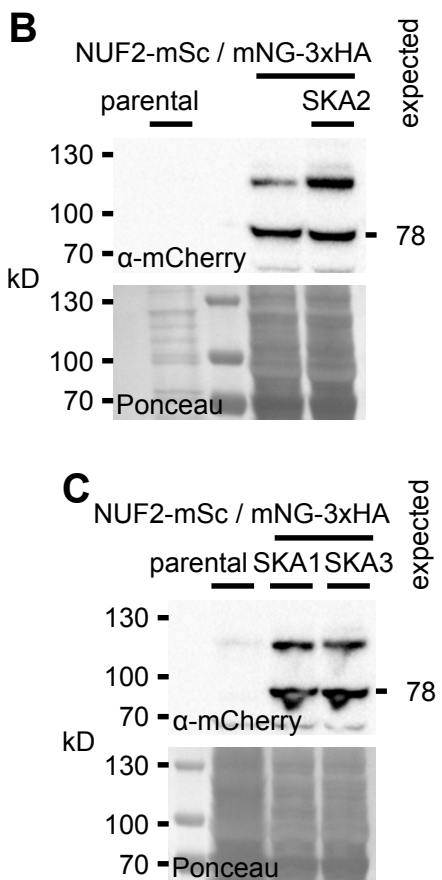

E

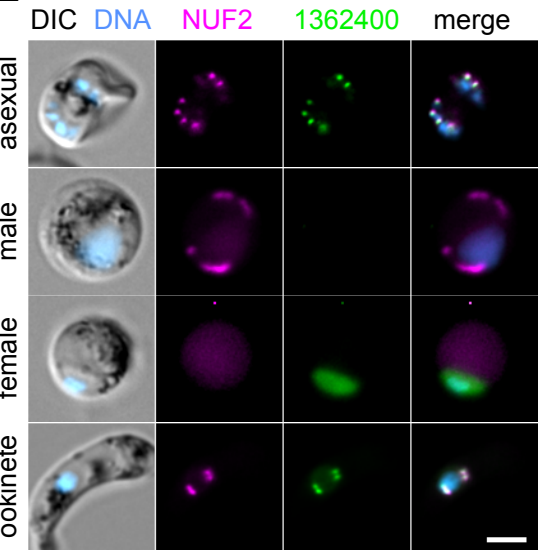

C

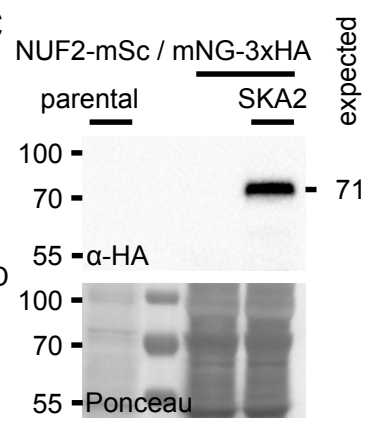

D NUF2-mSc / mNG-3xHA parental SKA1SKA3 100 -

$70=$

70

kD

$55=\alpha-H A$

$100=$

70 -

55 -Ponceau

F

DIC DNA NUF2 0812300 merge

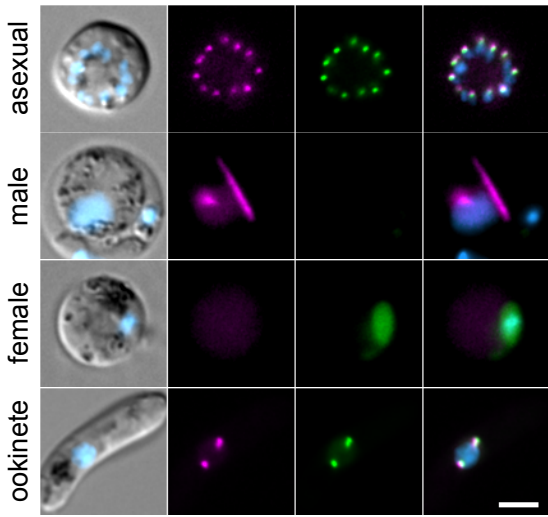


Figure S1. Generation and validation of tagged NUF2 and SKA components in Plasmodium. (A)

590 Presence/absence (bold/grey) of kinetochore proteins from model organisms in Plasmodium and Toxoplasma. Whilst most known components are apparently missing, the NDC80/NUF2 complex and SKA2 are present. (B-D) Immunoblots of malaria parasites expressing tagged kinetochore proteins, probed with either polyclonal $\alpha-m$ Cherry or monoclonal $\alpha-H A$ antibodies. Protein loading is shown by Ponceau $S$ stain. (B) Live native fluorescence validated SKA2-interacting proteins tagged with mNG-

$5953 \times 3$ H localize to kinetochore foci during asexual blood stages and sexual mosquito stages of development. Counter-staining of DNA with Hoechst 33342 (cyan) and DIC images are also shown. Bar: $2 \mu \mathrm{m}$. 
bioRxiv preprint doi: https://doi.org/10.1101/2021.11.03.466924: this version posted November 3, 2021. The copyright holder for this preprint (which was not certified by peer review) is the author/funder, who has granted bioRxiv a license to display the preprint in perpetuity. It is made available under aCC-BY-NC 4.0 International license.

Figure S2

A alveolate SKA vs kinetochore HMMs

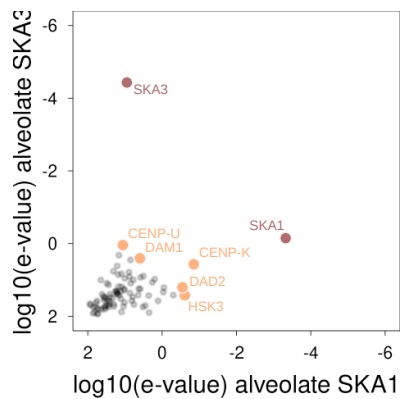

C

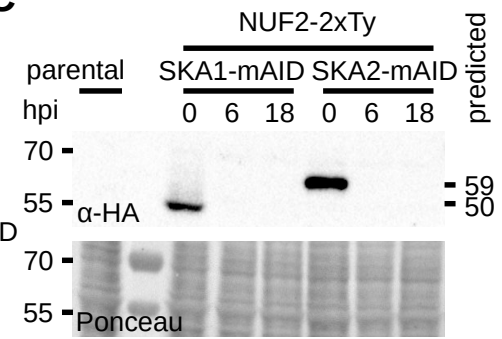

B

eukaryotic SKA vs kinetochore HMMs

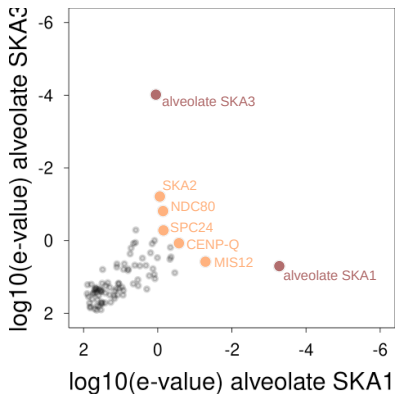

D

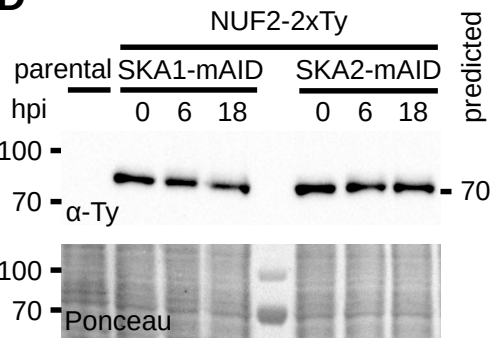

$\mathbf{E}$

DIC DNA marker 3XHA merge
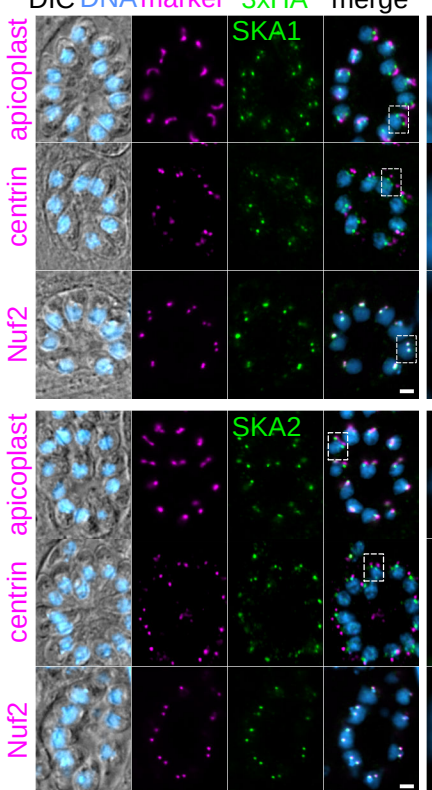

$\mathbf{F}$

parental

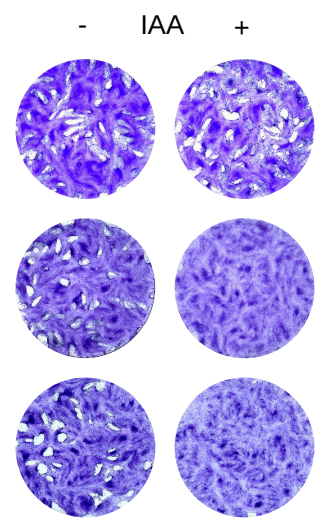

G

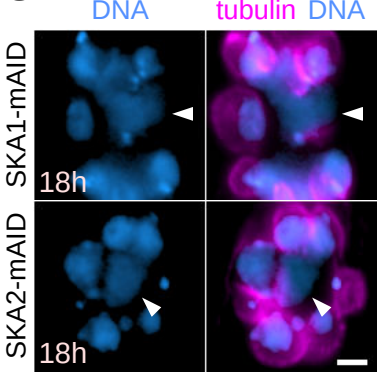


Figure S2. Generation and validation of tagged NUF2 and SKA components in Toxoplasma. (A \& B) Reciprocal HMM profile-profile comparisons using kinetochore HMMs, including alveolate 600 homologs of SKA2-interacting proteins PBANKA_0812300 and PBANKA_1362400 and pan-eukaryotic SKA1 and SKA3 HMMs, identify one another as highest scoring hits, respectively. In red are high confidence/scoring HMMs and in orange low confidence hits. (C \& D) Immunoblots of $T$. gondii parasites expressing tagged kinetochore proteins and showing depletion of mAID-3xHA tagged protein upon induction of auxin. Protein loading is shown by Ponceau $S$ stain. (E) Micrographs of fixed

605 immunofluorescence in T. gondii tachyzoites expressing tagged SKA1 and SKA2 throughout intracellular divisions. Counter-staining with antibodies raised against organelle markers (magenta) for the apicoplast (CPN60), centrosome (Centrin1) and kinetochores (NUF2-2xTy). DNA staining with DAPI (cyan) and DIC images are also shown. Bar: $5 \mu \mathrm{m}$. (F) Tachyzoites depleted for SKA1 or SKA2 tagged with a mini auxininducible degron (mAID-3xHA) failed to form lysis plaques 7 days post-inoculation compared to parental

610 controls. (G) Intracellular vacuoles containing accumulations of DNA (arrow) and no associated cell body were present 18 hours post-depletion of SKA1 or SKA2 tagged with mAID-3xHA. Bar: $5 \mu \mathrm{m}$. 
bioRxiv preprint doi: https://doi.org/10.1101/2021.11.03.466924; this version posted November 3, 2021. The copyright holder for this preprint (which was not certified by peer review) is the author/funder, who has granted bioRxiv a license to display the preprint in perpetuity. It is made available under aCC-BY-NC 4.0 International license.

Figure S3

A

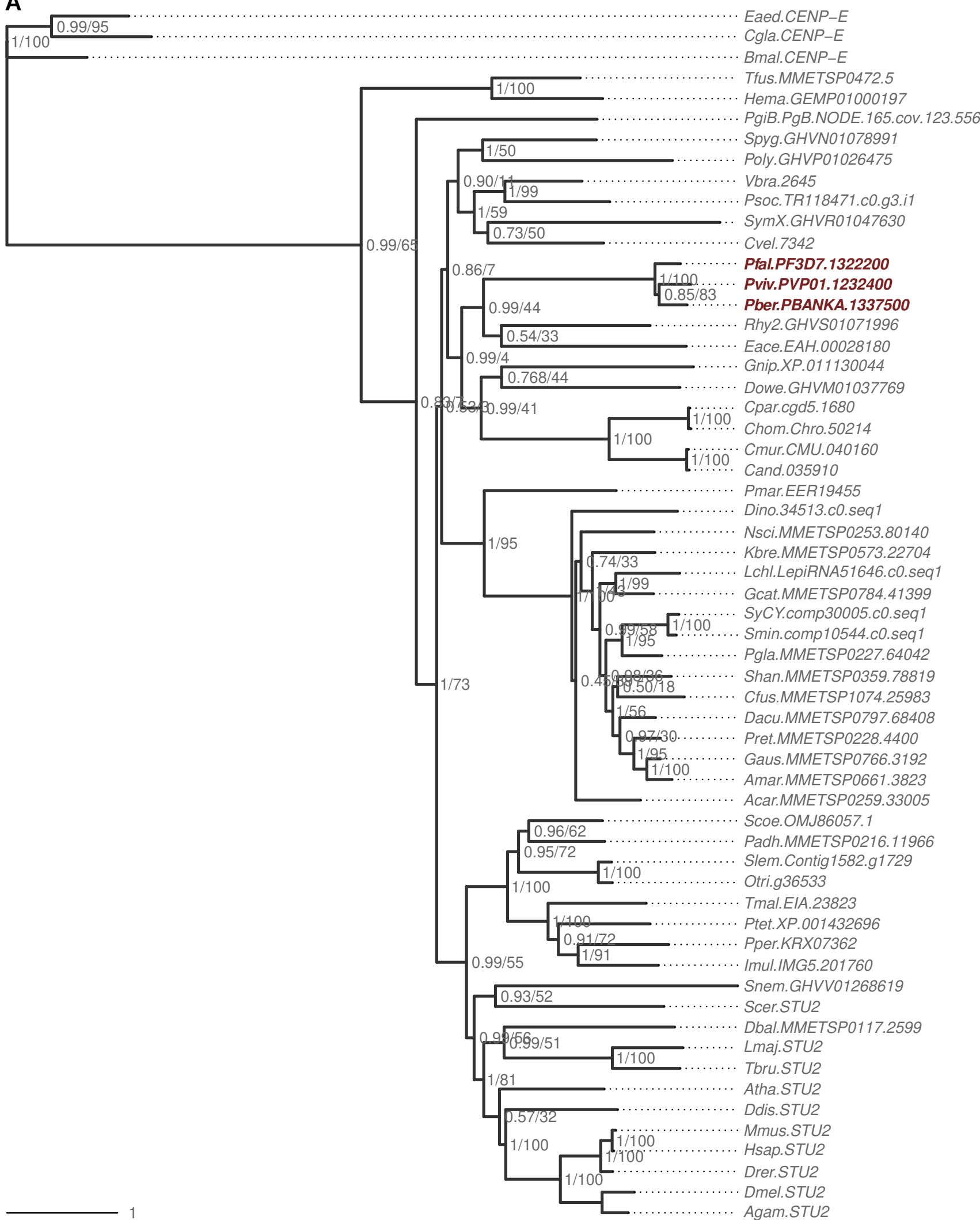


bioRxiv preprint doi: https://doi.org/10.1101/2021.11.03.466924; this version posted November 3, 2021. The copyright holder for this preprint (which was not certified by peer review) is the author/funder, who has granted bioRxiv a license to display the preprint in perpetuity. It is made available under aCC-BY-NC 4.0 International license.

Figure S3 cont.

B

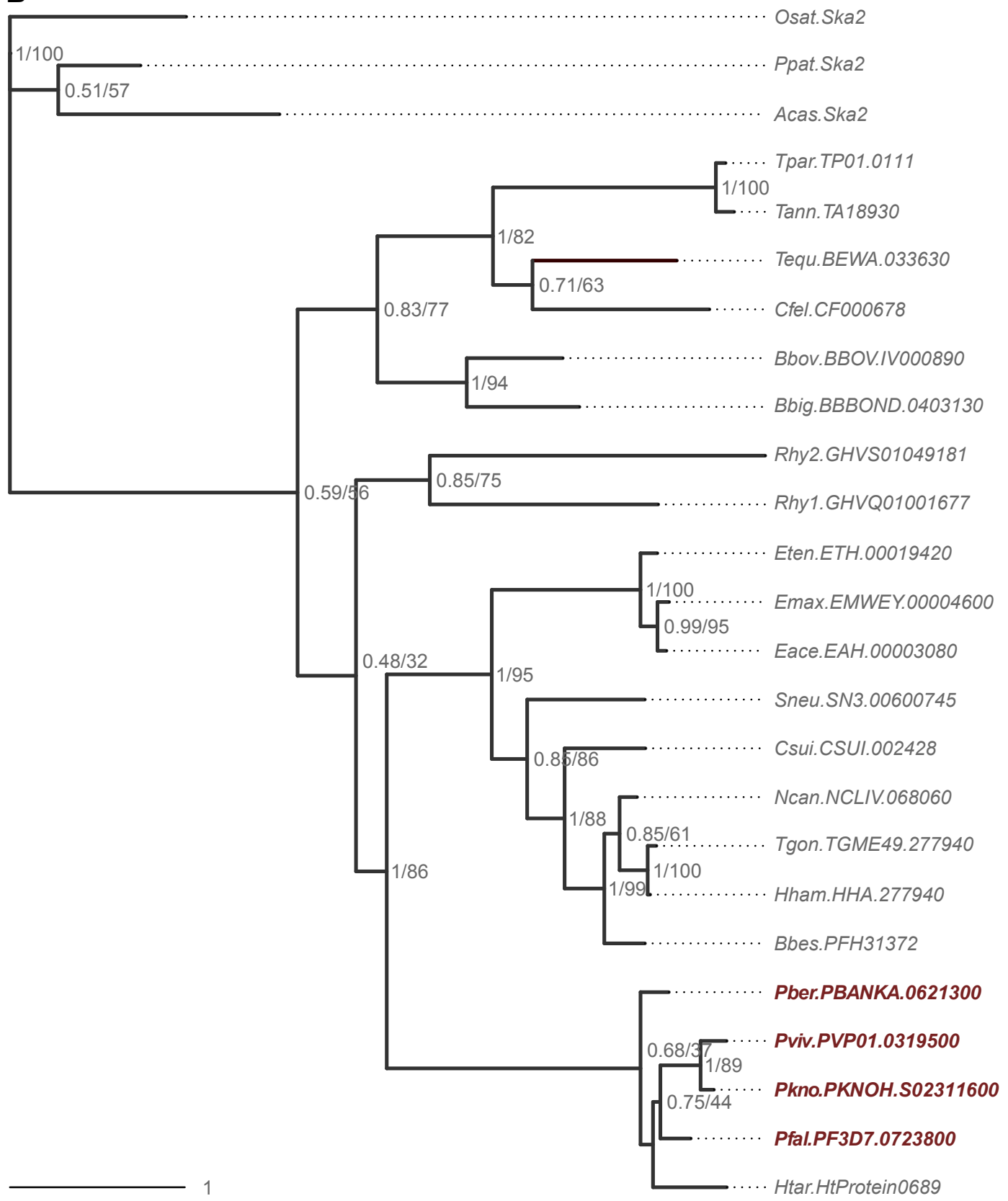


bioRxiv preprint doi: https://doi.org/10.1101/2021.11.03.466924; this version posted November 3, 2021. The copyright holder for this preprint (which was not certified by peer review) is the author/funder, who has granted bioRxiv a license to display the preprint in perpetuity. It is made available under aCC-BY-NC 4.0 International license.

Figure S3 cont.

C

sexual mosquito-stages
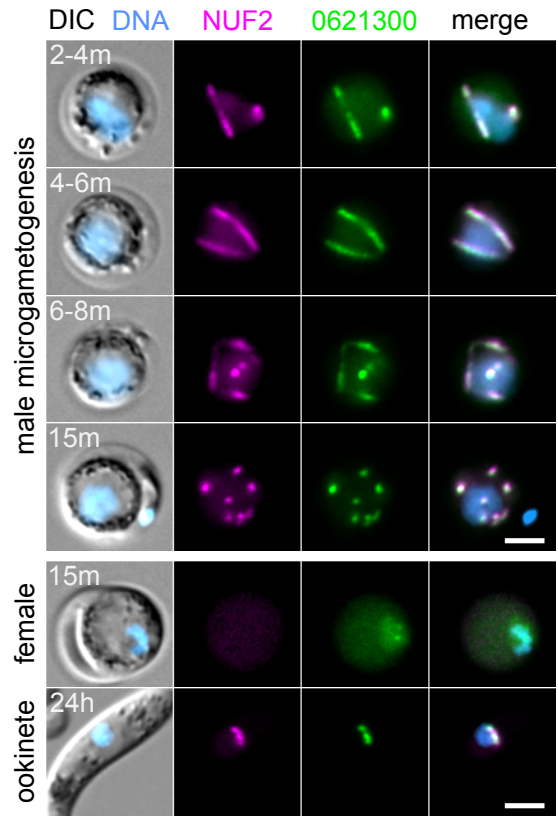

D

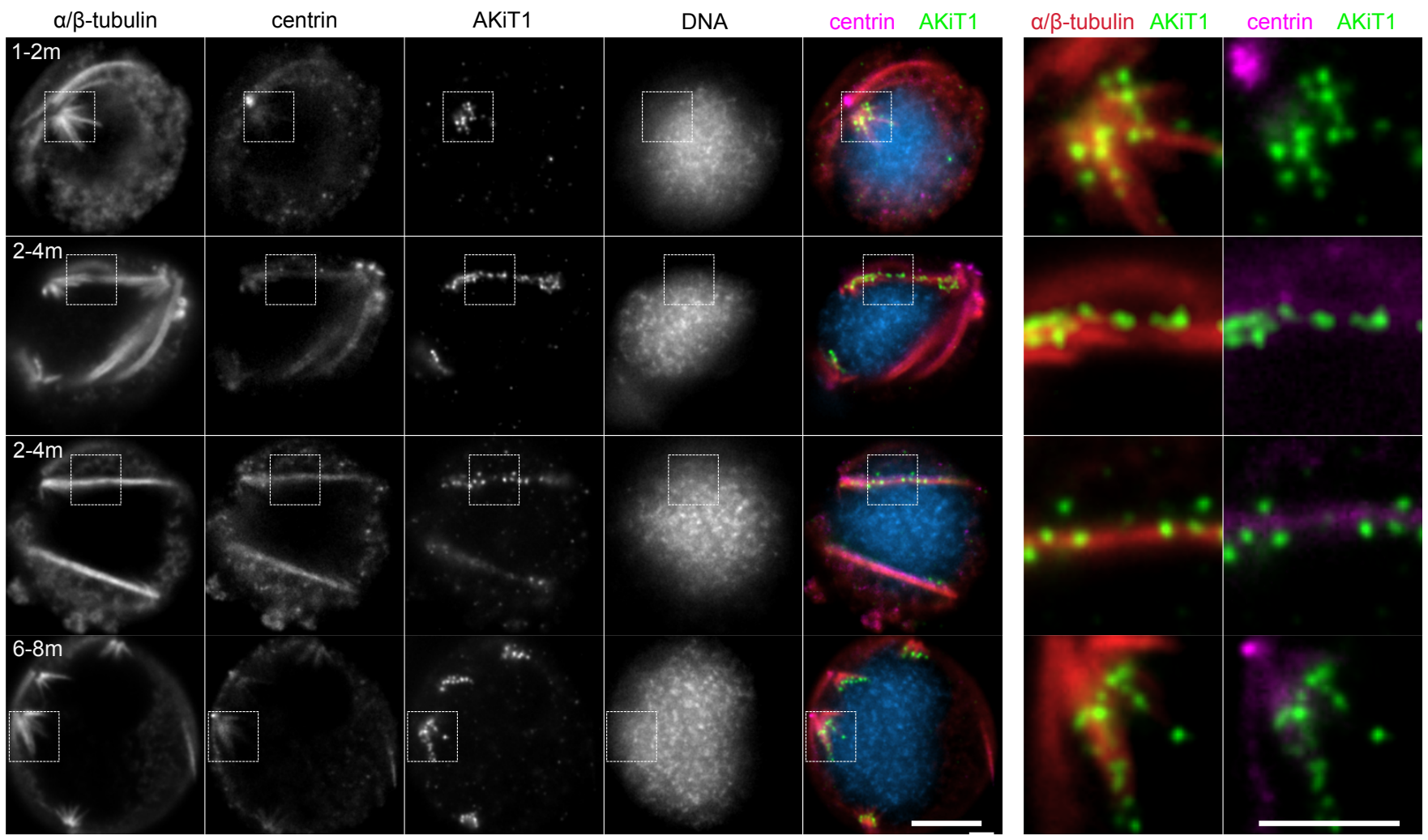


Figure S3. Cross-linking IP of NUF2 identifies novel Plasmodium kinetochore proteins. Result of a maximum likelihood inference based on an alignment of sequences retrieved following iterative HMM scans for homologs of STU2 (PBANKA_1337500; A) and AKiT1 (PBANKA_0621300; B). Numbers beside

615 nodes indicate support from Bayesian posterior probabilities / maximum likelihood-bootstrap values (100 replicates). (C) Micrographs of live native fluorescence in malaria parasites expressing tagged kinetochore components NUF2-mScarlet-I (magenta) and AKiT1-mNeonGreen-3xHA (green) during sexual mosquito-stages of development. Counter-staining of DNA with Hoechst 33342 (cyan) and differential interference contrast images (DIC) are also shown. Bar: $2 \mu \mathrm{m}$. (D) Widefield micrographs of

620 malaria parasites expressing tagged kinetochore components NUF2-mScarlet-I (magenta) and AKiT1mNeonGreen-3xHA (green) during microgametogenesis. U-ExM revealed AKiT1 along the spindle (identified by $\alpha / \beta$-tubulin counter-stain) and at spindle poles (centrin). Counter-staining of DNA with DAPI (cyan) also shown. Bar: $2 \mu \mathrm{m}$. 
bioRxiv preprint doi: https://doi.org/10.1101/2021.11.03.466924; this version posted November 3, 2021. The copyright holder for this preprint (which was not certified by peer review) is the author/funder, who has granted bioRxiv a license to display the preprint in perpetuity. It is made available under aCC-BY-NC 4.0 International license.

Figure S4

A

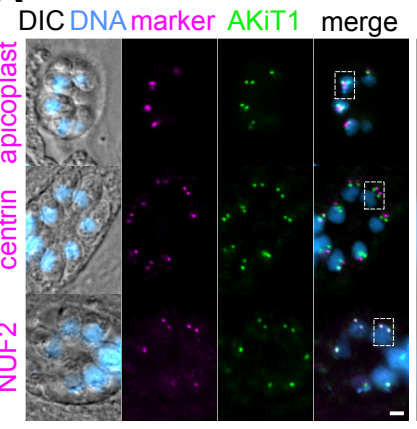

D

AKiT1-mAID
B

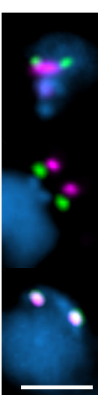

$$
\begin{aligned}
& \text { NUF2-2xTy / 용 } \\
& \text { ppi } \frac{\text { parental AKiT1-mAID }}{0 \quad 6 \quad 18}
\end{aligned}
$$$$
250 \text { - }
$$$$
k D^{130-\alpha-H A}
$$$$
250-
$$$$
130 \text {-Ponceau }
$$

C

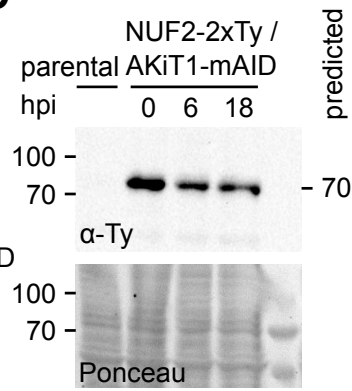

E

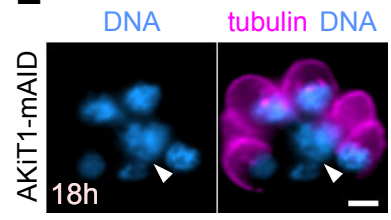


Figure S4. AKiT1 is required for kinetochore segregation in Toxoplasma gondii. (A) Micrographs of

625 fixed immunofluorescence in T. gondii tachyzoites expressing AKiT1-mAID-3xHA throughout intracellular divisions. Counter-staining with antibodies raised against organelle markers (magenta) for the apicoplast (CPN60), centrosome (Centrin1) and kinetochores (NUF2-2xTy). DNA staining with DAPI (cyan) and DIC images are also shown. Bar: $5 \mu \mathrm{m}$. (B \& C) Immunoblots of $T$. gondii parasites expressing tagged kinetochore proteins and showing depletion of tagged AKiT1 protein upon induction of auxin. Protein

630 loading is shown by Ponceau S stain. (D) Depletion of AKiT1-mAID-3xHA prevented proper formation of lysis plaques 7 days post-inoculation compared to parental controls. (E) Intracellular vacuoles containing abnormal accumulations of DNA (arrow) were present 18 hours post-depletion of AKiT1-mAID-3xHA. Bar: $5 \mu \mathrm{m}$. 
bioRxiv preprint doi: https://doi.org/10.1101/2021.11.03.466924; this version posted November 3, 2021. The copyright holder for this preprint (which was not certified by peer review) is the author/funder, who has granted bioRxiv a license to display the preprint in perpetuity. It is made available under aCC-BY-NC 4.0 International license.

\section{Figure S5}

A
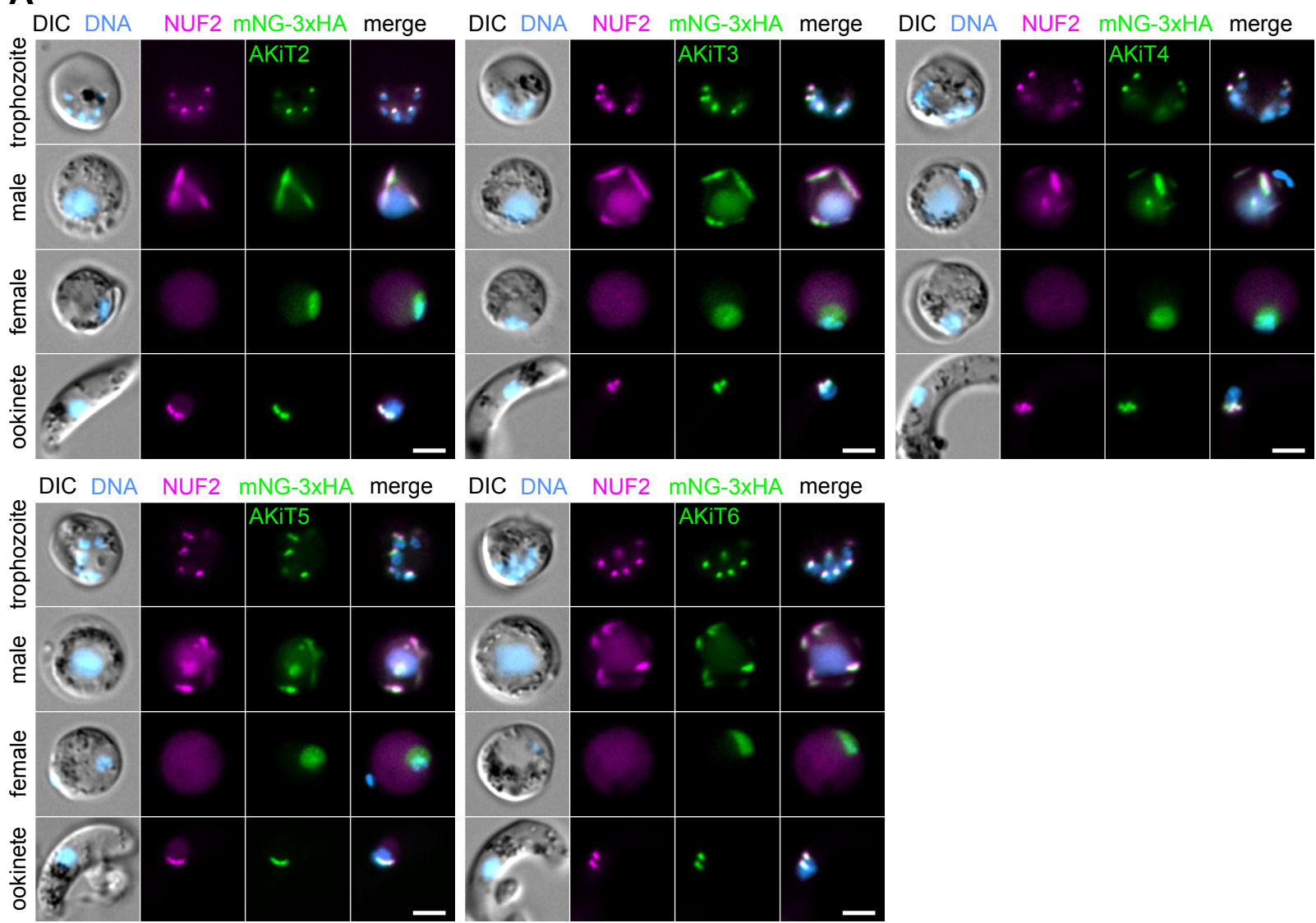

DIC DNA NUF2 mNG-3xHA merge

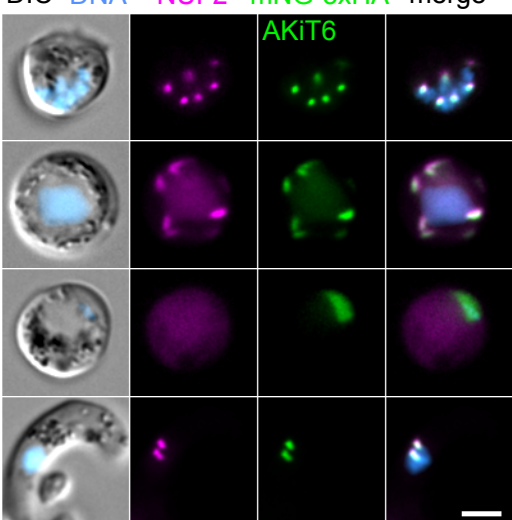

B
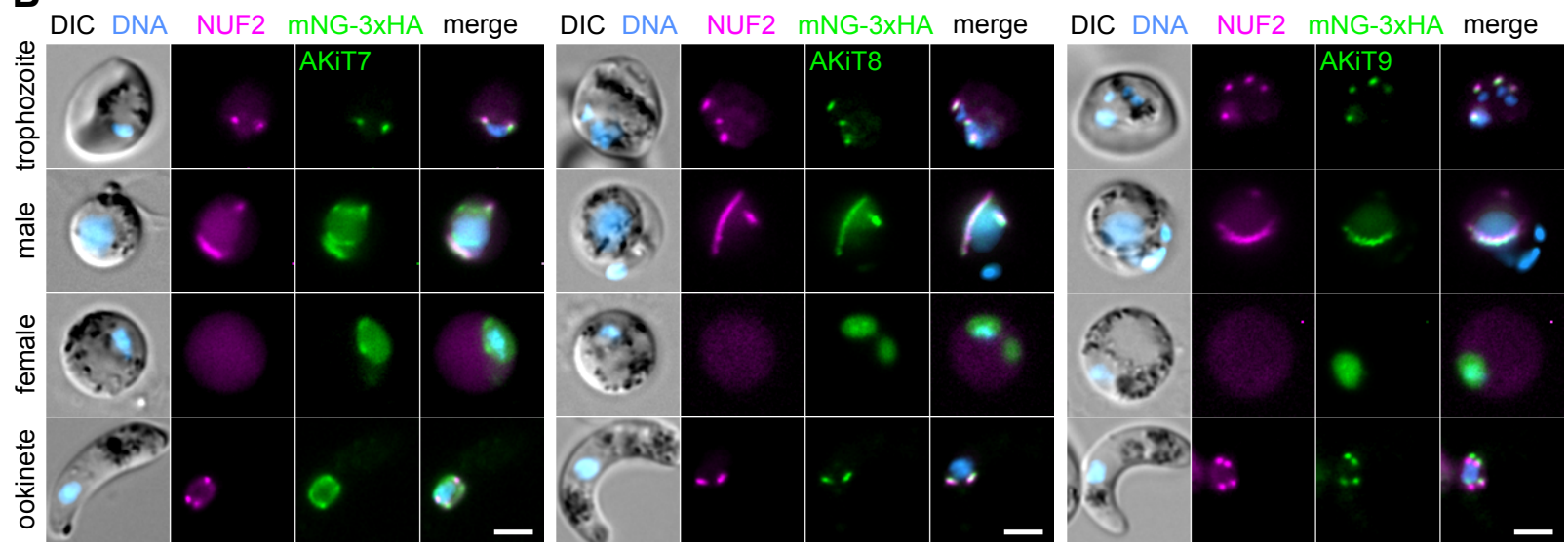
bioRxiv preprint doi: https://doi.org/10.1101/2021.11.03.466924; this version posted November 3, 2021. The copyright holder for this preprint (which was not certified by peer review) is the author/funder, who has granted bioRxiv a license to display the preprint in perpetuity. It is made available under aCC-BY-NC 4.0 International license.

Figure S5 cont.

C

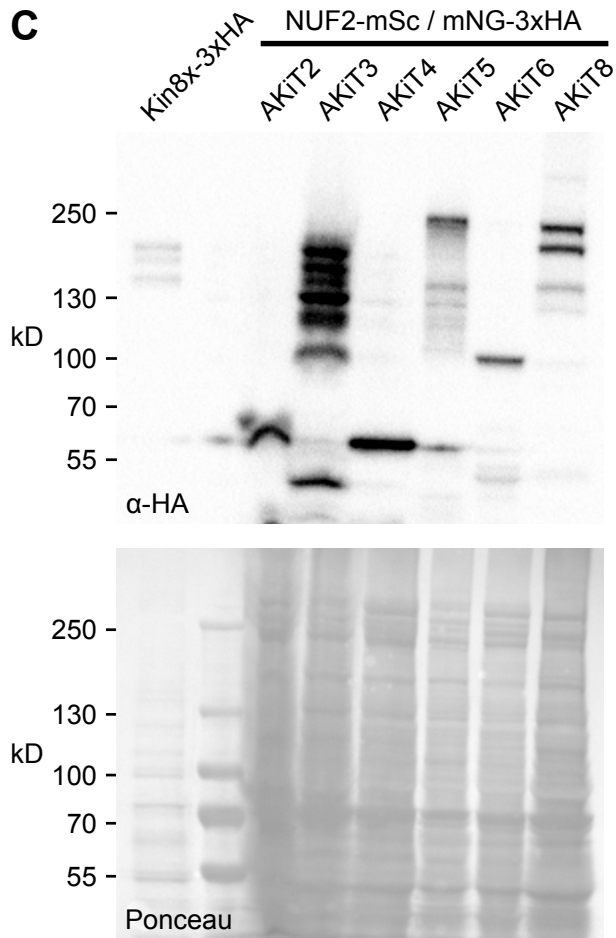

NUF2-mSc / mNG-3xHA

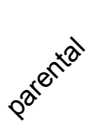

$250-$

130 -

$\mathrm{kD}$

$100-$

$70-$

$55-$

$\alpha-\mathrm{HA}$

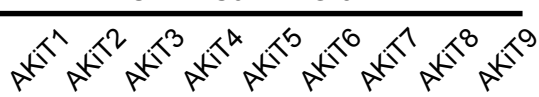

expected mobility $(\mathrm{kD})$

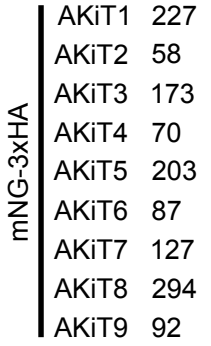

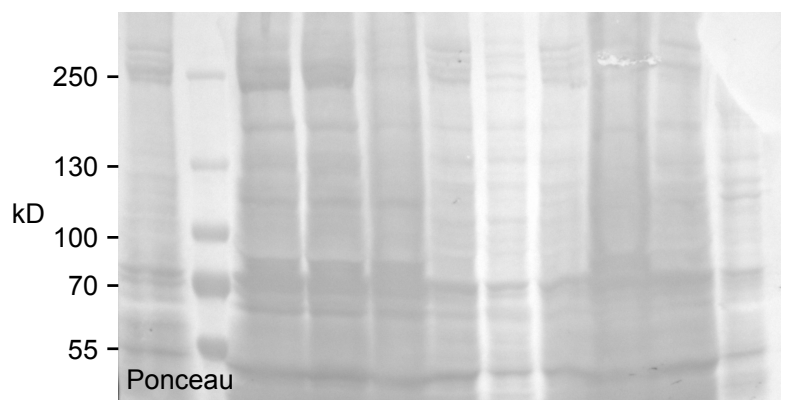


bioRxiv preprint doi: https://doi org/10.1101/2021.11.03.466924 t this version posted November 3, 2021. The copyright holder for this preprint (which was not certified by peer review) is the author/funder, who has granted bioRxiv a license to display the preprint in perpetuity. It is made available under aCC-BY-NC 4.0 International license.

Figure S5. AKiTs are novel identified components of the Plasmodium kinetochore. Micrographs of 635 live native fluorescence in malaria parasites expressing NUF2-mScarlet-I (magenta) and tagged AKiTs 1 - 6 (A) and AKiTs 7-9 (B) with mNG-3xHA (green) at proliferative stages of the lifecycle. Counter-staining of DNA with Hoechst 33342 (cyan) and differential interference contrast images (DIC) are also shown. Bar: $2 \mu \mathrm{m}$. (B) Immunoblots of malaria parasites expressing tagged AKiT proteins, probed with a monoclonal $\alpha-\mathrm{HA}$ antibody. Protein loading is shown by Ponceau $\mathrm{S}$ stain. 
bioRxiv preprint doi: https://doi.org/10.1101/2021.11.03.466924; this version posted November 3, 2021. The copyright holder for this preprint (which was not certified by peer review) is the author/funder, who has granted bioRxiv a license to display the preprint in perpetuity. It is made available under aCC-BY-NC 4.0 International license.

\section{Figure S6}

A

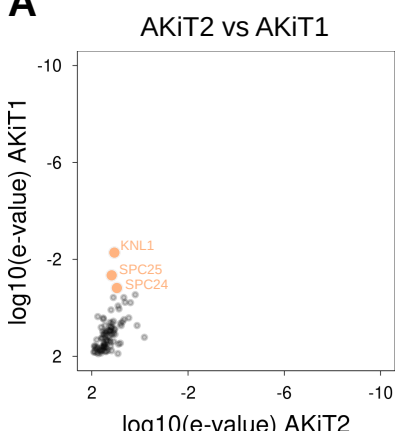

E

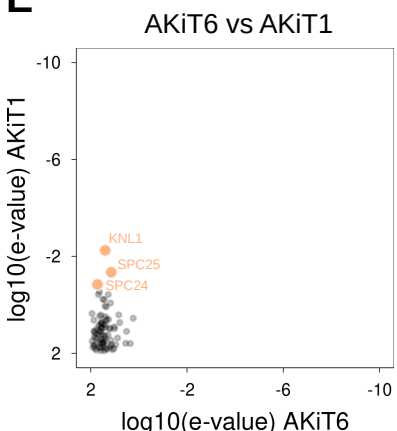

B

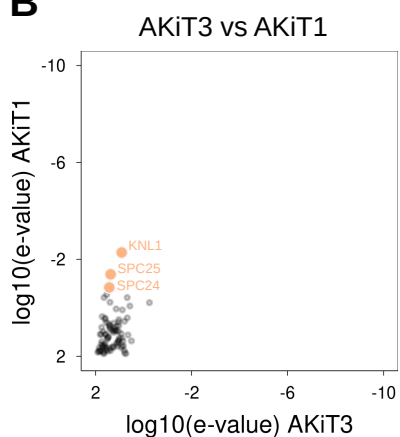

$\mathbf{F}$

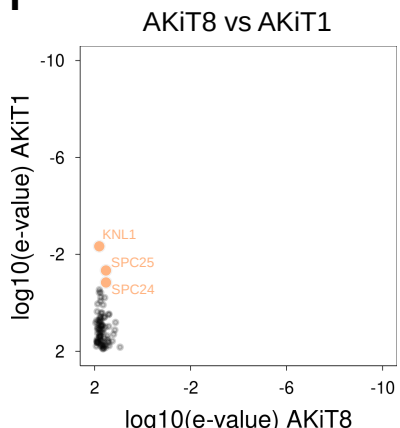

C

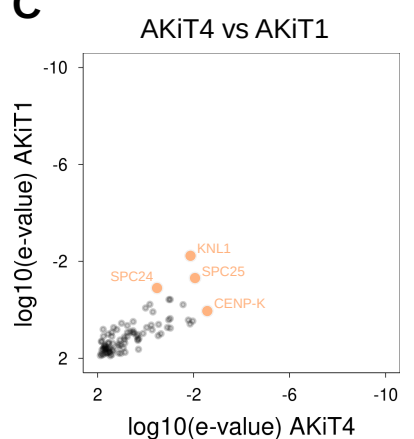

G

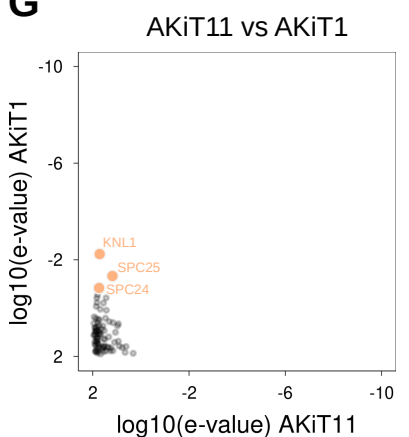

I

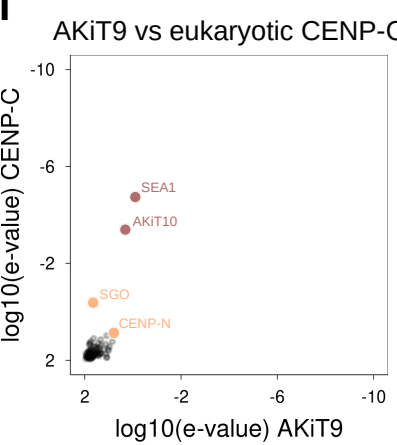

K

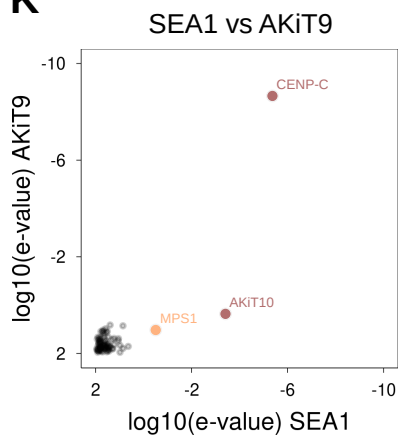

$\log 10($ e-value) SEA1

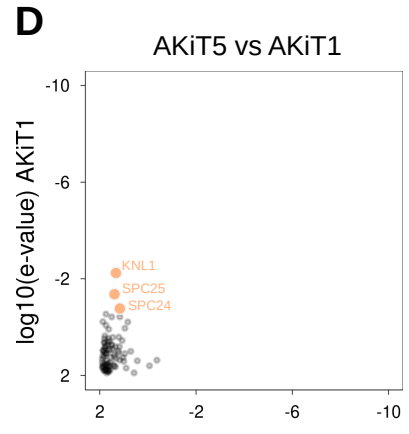

$\log 10$ (e-value) AKiT5

H

N. vectensis $K n l 1$

D. melanogaster Knl1

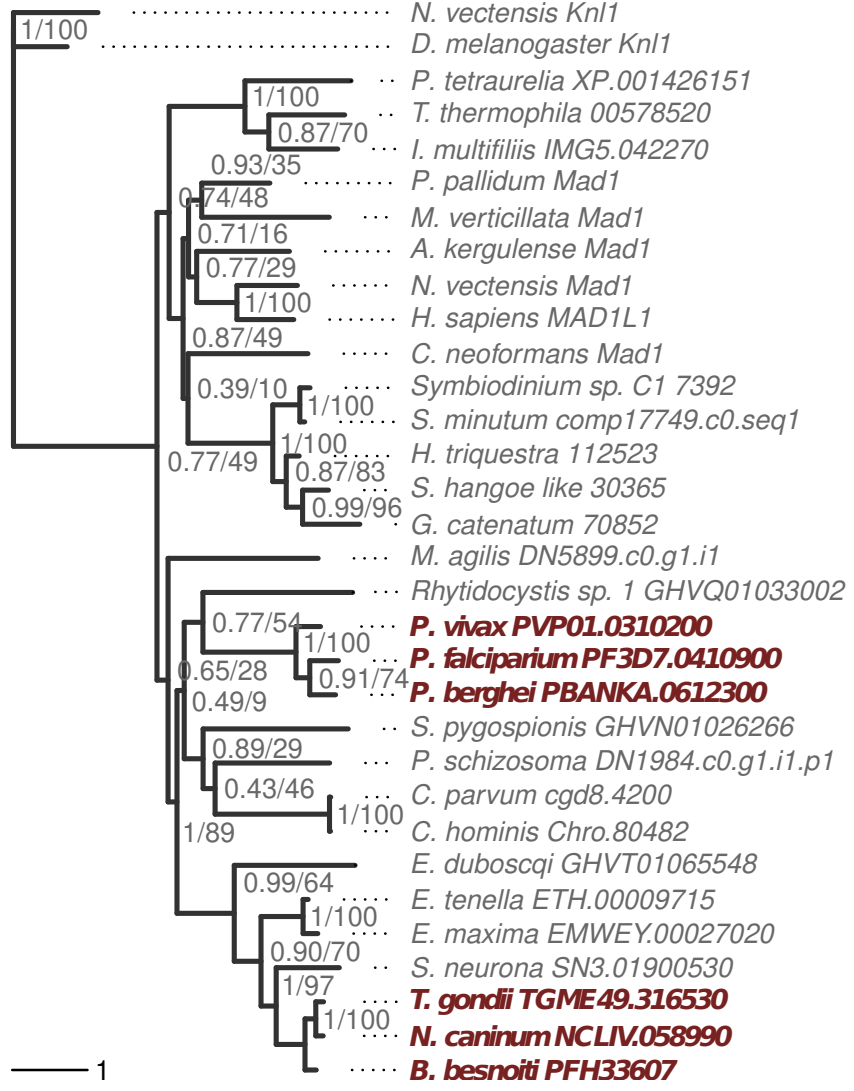

J

AKiT10 vs eukaryotic CENP-C

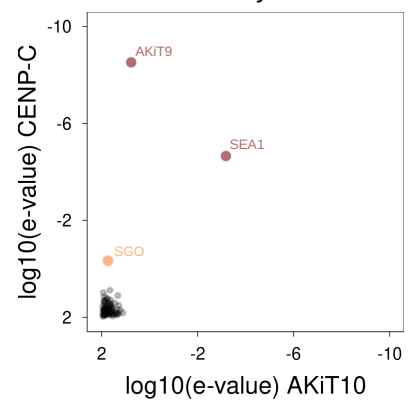

$\mathbf{L}$

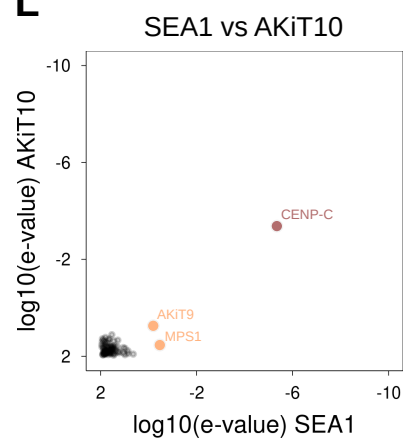


640 Figure S6. Most AKiTs are not similar to known kinetochore components. (A - G \& I - L) HMM profile-profile comparisons using kinetochore HMMs that include alveolate homologs of AKiT proteins and using against AKiT1 as a control set. In red are high confidence/scoring HMMs and in orange low confidence hits. $(\mathrm{H})$ Result of a maximum likelihood inference based on an alignment of sequences retrieved following iterative HMM scans for homologs of Plasmodium AKiT7 (PBANKA_0612300).

645 Numbers beside nodes indicate support from Bayesian posterior probabilities / maximum likelihoodbootstrap values (100 replicates). 
bioRxiv preprint doi: https://doi.org/10.1101/2021.11.03.466924; this version posted November 3, 2021. The copyright holder for this preprint (which was not certified by peer review) is the author/funder, who has granted bioRxiv a license to display the preprint in perpetuity. It is made available under aCC-BY-NC 4.0 International license.

Figure S7

A

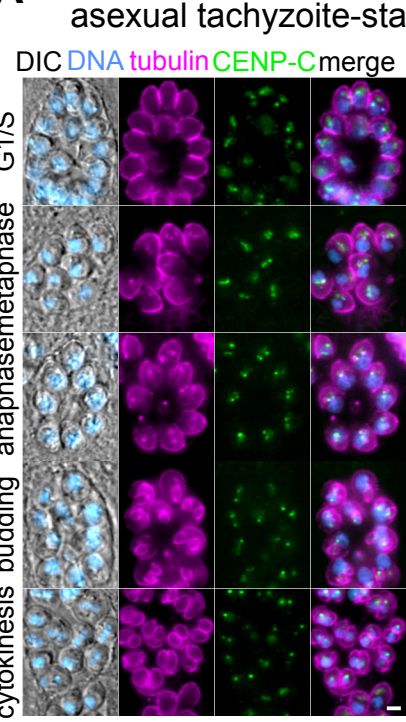

C

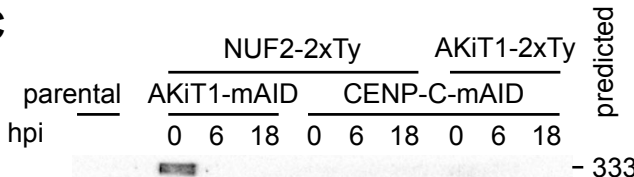

$250-$

$\mathrm{kD}^{130-\alpha-\mathrm{HA}}$

$250-$

130 - Ponceau

D IAA

parental

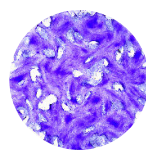

CENP-C-mAID
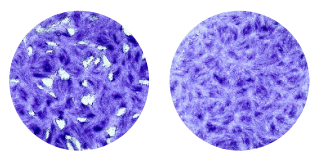

E

parental CENP-C-mAID DNA tubulin

$n=825685467390$

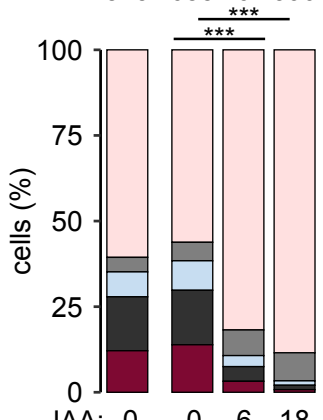

time (h)
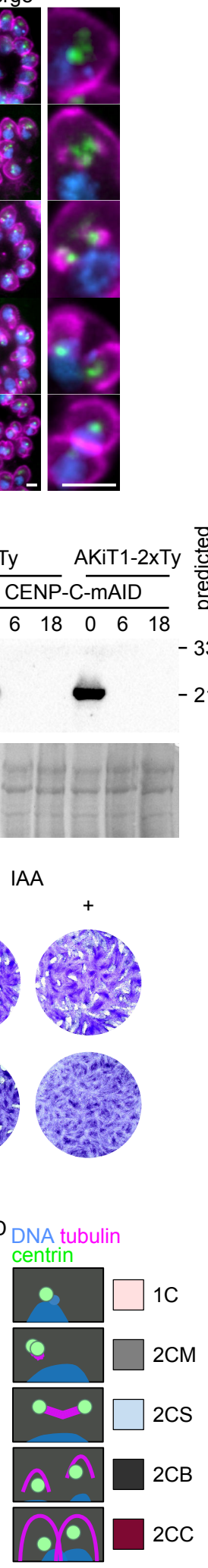

B

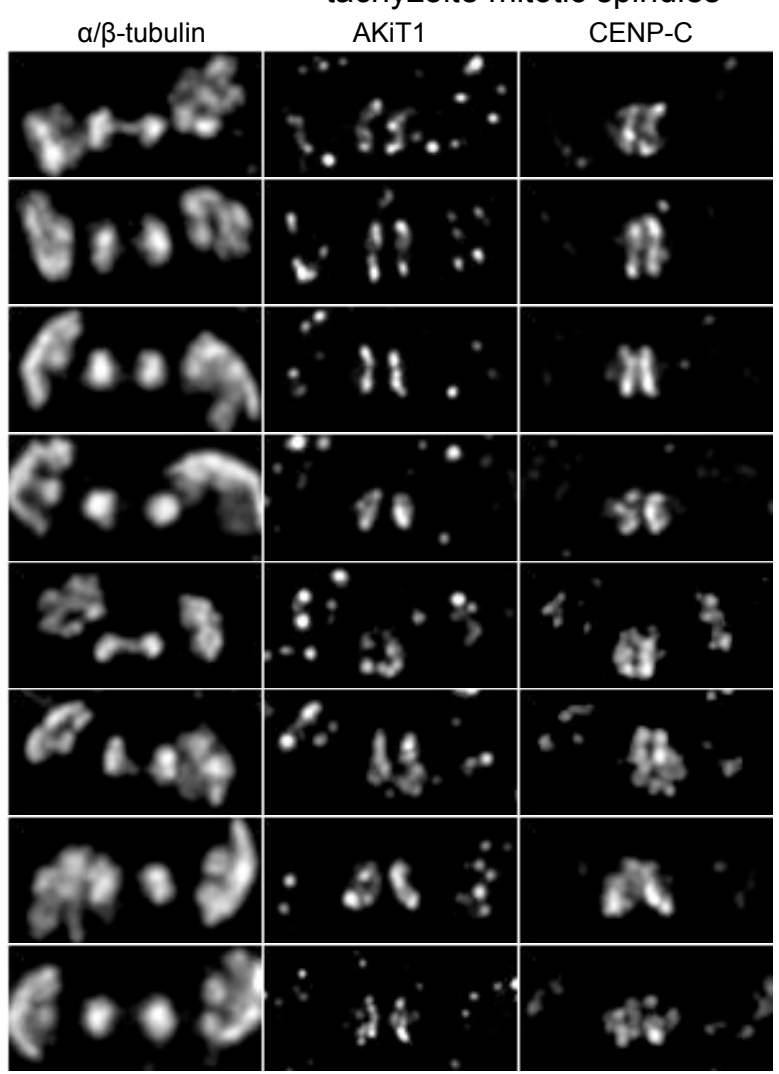

tachyzoite mitotic spindles

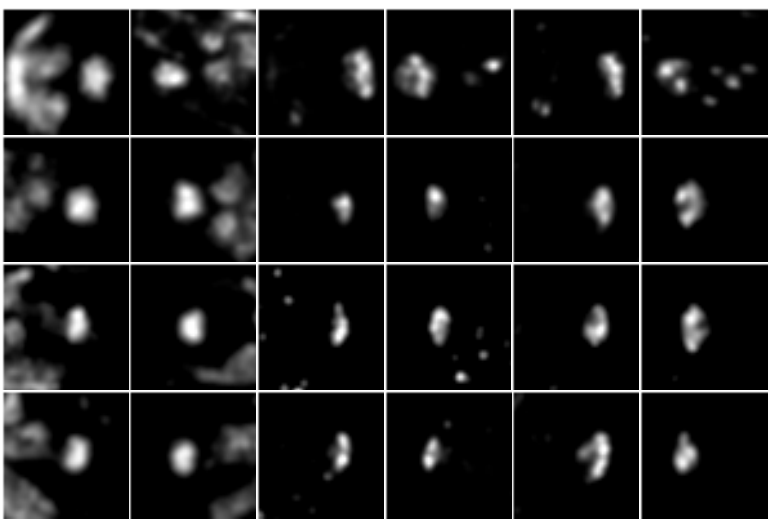

AKiT1 CENP-C
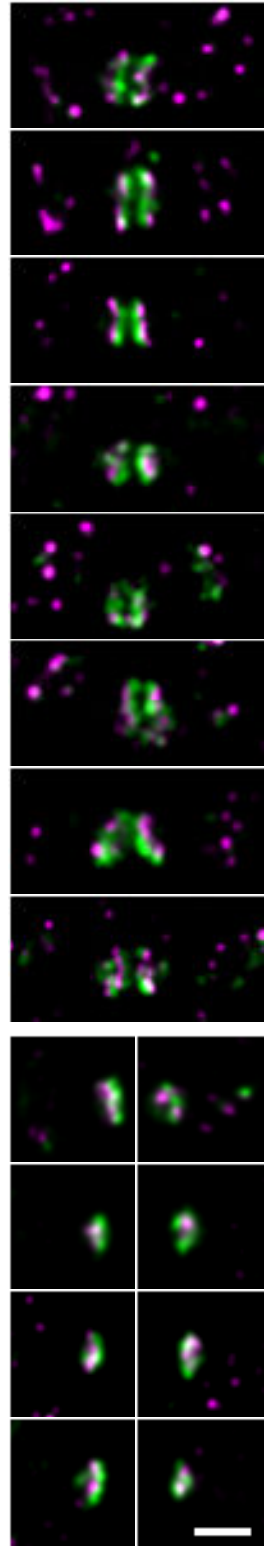
Figure S7. CENP-C is required for T. gondii parasite proliferation. (A) Micrographs of fixed immunofluorescence in $T$. gondii tachyzoites expressing tagged CENP-C-mAID-3xHA throughout intracellular divisions. Counter-staining of tubulin (magenta) and DNA staining with DAPI (cyan), in 650 addition to DIC images are also shown. Bar: $5 \mu \mathrm{m}$. (B) U-ExM revealed tagged CENP-C (green) localizes to the centromeric side of the metaphase plate relative to AKiT1 (magenta). Bar: $1 \mu \mathrm{m}$. (C) Immunoblots of $T$. gondii parasites expressing tagged kinetochore proteins and showing depletion of tagged AKiT1 and CENP-C protein upon induction of auxin. Protein loading is shown by Ponceau $S$ stain. (D) Tachyzoites depleted for CENP-C-mAID-3xHA failed to form lysis plaques 7 days post-

655 inoculation compared to parental controls. (E) Morphological analysis of cells depleted for CENP-CmAID-3xHA shows a buildup of cells arrested at the onset of mitosis (1C), compared to cells with duplicated centrosomes and monopolar spindles (2CM), bipolar spindles (2CB), segregated centrosomes into daughter cell caps (2CS) and cells in cytokinesis (2CC), assessed by immunofluorescence against Centrin1 (green) and tubulin (magenta) ${ }^{* *}, \mathrm{P}<0.01 ;{ }^{* * *}, \mathrm{P}<0.001 ; \mathrm{Chi}^{2}$ 660 test). 
Table S1. Sources for detection of putative homologs of apicomplexan kinetochore proteins. Strategy and nomenclature follows as described (Koreny et al., 2021).

Table S2. Oligonucleotide primers used for generation of $P$. berghei and T. gondii transgenic parasites.

665 Table S3. Label-free semi quantitative mass spectrometry of $P$. berghei kinetochore proteins.

Table S4. Apicomplexan kinetochore proteins described in this study. Essentiality determined by mutagenesis screens deposited on PlasmoDB, for rodent and human malaria parasites (Bushell et al., 2017; Zhang et al., 2018), and ToxoDB, for T. gondii (Sidik et al., 2016). Toxoplasma protein subcellular compartmentalizations determined by HyperLOPIT (Barylyuk et al., 2020) are also shown.

670 Table S5. Antibodies for immunodetection and subcellular localization studies of tagged AKiTs. 


\section{Author Contributions}

Conceptualization: LB, MB. Methodology: LB. Software: LB. Formal analysis: LB. Investigation: LB, NDSP. Original draft preparation: LB. Review and editing: LB, NDSP, MB, DSF. Supervision: MB. Funding acquisition: MB, DSF. All authors contributed to the article and approved the submitted version.

\section{Acknowledgments}

Mass spectrometry and initial quantitation were performed at the Proteomics Core Facility, University of Geneva (www.unige.ch/medecine/proteomique). We thank in particular the service of Alexandre Hainard, Patrizia Arboit and Carla Pasquarello Mosimann in preparation and running of mass spectrometry samples. Microscopy was performed at the Bioimaging core facility, University of Geneva (www.unige.ch/

680 medecine/bioimaging/en/bioimaging-core-facility), and we thank for the technical assistance of Olivier Brun and François Prodon. We thank Natacha Klages for technical assistance. We also thank Bill Wickstead and Patrick Meraldi for general discussions and critical reading of the manuscript. This work was supported by the Swiss National Science Foundation grant 31003A_179321 MB and 310245753030_185325 DSF. MB is an INSERM and EMBO young investigator.

\section{Competing Interests}

The authors declare that they have no competing interests.

\section{Data and materials availability}

All data needed to evaluate the conclusions in the paper are present in the paper and/or the supplementary materials. Additional data or reagents are available from authors upon request.

690 Correspondence and requests for materials should be addressed to LB (lorenzo.brusini@unige.ch) and MB (mathieu.brochet@unige.ch). 


\section{Methods}

\section{Ethics statement}

695 All animal experiments were conducted with the authorization numbers AB_GE18, according to the guidelines and regulations issued by the Swiss Federal Veterinary Office.

\section{Generation of transgenic parasites targeting constructs}

The oligonucleotides used to generate transgenic parasite lines are in Table S2.

For C-terminal tagging of $P$. berghei proteins by PbGEM technology, 3xHA and mScarlet-I tagging

constructs were generated using phage recombineering in E. coli TSA strain with PlasmoGEM vectors (http://plasmogem.sanger.ac.uk/) using sequential recombineering and gateway steps as described previously (Pfander et al., 2011). For genes SKA2 and NUF2, the Zeocin-resistance/Phe-sensitivity cassette was introduced using oligonucleotides goi-recR1 $x$ goi-recR2 for 3xHA tagging and goi mSc-F $\mathrm{x}$ goi $\mathrm{mSc}-\mathrm{R}$ for $\mathrm{mSc}$ tagging vectors. Insertion of the $\mathrm{GW}$ cassette following gateway reaction was confirmed using primer pairs GW1 x goi-QCR1 and GW2 x goi-QCR2.

For C-terminal tagging of $P$. berghei proteins by $\mathrm{pCP}$, constructs were newly derived from pOB277 (Patzewitz et al., 2013) in order to target endogenous loci by allele replacement instead of insertion. Briefly a 588 bp fragment encompassing the coding sequence of 3xHA and DHFR flanked by Kpnl and EcoRI was amplified from PbGEM plasmid GW-R6K-3xHA using primers MB1033 and MB1034 and replaced the corresponding fragment in pOB277 to generate pCP-3xHA. The coding sequence for mNG flanked by Avrll and Sacll sites was purchased from GeneArt and inserted upstream to 3xHA to generate pCP-mNG-3xHA. Sequences comprising $\sim 500 \mathrm{bp}$ from the C-terminus of the coding sequence and 500 bp from the immediate 3' UTR for genes SKA1, SKA3 and AKiTs 1 - 9 were cloned into Kpnl and Avrll sites upstream to the mNG coding sequence, along with a Notl linearisation site between the 715 targeting sequences.

For C-terminal tagging of $T$. gondii, constructs were generated by KOD PCR as described in (Brown et al. 2018). Genomic DNA extractions were performed with the Wizard SV genomic DNA purification kit (Promega). PCRs to generate specific gRNAs were performed with Q5 polymerase (New England Biolabs) while PCRs to generate specific knock-in constructs (mAID fusions and epitope tagging) were

720 performed with KOD polymerase (Novagen). Specific gRNA were generated using the Q5 site-directed mutagenesis kit (New England Biolabs) on the pSAG1::Cas9-U6::sgUPRT vector, as described previously (Shen et al. 2014).

\section{Plasmodium berghei maintenance and transfection}

P. berghei ANKA strain-derived clones 2.34 (Billker et al., 2004) together with derived transgenic lines 725 were grown and maintained in CD1 outbred mice. Six to ten weeks-old mice were obtained from Charles 
bioRxiv preprint doi: https://doi.org/10.1101/2021.11.03.466924; this version posted November 3, 2021. The copyright holder for this preprint (which was not certified by peer review) is the author/funder, who has granted bioRxiv a license to display the preprint in perpetuity. It is made available under aCC-BY-NC 4.0 International license.

River laboratories and females were used for all experiments. Mice were specific pathogen free (including Mycoplasma pulmonis) and subjected to regular pathogen monitoring by sentinel screening.

They were housed in individually ventilated cages furnished with a cardboard mouse house and Nestlet, maintained at $21 \pm 2^{\circ} \mathrm{C}$ under a $12 \mathrm{hr}$ light/dark cycle and given commercially prepared autoclaved dry rodent diet and water ad libitum. The parasitaemia of infected animals was determined by microscopy of methanol-fixed and Giemsa-stained thin blood smears. For gametocyte production, parasites were grown in mice that had been phenyl hydrazine treated three days before infection. Exflagellation was induced in exflagellation medium (RPMI 1640 containing 25 mM HEPES, 4 mM sodium bicarbonate, 5\% fetal calf serum (FCS), $100 \mathrm{mM}$ xanthurenic acid, $\mathrm{pH}$ 7.8). For gametocyte purification, parasites were

735 harvested in suspended animation medium (SA; RPMI 1640 containing 25 mM HEPES, 5\% FCS, 4 mM sodium bicarbonate, $\mathrm{pH}$ 7.20) and separated from uninfected erythrocytes on a Histodenz/Nycodenz cushion made from $48 \%$ of a Histodenz/Nycodenz stock (27.6\% [w/v] Histodenz/Nycodenz [Sigma/ Alere Technologies] in $5.0 \mathrm{mM}$ Tris $\mathrm{HCl}, 3.0 \mathrm{mM} \mathrm{KCl}, 0.3 \mathrm{mM}$ EDTA, $\mathrm{pH} 7.20$ ) and 52\% SA, final $\mathrm{pH} 7.2$. Gametocytes were harvested from the interface.

740 Schizonts for transfection were purified from overnight in vitro culture on a Histodenz cushion made from $55 \%$ of the Histodenz/Nycodenz stock and $45 \%$ PBS. Parasites were harvested from the interface and collected by centrifugation at $500 \mathrm{~g}$ for $3 \mathrm{~min}$, resuspended in $25 \mathrm{~mL}$ Amaxa Basic Parasite Nucleofector solution (Lonza) and added to $10 \mu \mathrm{g}$ DNA dissolved in $10 \mu \mathrm{l} \mathrm{H}_{2} \mathrm{O}$. Cells were electroporated using the FI115 program of the Amaxa Nucleofector 4D. Transfected parasites were resuspended in $200 \mathrm{ml}$ fresh

745 RBCs and injected intraperitoneally into mice. Parasite selection with $0.07 \mathrm{mg} / \mathrm{mL}$ pyrimethamine (Sigma) in the drinking water $(\mathrm{pH} \sim 4.5)$ was initiated one day after infection.

\section{Toxoplasma gondii maintenance and transfection}

Toxoplasma gondii tachyzoites were grown in human foreskin fibroblasts (HFFs, American Type Culture Collection-CRL 1634) maintained in Dulbecco's Modified Eagle's Medium (DMEM, Gibco) supplemented

750 with $5 \%$ fetal calf serum (FCS), $2 \mathrm{mM}$ glutamine and $25 \mu \mathrm{g} / \mathrm{ml}$ gentamicin. Absence of Mycoplasma contamination was checked regularly by immunofluorescence. All mAiD fusion strains were generated in a Tir1 expressing cell line and depletion of protein achieved by incubation with $500 \mu \mathrm{M}$ of indole-3-acetic acid (IAA) as described in (Brown et al. 2017).

Freshly egressed tachyzoites were transfected by electroporation as previously described (Soldati-Favre

755 \& Boothroyd 1993). For each transfection, $40 \mu \mathrm{g}$ of specific gRNA was used to target the 3'UTR of the gene of interest. Mycophenolic acid $(25 \mathrm{mg} / \mathrm{mL})$ and xanthine $(50 \mathrm{mg} / \mathrm{mL})$ or pyrimethamine $(1 \mu \mathrm{g} / \mathrm{ml})$ were employed to select resistant parasites carrying the HXGPRT and DHFR cassette, respectively.

For assessment of protein depletion by plaque assays, HFFs were infected with fresh parasites and grown for 7 days before fixation with PFA/GA. After fixation, HFFs were washed with PBS and the host cells monolayer was stained with crystal violet. 
bioRxiv preprint doi: https://doi.org/10.1101/2021.11.03.466924; this version posted November 3, 2021. The copyright holder for this preprint (which was not certified by peer review) is the author/funder, who has granted bioRxiv a license to display the preprint in perpetuity. It is made available under aCC-BY-NC 4.0 International license.

For morphological analysis of cells depleted for kinetochore components, parasites were processed for immunofluorescence as described above and stained for tubulin, Centrin1 and DNA stains (Table S5). The mitotic index of cells was calculated in both induced and non-induced cells.

\section{Immunoblotting}

765 Immunoblotting was used to confirm expression of tagged proteins. Actively dividing cells were washed in PBS and resuspended at between $1-5 \times 10^{5}$ cells $\mu l^{-1}$. Lysis was in Laemmli buffer $(2 \% \mathrm{w} / \mathrm{v}$ SDS, $0.4 \mathrm{M}$ 2-mercaptoethanol, $10 \%$ glycerol, $50 \mathrm{mM}$ Tris- $\mathrm{HCl} \mathrm{pH} \mathrm{7.2)} \mathrm{at} 95^{\circ} \mathrm{C}$ for $5 \mathrm{~min}$. Lysates containing around $5 \times 10^{6}$ cells were separated on $4-20 \%$ polyacrylamide gels (Invitrogen) in running buffer (25 mM Tris, $250 \mathrm{mM}$ glycine and $0.1 \% \mathrm{w} / \mathrm{v}$ SDS). Proteins were electrophoretically transferred to $0.45 \mu \mathrm{m}$ pore-

770 size nitrocellulose membrane at $1.6 \mathrm{~V} \mathrm{~cm}^{-1}$ for $14 \mathrm{~h}$ in transfer buffer $(25 \mathrm{mM}$ Tris, $192 \mathrm{mM}$ glycine, $0.02 \%$ $\mathrm{w} / \mathrm{v}$ SDS and $10-20 \%$ methanol). Membranes were blocked and in $5 \% \mathrm{w} / \mathrm{v}$ milk powder in TBS-T (20 mM Tris- $\mathrm{HCl} \mathrm{pH} \mathrm{7.5,} 150 \mathrm{mM} \mathrm{NaCl}, 0.05 \%$ Tween-20) for $1 \mathrm{~h}$. Membranes were incubated in primary antibody (Table S5) in 1\% w/v milk in TBS-T for $1 \mathrm{~h}$ and washed in TBS-T. Detection was by secondary peroxidase-conjugated antibody (Table S5), in 1\% w/v milk in TBS-T for $1 \mathrm{~h}$. Membranes were washed

775 and detected by chemiluminescence with Western Lightning ECL (PerkinElmer) and exposure to photographic film.

\section{Protein localization}

For localization of tagged proteins in $P$. berghei by native fluorescence, cells from different proliferative stages during the parasite lifecycle were mounted in exflagellation medium (RPMI 1640 containing $78025 \mathrm{mM}$ HEPES, $4 \mathrm{mM}$ sodium bicarbonate, $5 \%$ fetal calf serum (FCS), $100 \mathrm{mM}$ xanthurenic acid, $\mathrm{pH}$ 7.8), and imaged using an inverted Zeiss Axio Observer Z1 microscope fitted with an Axiocam 506 mono 14 bit camera and Plan Apochromat 63x / 1.4 Oil DIC III objective.

For immunofluorescence of $T$. gondii, parasites were inoculated on an HFF monolayer with coverslips in 24-well plates, grown for 16-30 hours depending on the experiment, and fixed with cold methanol ($78520^{\circ} \mathrm{C}$ ) for $7 \mathrm{~min}$. Coverslips were then washed with PBS and blocked for $20 \mathrm{~min}$ in PBS-BSA 5\%. Primary and secondary antibodies (Table S5) were then incubated sequentially for 1 hour each in PBSBSA $2 \%$. Three washes of 5 minutes each were performed between primary and secondary antibodies incubations, using PBS. Coverslips were mounted in VECTASHIELD® Antifade Mounting Medium with DAPI and imaged using the inverted Zeiss Axio Observer, as described above.

790 For ultrastructure expansion microscopy (U-ExM), cells were sedimented on poly-D-lysine (A-003-E, Sigma) coverslips (150 $\mu \mathrm{L} /$ coverslip) during 10 minutes at room temperature (RT) and fixed in $-20^{\circ} \mathrm{C}$ methanol during 7 minutes and prepared for U-ExM as previously published (Bertiaux et al., 2021). Briefly, coverslips were incubated for 5 hours in $2 \mathrm{X} 1.4 \% \mathrm{AA} / 2 \% \mathrm{FA}$ mix at $37^{\circ} \mathrm{C}$ prior gelation in APS/Temed/Monomer solution (19\% Sodium Acrylate; 10\% AA; 0,1\% BIS-AA in PBS 10X) during 1 hour

795 at $37^{\circ} \mathrm{C}$. Gels were denatured at $95^{\circ} \mathrm{C}$ for 1 hour. Gels were incubated in $\mathrm{ddH}_{2} \mathrm{O}$ overnight for expansion. The following day, gels were washed in PBS before incubation with primary antibodies (Table S5) for 3 
hours at $37^{\circ} \mathrm{C}$. Gels were washed in PBS-Tween $0.1 \%$ prior incubation with secondary antibodies (Table S5) for 3 hours at $37^{\circ} \mathrm{C}$. Gels were washed in PBS-Tween $0.1 \%$. Gels were incubated in $\mathrm{ddH}_{2} \mathrm{O}$ for a second round of expansion before imaging. For NHS-ester staining, directly after antibody stainings 800 gels were incubated in NHS-Ester (Thermo Fisher Scientific catalog number: 46402) $10 \mu \mathrm{g} / \mathrm{mL}$ in PBS for 1 hour and 30 minutes at RT on a rocking platform and washed $3 x$ in PBS before overnight expansion. Confocal microscopy was performed on a Inverted Leica DMi8 with a HC PL Apo 100x/ 1.40 Oil immersion objective fitted with a Leica DFC7000T camera.

All images of fluorescent proteins were captured at RT with equal exposure settings. Images for level comparison were processed with the same alterations to minimum and maximum display levels. For analysis of relative positions of kinetochore components, peak locations of tagged proteins of focus centroids in each channel were calculated. Analysis was performed in Fiji (Schindelin et al., 2012) and the statistical programming package $\mathrm{R}$ (http ://www.r-project.org). Distances were always measured from dual staining experiments. The expansion factor of each gel was after applied to the value to obtain the

810 real distance.

\section{Immunopurification}

For the purification of kinetochore complexes, gametocytes were purified from 5-10 ml P. berghei infected mouse blood. Cells were washed twice in HKMEG (150 mM KCl, $150 \mathrm{mM}$ glucose, $25 \mathrm{mM}$ HEPES, $4 \mathrm{mM} \mathrm{MgCl2,} 1 \mathrm{mM}$ EGTA, pH7.8) containing $100 \mathrm{x}$ protease inhibitor cocktail and $20 \mu \mathrm{M}$

815 MG132. Sequential chemical cross-linking IP followed as described (D'Archivio \& Wickstead, 2017). Briefly, cells were treated with $0,0.1$, or $1 \%$ formaldehyde in HKMEG for 10 min, quenched with $10 \mathrm{ml}$ of $1 \mathrm{M}$ glycine, and lysed in HKMEG containing 1\% (vol/vol) Nonidet P-40, 0.5\% sodium deoxycholate, $0.1 \%$ SDS, $1 \mathrm{mM}$ dithiothreitol (DTT), $100 \times$ protease inhibitor cocktail and $20 \mu \mathrm{M}$ MG132. Lysate was sonicated in an Ultrasonic water bath for $20 \mathrm{~min}$ applied for $50 \%$ of the cycle and cleared by

820 centrifugation at $>20,000 \mathrm{~g}$ for $30 \mathrm{~min}$. The soluble fraction was then allowed to bind to affinity-purified rat anti-HA antibody (Sigma) attached to paramagnetic beads (Dynabeads protein G; Invitrogen) for 4 hours. Beads were washed in HKMEG containing $0.1 \%$ (vol/vol) Nonidet P-40, 0.5mM dithiothreitol. Beads were re-suspended in $100 \mu \mathrm{l}$ of $6 \mathrm{M}$ urea in $50 \mathrm{mM}$ ammonium bicarbonate (AB). $2 \mu \mathrm{l}$ of $50 \mathrm{mM}$ dithioerythritol (DTE) were added and the reduction was carried out at $37^{\circ} \mathrm{C}$ for $1 \mathrm{hr}$. Alkylation was

825 performed by adding $2 \mu \mathrm{l}$ of $400 \mathrm{mM}$ iodoacetamide for $1 \mathrm{hr}$ at room temperature in the dark. Urea was reduced to $1 \mathrm{M}$ by addition of $500 \mathrm{ml} \mathrm{AB}$ and overnight digestion was performed at $37^{\circ} \mathrm{C}$ with $5 \mathrm{ml}$ of freshly prepared $0.2 \mathrm{mg} / \mathrm{ml}$ trypsin (Promega) in AB. Supernatants were collected and completely dried under speed-vacuum. Samples were then desalted with a C18 microspin column (Harvard Apparatus) according to manufacturer's instructions, completely dried under speed-vacuum and stored at $-20^{\circ} \mathrm{C}$.

\section{Mass spectrometry}

Protein identification followed as described (Balestra et al., 2020). Samples were diluted in $20 \mu$ loading buffer ( $5 \%$ acetonitrile, $0.1 \%$ formic acid [FA]) and $2 \mu \mathrm{l}$ were injected onto the column. LC-ESI-MS/MS was performed either on a Q-Exactive Plus Hybrid Quadrupole-Orbitrap Mass Spectrometer (Thermo 
Fisher Scientific) equipped with an Easy nLC 1000 liquid chromatography system (Thermo Fisher

835 Scientific) or an Orbitrap Fusion Lumos Tribrid mass Spectrometer (Thermo Fisher Scientific) equipped with an Easy nLC 1200 liquid chromatography system (Thermo Fisher Scientific). Peptides were trapped on an Acclaim pepmap100, $3 \mu \mathrm{m}$ C18, $75 \mu \mathrm{m} \times 20 \mathrm{~mm}$ nano trap-column (Thermo Fisher Scientific) and separated on a $75 \mu \mathrm{m} \times 250 \mathrm{~mm}$ (Q-Exactive) or $500 \mathrm{~mm}$ (Orbitrap Fusion Lumos), $2 \mu \mathrm{m} \mathrm{C18,} 100 \mathrm{~A}^{\circ}$ Easy-Spray column (Thermo Fisher Scientific). The analytical separation used a gradient of $\mathrm{H}_{2} \mathrm{O} / 0.1 \%$ $840 \mathrm{FA}$ (solvent $\mathrm{A}$ ) and $\mathrm{CH}_{3} \mathrm{CN} / 0.1 \% \mathrm{FA}$ (solvent $\mathrm{B}$ ). The gradient was run as follows: 0 to $5 \mathrm{~min} 95 \% \mathrm{~A}$ and $5 \% \mathrm{~B}$, then to $65 \% \mathrm{~A}$ and $35 \% \mathrm{~B}$ for $60 \mathrm{~min}$, then to $10 \% \mathrm{~A}$ and $90 \% \mathrm{~B}$ for $10 \mathrm{~min}$ and finally for $15 \mathrm{~min}$ at $10 \% \mathrm{~A}$ and $90 \% \mathrm{~B}$. Flow rate was $250 \mathrm{~nL} / \mathrm{min}$ for a total run time of $90 \mathrm{~min}$. Data-dependent analysis (DDA) was performed on the Q-Exactive Plus with MS1 full scan at a resolution of 70,000 Full width at half maximum (FWHM) followed by MS2 scans on up to 15 selected precursors. MS1 was performed

845 with an AGC target of $3 \times 10^{6}$, a maximum injection time of $100 \mathrm{~ms}$ and a scan range from 400 to 2000 $\mathrm{m} / \mathrm{z}$. MS2 was performed at a resolution of $17,500 \mathrm{FWHM}$ with an automatic gain control (AGC) target at $1 \times 10^{5}$ and a maximum injection time of $50 \mathrm{~ms}$. Isolation window was set at $1.6 \mathrm{~m} / \mathrm{z}$ and $27 \%$ normalised collision energy was used for higher-energy collisional dissociation (HCD). DDA was performed on the Orbitrap Fusion Lumos with MS1 full scan at a resolution of 120,000 FWHM followed by as many

850 subsequent MS2 scans on selected precursors as possible within a $3 \mathrm{~s}$ maximum cycle time. MS1 was performed in the Orbitrap with an AGC target of $4 \times 10^{5}$, a maximum injection time of $50 \mathrm{~ms}$ and a scan range from 400 to $2000 \mathrm{~m} / \mathrm{z}$. MS2 was performed in the lon Trap with a rapid scan rate, an AGC target of $1 \times 10^{4}$ and a maximum injection time of $35 \mathrm{~ms}$. Isolation window was set at $1.2 \mathrm{~m} / \mathrm{z}$ and $30 \%$ normalised collision energy was used for HCD.

\section{Label-free quantitation}

Label-free quantitation followed as described (Brusini et al., 2021; D'Archivio \& Wickstead, 2017) and performed on .mgf data files using the Central Proteomics Facilities Pipeline (cpfp.sourceforge.io). Data were searched with X!Tandem and OMS SA engines against a custom, nonredundant protein database of predicted protein sequences from ANKA 2.34 strain including exogenous protein sequences

860 (fluorescent proteins, drug selection markers, and exogenous proteins expressed in the parental cells) and common contaminating peptides. Possible modification of peptides by $\mathrm{N}$-terminal acetylation, phosphorylation $(P)$, ubiquitination $(\mathrm{Ub})$, carbamidomethylation $(C)$, oxidation $(\mathrm{M})$, and deamidation $(\mathrm{N} / \mathrm{Q})$ was permitted in searches. Peptide identifications were validated with PeptideProphet and ProteinProphet (Nesvizhskii et al., 2003) and lists compiled at the peptide and protein level. iProphet was

865 used to combine search engine identifications and refine identifications and probabilities. Normalized spectral index quantitation (SINQ) was applied to the grouped metasearches to give protein-level quantitation between labelled samples and controls (Trudgian et al., 2011), and implemented by the Central Proteomics Facilities Pipeline. SINQ values are summed intensities of matched fragment ions for all spectra assigned to a peptide (identified by ProteinProphet), normalized for differences in protein

870 loading between datasets and for individual protein length. Proteins with 1 detected peptide and an estimated false discovery rate of $\leq 1 \%$ relative to a target-decoy database were considered. A total of 
780 distinguishable Plasmodium proteins were detected across all experiments. Mass spectrometry proteomics data have been deposited to the ProteomeXchange Consortium via the PRIDE (PerezRiverol et al., 2019) partner repository with the dataset identifier PXD028595. Processed data are also 875 provided in Table S2.

Enrichment and principal component analyses were performed in the statistical programming package 'R' (www.r-project.org). Quantitative values were analyzed as either log-transformed SINQ values (for principal component analysis) or log-transformed ratio of sample SINQ value versus control immunopurification (enrichment analysis).

\section{Bioinformatic analyses}

Searches were based on predicted protein datasets for 90 alveolate organisms from genomes and transcriptomes (Table S1), in addition to kinetochore protein sequences identified previously (van Hooff et al., 2017). For transcriptomes, ORFs were predicted using TransDecoder. Initial profiles for each identified apicomplexan kinetochore protein were aligned using MAFFT (Katoh et al., 2005), the L-INS-i

885 strategy, trimmed to conserved regions with trimAl, modelled by HMMER3 (Eddy, 2009) and searched to find similar sequences in all predicted proteomes and kinetochore sequences. Hits were added iteratively and used to create new profiles until no new sequences were identified. HMMs for all apicomplexan orthologous groups were also generated and defined by OrthoFinder (Emms \& Kelly, 2019). Alignments were visualized and modified using Jalview (Waterhouse et al., 2009). Profile-profile 890 comparisons were performed using $\mathrm{HH}$-suite3 (Söding, 2005). For phylogenies, trimmed alignments were used to infer maximum likelihood phylogenies using IQ-TREE2 (Minh et al., 2020). Trees were visualized in FigTree (tree.bio.ed.ac.uk/software/figtree) and Phytools (Revell, 2012), as part of the statistical programming package 'R' (www.r-project.org). 


\section{References}

Akiyoshi, B., \& Gull, K. (2014). Discovery of unconventional kinetochores in kinetoplastids. Cell, 156(6), 1247-1258.

Alvarez, C. A., \& Suvorova, E. S. (2017). Checkpoints of apicomplexan cell division identified in Toxoplasma gondii. PLoS Pathogens, 13(7), e1006483.

900 Aly, A. S. I., Vaughan, A. M., \& Kappe, S. H. I. (2009). Malaria parasite development in the mosquito and infection of the mammalian host. Annual Review of Microbiology, 63, 195-221.

Aravind, L., \& Landsman, D. (1998). AT-hook motifs identified in a wide variety of DNA-binding proteins. Nucleic Acids Research, 26(19), 4413-4421.

Arnot, D. E., \& Gull, K. (1998). The Plasmodium cell-cycle: facts and questions. Annals of Tropical Medicine and Parasitology, 92(4), 361-365.

Arnot, David E, Ronander, E., \& Bengtsson, D. C. (2011). The progression of the intra-erythrocytic cell cycle of Plasmodium falciparum and the role of the centriolar plaques in asynchronous mitotic division during schizogony. International Journal for Parasitology, 41(1), 71-80.

Balestra, A. C., Zeeshan, M., Rea, E., Pasquarello, C., Brusini, L., Mourier, T., Subudhi, A. K., Klages, N., Arboit, P., Pandey, R., Brady, D., Vaughan, S., Holder, A. A., Pain, A., Ferguson, D. J. P., Hainard, A., Tewari, R., \& Brochet, M. (2020). A divergent cyclin/cyclin-dependent kinase complex controls the atypical replication of a malaria parasite during gametogony and transmission. ELife, 9, 1-25.

Barylyuk, K., Koreny, L., Ke, H., Butterworth, S., Crook, O. M., Lassadi, I., Gupta, V., Tromer, E., Mourier, T., Stevens, T. J., Breckels, L. M., Pain, A., Lilley, K. S., \& Waller, R. F. (2020). A Comprehensive Subcellular Atlas of the Toxoplasma Proteome via hyperLOPIT Provides Spatial Context for Protein Functions. Cell Host \& Microbe, 28(5), 752-766.e9.

Berry, L., Chen, C.-T., Francia, M. E., Guerin, A., Graindorge, A., Saliou, J.-M., Grandmougin, M., Wein, S., Bechara, C., Morlon-Guyot, J., Bordat, Y., Gubbels, M.-J., Lebrun, M., Dubremetz, J.F., \& Daher, W. (2018). Toxoplasma gondii chromosomal passenger complex is essential for the organization of a functional mitotic spindle: a prerequisite for productive endodyogeny. Cellular and Molecular Life Sciences: CMLS, 75(23), 4417-4443.

Bertiaux, E., Balestra, A. C., Bournonville, L., Louvel, V., Maco, B., Soldati-Favre, D., Brochet, M., Guichard, P., \& Hamel, V. (2021). Expansion microscopy provides new insights into the cytoskeleton of malaria parasites including the conservation of a conoid. PLoS Biology, 19(3), e3001020.

Billker, O., Dechamps, S., Tewari, R., Wenig, G., Franke-Fayard, B., \& Brinkmann, V. (2004). Calcium and a calcium-dependent protein kinase regulate gamete formation and mosquito transmission in a malaria parasite. Cell, 117(4), 503-514.

930 Brooks, C. F., Francia, M. E., Gissot, M., Croken, M. M., Kim, K., \& Striepen, B. (2011). Toxoplasma gondii sequesters centromeres to a specific nuclear region throughout the cell cycle.

Proceedings of the National Academy of Sciences of the United States of America, 108(9), 3767-3772. https://doi.org/10.1073/pnas.1006741108 
Brusini, L., D’Archivio, S., McDonald, J., \& Wickstead, B. (2021). Trypanosome KKIP1 Dynamically Links the Inner Kinetochore to a Kinetoplastid Outer Kinetochore Complex. Frontiers in Cellular and Infection Microbiology, 11(March), 641174.

Bushell, E., Gomes, A. R., Sanderson, T., Anar, B., Girling, G., Herd, C., Metcalf, T., Modrzynska, K., Schwach, F., Martin, R. E., Mather, M. W., McFadden, G. I., Parts, L., Rutledge, G. G., Vaidya, A. B., Wengelnik, K., Rayner, J. C., \& Billker, O. (2017). Functional Profiling of a Plasmodium Genome Reveals an Abundance of Essential Genes. Cell, 170(2), 260-272.e8.

Carroll, C. W., Milks, K. J., \& Straight, A. F. (2010). Dual recognition of CENP-A nucleosomes is required for centromere assembly. The Journal of Cell Biology, 189(7), 1143-1155.

Cheeseman, I. M. (2014). The kinetochore. Cold Spring Harbor Perspectives in Biology, 6(7), a015826.

945 Cheeseman, I. M., Chappie, J. S., Wilson-Kubalek, E. M., \& Desai, A. (2006). The conserved KMN network constitutes the core microtubule-binding site of the kinetochore. Cell, 127(5), 983-997.

Cheeseman, I. M., \& Desai, A. (2008). Molecular architecture of the kinetochore-microtubule interface. Nature Reviews. Molecular Cell Biology, 9(1), 33-46.

Cohen, R. L., Espelin, C. W., De Wulf, P., Sorger, P. K., Harrison, S. C., \& Simons, K. T. (2008). Structural and functional dissection of Mif2p, a conserved DNA-binding kinetochore protein. Molecular Biology of the Cell, 19(10), 4480-4491.

Cortes-Silva, N., Ulmer, J., Kiuchi, T., Hsieh, E., Cornilleau, G., Ladid, I., Dingli, F., Loew, D., Katsuma, S., \& Drinnenberg, I. A. (2020). CenH3-Independent Kinetochore Assembly in Lepidoptera Requires CCAN, Including CENP-T. Current Biology: CB, 30(4), 561-572.e10.

955 D’Archivio, S., \& Wickstead, B. (2017). Trypanosome outer kinetochore proteins suggest conservation of chromosome segregation machinery across eukaryotes. The Journal of Cell Biology, 216(2), 379-391.

Dorin-Semblat, D., Schmitt, S., Semblat, J., Sicard, A., Reininger, L., Goldring, D., Patterson, S., Quashie, N., Chakrabarti, D., Meijer, L., \& Doerig, C. (2011). Plasmodium falciparum NIMArelated kinase Pfnek-1: sex specificity and assessment of essentiality for the erythrocytic asexual cycle. Microbiology (Reading, England), 157(Pt 10), 2785-2794.

Dubremetz, J. F. (1973). Ultrastructural study of schizogonic mitosis in the coccidian, Eimeria necatrix. Journal of Ultrastructure Research, 42(3), 354-376.

Eddy, S. R. (2009). A new generation of homology search tools based on probabilistic inference. Genome Informatics. International Conference on Genome Informatics, 23(1), 205-211.

Emms, D. M., \& Kelly, S. (2019). OrthoFinder: phylogenetic orthology inference for comparative genomics. Genome Biology, 20(1), 238.

Farrell, M., \& Gubbels, M. (2014). The Toxoplasma gondii kinetochore is required for centrosome association with the centrocone (spindle pole). Cellular Microbiology, 16(1), 78-94.

970 Foltz, D. R., Jansen, L. E. T., Black, B. E., Bailey, A. O., Yates, J. R., \& Cleveland, D. W. (2006). The human CENP-A centromeric nucleosome-associated complex. Nature Cell Biology, 8(5), 458469. 
Francia, M. E., Bhavsar, S., Ting, L. M., Croken, M. M., Kim, K., Dubremetz, J. F., \& Striepen, B. (2020). A Homolog of Structural Maintenance of Chromosome 1 Is a Persistent Centromeric Protein Which Associates With Nuclear Pore Components in Toxoplasma gondii. Frontiers in Cellular and Infection Microbiology, 10(July), 1-12.

Francia, M. E., \& Striepen, B. (2014). Cell division in apicomplexan parasites. Nature Reviews. Microbiology, 12(2), 125-136.

Fukagawa, T., \& Earnshaw, W. C. (2014). The centromere: chromatin foundation for the kinetochore machinery. Developmental Cell, 30(5), 496-508.

Gambarotto, D., Zwettler, F. U., Le Guennec, M., Schmidt-Cernohorska, M., Fortun, D., Borgers, S., Heine, J., Schloetel, J.-G., Reuss, M., Unser, M., Boyden, E. S., Sauer, M., Hamel, V., \& Guichard, P. (2019). Imaging cellular ultrastructures using expansion microscopy (U-ExM). Nature Methods, 16(1), 71-74.

Gascoigne, K. E., Takeuchi, K., Suzuki, A., Hori, T., Fukagawa, T., \& Cheeseman, I. M. (2011). Induced ectopic kinetochore assembly bypasses the requirement for CENP-A nucleosomes. Cell, 145(3), 410-422.

Gerald, N., Mahajan, B., \& Kumar, S. (2011). Mitosis in the human malaria parasite Plasmodium falciparum. Eukaryotic Cell, 10(4), 474-482.

990 Guse, A., Carroll, C. W., Moree, B., Fuller, C. J., \& Straight, A. F. (2011). In vitro centromere and kinetochore assembly on defined chromatin templates. Nature, 477(7364), 354-358.

Guttery, D. S., Ferguson, D. J. P., Poulin, B., Xu, Z., Straschil, U., Klop, O., Solyakov, L., Sandrini, S. M., Brady, D., Nieduszynski, C. a, Janse, C. J., Holder, A. a, Tobin, A. B., \& Tewari, R. (2012). A putative homologue of $\mathrm{CDC} 20 / \mathrm{CDH} 1$ in the malaria parasite is essential for male gamete development. PLoS Pathogens, 8(2), e1002554.

Hanisch, A., Silljé, H. H. W., \& Nigg, E. A. (2006). Timely anaphase onset requires a novel spindle and kinetochore complex comprising Ska1 and Ska2. The EMBO Journal, 25(23), 5504-5515.

He, D., Fiz-Palacios, O., Fu, C.-J., Fehling, J., Tsai, C.-C., \& Baldauf, S. L. (2014). An alternative root for the eukaryote tree of life. Current Biology: CB, 24(4), 465-470.

1000 Helgeson, L. A., Zelter, A., Riffle, M., MacCoss, M. J., Asbury, C. L., \& Davis, T. N. (2018). Human Ska complex and Ndc80 complex interact to form a load-bearing assembly that strengthens kinetochore-microtubule attachments. Proceedings of the National Academy of Sciences of the United States of America, 115(11), 2740-2745.

Hoeijmakers, W. A. M., Flueck, C., Françoijs, K., Smits, A. H., Wetzel, J., Volz, J. C., Cowman, A. F., Voss, T., Stunnenberg, H. G., \& Bártfai, R. (2012). Plasmodium falciparum centromeres display a unique epigenetic makeup and cluster prior to and during schizogony. Cellular Microbiology, 14(9), 1391-1401.

Iwanaga, S., Kaneko, I., \& Yuda, M. (2012). A high-coverage artificial chromosome library for the genome-wide screening of drug-resistance genes in malaria parasites. Genome Research, 1010 22(5), 985-992.

Iwanaga, S., Khan, S. M., Kaneko, I., Christodoulou, Z., Newbold, C., Yuda, M., Janse, C. J., \& Waters, A. P. (2010). Functional identification of the Plasmodium centromere and generation of 
a Plasmodium artificial chromosome. Cell Host \& Microbe, 7(3), 245-255.

Katoh, K., Kuma, K., Toh, H., \& Miyata, T. (2005). MAFFT version 5: improvement in accuracy of multiple sequence alignment. Nucleic Acids Research, 33(2), 511-518.

Kops, G. J. P. L., Snel, B., \& Tromer, E. C. (2020). Evolutionary Dynamics of the Spindle Assembly Checkpoint in Eukaryotes. Current Biology: CB, 30(10), R589-R602.

Koreny, L., Zeeshan, M., Barylyuk, K., Tromer, E. C., van Hooff, J. J. E., Brady, D., Ke, H., Chelaghma, S., Ferguson, D. J. P., Eme, L., Tewari, R., \& Waller, R. F. (2021). Molecular characterization of the conoid complex in Toxoplasma reveals its conservation in all apicomplexans, including Plasmodium species. PLoS Biology, 19(3), e3001081.

Kozgunova, E., Nishina, M., \& Goshima, G. (2019). Kinetochore protein depletion underlies cytokinesis failure and somatic polyploidization in the moss Physcomitrella patens. ELife, 8, 116.

Lampert, F., Hornung, P., \& Westermann, S. (2010). The Dam1 complex confers microtubule plus end-tracking activity to the Ndc80 kinetochore complex. The Journal of Cell Biology, 189(4), 641-649.

Lampert, F., Mieck, C., Alushin, G. M., Nogales, E., \& Westermann, S. (2013). Molecular requirements for the formation of a kinetochore-microtubule interface by Dam1 and Ndc80 complexes. The Journal of Cell Biology, 200(1), 21-30.

Lampson, M. A., \& Cheeseman, I. M. (2011). Sensing centromere tension: Aurora B and the regulation of kinetochore function. Trends in Cell Biology, 21(3), 133-140.

Mathur, V., Kolísko, M., Hehenberger, E., Irwin, N. A. T., Leander, B. S., Kristmundsson, Á., Freeman, M. A., \& Keeling, P. J. (2019). Multiple Independent Origins of Apicomplexan-Like Parasites. Current Biology: CB, 29(17), 2936-2941.e5.

Meraldi, P., McAinsh, A. D., Rheinbay, E., \& Sorger, P. K. (2006). Phylogenetic and structural analysis of centromeric DNA and kinetochore proteins. Genome Biology, 7(3), R23.

Miao, J., Fan, Q., Cui, L., Li, J., Li, J., \& Cui, L. (2006). The malaria parasite Plasmodium falciparum histones: organization, expression, and acetylation. Gene, 369(1-2), 53-65.

1040 Miller, M. P., Asbury, C. L., \& Biggins, S. (2016). A TOG Protein Confers Tension Sensitivity to Kinetochore-Microtubule Attachments. Cell, 165(6), 1428-1439.

Miller, M. P., Evans, R. K., Zelter, A., Geyer, E. A., MacCoss, M. J., Rice, L. M., Davis, T. N., Asbury, C. L., \& Biggins, S. (2019). Kinetochore-associated Stu2 promotes chromosome biorientation in vivo. PLoS Genetics, 15(10), e1008423.

1045 Minh, B. Q., Schmidt, H. A., Chernomor, O., Schrempf, D., Woodhams, M. D., von Haeseler, A., \& Lanfear, R. (2020). IQ-TREE 2: New Models and Efficient Methods for Phylogenetic Inference in the Genomic Era. Molecular Biology and Evolution, 37(5), 1530-1534.

Morahan, B. J., Abrie, C., Al-Hasani, K., Batty, M. B., Corey, V., Cowell, A. N., Niemand, J., Winzeler, E. A., Birkholtz, L.-M., Doerig, C., \& Garcia-Bustos, J. F. (2020). Human Aurora kinase inhibitor $1050 \quad$ Hesperadin reveals epistatic interaction between Plasmodium falciparum PfArk1 and PfNek1 kinases. Communications Biology, 3(1), 701. 
Morrissette, N. S., \& Sibley, L. D. (2002). Disruption of microtubules uncouples budding and nuclear division in Toxoplasma gondii. Journal of Cell Science, 115(Pt 5), 1017-1025.

Musacchio, A., \& Salmon, E. D. (2007). The spindle-assembly checkpoint in space and time. Nature Reviews. Molecular Cell Biology, 8(5), 379-393.

Nesvizhskii, A. I., Keller, A., Kolker, E., \& Aebersold, R. (2003). A statistical model for identifying proteins by tandem mass spectrometry. Analytical Chemistry, 75(17), 4646-4658.

Patzewitz, E.-M., Guttery, D. S., Poulin, B., Ramakrishnan, C., Ferguson, D. J. P., Wall, R. J., Brady, D., Holder, A. a, Szöör, B., \& Tewari, R. (2013). An ancient protein phosphatase, SHLP1, is critical to microneme development in Plasmodium ookinetes and parasite transmission. Cell Reports, 3(3), 622-629.

Perez-Riverol, Y., Csordas, A., Bai, J., Bernal-Llinares, M., Hewapathirana, S., Kundu, D. J., Inuganti, A., Griss, J., Mayer, G., Eisenacher, M., Pérez, E., Uszkoreit, J., Pfeuffer, J., Sachsenberg, T., Yilmaz, S., Tiwary, S., Cox, J., Audain, E., Walzer, M., ... Vizcaíno, J. A. (2019). The PRIDE database and related tools and resources in 2019: improving support for quantification data. Nucleic Acids Research, 47(D1), D442-D450.

Perrin, A. J., Bisson, C., Faull, P. A., Renshaw, M. J., Lees, R. A., Fleck, R. A., Saibil, H. R., Snijders, A. P., Baker, D. A., \& Blackman, M. J. (2021). Malaria Parasite Schizont Egress Antigen-1 Plays an Essential Role in Nuclear Segregation during Schizogony. MBio, 12(2), 116.

Petrovic, A., Pasqualato, S., Dube, P., Krenn, V., Santaguida, S., Cittaro, D., Monzani, S., Massimiliano, L., Keller, J., Tarricone, A., Maiolica, A., Stark, H., \& Musacchio, A. (2010). The MIS12 complex is a protein interaction hub for outer kinetochore assembly. The Journal of Cell Biology, 190(5), 835-852.

Pfander, C., Anar, B., Schwach, F., Otto, T. D., Brochet, M., Volkmann, K., Quail, M. A., Pain, A., Rosen, B., Skarnes, W., Rayner, J. C., \& Billker, O. (2011). A scalable pipeline for highly effective genetic modification of a malaria parasite. Nature Methods, 8(12), 1078-1082.

Przewloka, M. R., Venkei, Z., Bolanos-Garcia, V. M., Debski, J., Dadlez, M., \& Glover, D. M. (2011). CENP-C is a structural platform for kinetochore assembly. Current Biology: CB, 21(5), 399405.

Przewloka, M. R., Zhang, W., Costa, P., Archambault, V., D’Avino, P. P., Lilley, K. S., Laue, E. D., McAinsh, A. D., \& Glover, D. M. (2007). Molecular analysis of core kinetochore composition and assembly in Drosophila melanogaster. PloS One, 2(5), e478.

Revell, L. J. (2012). phytools: An R package for phylogenetic comparative biology (and other things). Methods in Ecology and Evolution, 3(2), 217-223.

Schindelin, J., Arganda-Carreras, I., Frise, E., Kaynig, V., Longair, M., Pietzsch, T., Preibisch, S., Rueden, C., Saalfeld, S., Schmid, B., Tinevez, J.-Y., White, D. J., Hartenstein, V., Eliceiri, K., Tomancak, P., \& Cardona, A. (2012). Fiji: an open-source platform for biological-image analysis. Nature Methods, 9(7), 676-682.

1090 Screpanti, E., De Antoni, A., Alushin, G. M., Petrovic, A., Melis, T., Nogales, E., \& Musacchio, A. (2011). Direct binding of Cenp-C to the Mis12 complex joins the inner and outer kinetochore. 
Current Biology: CB, 21(5), 391-398.

Sidik, S. M., Huet, D., Ganesan, S. M., Huynh, M.-H., Wang, T., Nasamu, A. S., Thiru, P., Saeij, J. P. J., Carruthers, V. B., Niles, J. C., \& Lourido, S. (2016). A Genome-wide CRISPR Screen in Toxoplasma Identifies Essential Apicomplexan Genes. Cell, 166(6), 1423-1435.e12.

Söding, J. (2005). Protein homology detection by HMM-HMM comparison. Bioinformatics (Oxford, England), 21(7), 951-960.

Speer, C. A., \& Dubey, J. P. (2001). Ultrastructure of schizonts and merozoites of Sarcocystis neurona. Veterinary Parasitology, 95(2-4), 263-271.

1100 Striepen, B., Jordan, C. N., Reiff, S., \& van Dooren, G. G. (2007). Building the perfect parasite: cell division in apicomplexa. PLoS Pathogens, 3(6), e78.

Trelle, M. B., Salcedo-Amaya, A. M., Cohen, A. M., Stunnenberg, H. G., \& Jensen, O. N. (2009). Global histone analysis by mass spectrometry reveals a high content of acetylated lysine residues in the malaria parasite Plasmodium falciparum. Journal of Proteome Research, 8(7),

$1105 \quad 3439-3450$.

Tromer, E. C., van Hooff, J. J. E., Kops, G. J. P. L., \& Snel, B. (2019). Mosaic origin of the eukaryotic kinetochore. Proceedings of the National Academy of Sciences of the United States of America, 116(26), 12873-12882.

Tromer, E. C., Wemyss, T. A., Ludzia, P., Waller, R. F., \& Akiyoshi, B. (2021). Repurposing of synaptonemal complex proteins for kinetochores in Kinetoplastida. Open Biology, 11(5), 210049.

Trudgian, D. C., Ridlova, G., Fischer, R., Mackeen, M. M., Ternette, N., Acuto, O., Kessler, B. M., \& Thomas, B. (2011). Comparative evaluation of label-free SINQ normalized spectral index quantitation in the central proteomics facilities pipeline. Proteomics, 11(14), 2790-2797.

1115 van Hooff, J. J., Tromer, E., van Wijk, L. M., Snel, B., \& Kops, G. J. (2017). Evolutionary dynamics of the kinetochore network in eukaryotes as revealed by comparative genomics. EMBO Reports, 18(9), 1559-1571.

Varma, D., \& Salmon, E. D. (2012). The KMN protein network--chief conductors of the kinetochore orchestra. Journal of Cell Science, 125(Pt 24), 5927-5936.

1120 Verma, G., \& Surolia, N. (2014). The dimerization domain of PfCENP-C is required for its functions as a centromere protein in human malaria parasite Plasmodium falciparum. Malaria Journal, $13,475$.

Verma, G., \& Surolia, N. (2018). Centromere and its associated proteins-what we know about them in Plasmodium falciparum. IUBMB Life, 70(8), 732-742.

1125 Volz, J., Carvalho, T. G., Ralph, S. A., Gilson, P., Thompson, J., Tonkin, C. J., Langer, C., Crabb, B. S., \& Cowman, A. F. (2010). Potential epigenetic regulatory proteins localise to distinct nuclear sub-compartments in Plasmodium falciparum. International Journal for Parasitology, 40(1), $109-121$.

Wall, R. J., Ferguson, D. J. P., Freville, A., Franke-Fayard, B., Brady, D., Zeeshan, M., Bottrill, A. R., Wheatley, S., Fry, A. M., Janse, C. J., Yamano, H., Holder, A. A., Guttery, D. S., \& Tewari, R. 
(2018). Plasmodium APC3 mediates chromosome condensation and cytokinesis during atypical mitosis in male gametogenesis. Scientific Reports, 8(1), 5610.

Waterhouse, A. M., Procter, J. B., Martin, D. M. A., Clamp, M., \& Barton, G. J. (2009). Jalview Version 2--a multiple sequence alignment editor and analysis workbench. Bioinformatics (Oxford, England), 25(9), 1189-1191.

Weir, J. R., Faesen, A. C., Klare, K., Petrovic, A., Basilico, F., Fischböck, J., Pentakota, S., Keller, J., Pesenti, M. E., Pan, D., Vogt, D., Wohlgemuth, S., Herzog, F., \& Musacchio, A. (2016). Insights from biochemical reconstitution into the architecture of human kinetochores. Nature, 537(7619), 249-253.

1140 Welburn, J. P. I., Grishchuk, E. L., Backer, C. B., Wilson-Kubalek, E. M., Yates, J. R., \& Cheeseman, I. M. (2009). The human kinetochore Ska1 complex facilitates microtubule depolymerizationcoupled motility. Developmental Cell, 16(3), 374-385.

Westermann, S., \& Schleiffer, A. (2013). Family matters: structural and functional conservation of centromere-associated proteins from yeast to humans. Trends in Cell Biology, 23(6), 260-269.

1145 Westhorpe, F. G., \& Straight, A. F. (2013). Functions of the centromere and kinetochore in chromosome segregation. Current Opinion in Cell Biology, 25(3), 334-340.

Xiao, H., Wang, F., Wisniewski, J., Shaytan, A. K., Ghirlando, R., FitzGerald, P. C., Huang, Y., Wei, D., Li, S., Landsman, D., Panchenko, A. R., \& Wu, C. (2017). Molecular basis of CENP-C association with the CENP-A nucleosome at yeast centromeres. Genes \& Development, $1150 \quad 31(19), 1958-1972$.

Zeeshan, M., Pandey, R., Ferguson, D. J. P., Tromer, E. C., Markus, R., Abel, S., Brady, D., Daniel, E., Limenitakis, R., Bottrill, A. R., Le Roch, K. G., Holder, A. A., Waller, R. F., Guttery, D. S., \& Tewari, R. (2020). Real-time dynamics of Plasmodium NDC80 reveals unusual modes of chromosome segregation during parasite proliferation. Journal of Cell Science, 134(5),

1155 jcs.245753.

Zeeshan, M., Shilliday, F., Liu, T., Abel, S., Mourier, T., Ferguson, D. J. P., Rea, E., Stanway, R. R., Roques, M., Williams, D., Daniel, E., Brady, D., Roberts, A. J., Holder, A. A., Pain, A., Le Roch, K. G., Moores, C. A., \& Tewari, R. (2019). Plasmodium kinesin-8X associates with mitotic spindles and is essential for oocyst development during parasite proliferation and transmission. PLoS Pathogens, 15(10), e1008048.

Zhang, M., Wang, C., Otto, T. D., Oberstaller, J., Liao, X., Adapa, S. R., Udenze, K., Bronner, I. F., Casandra, D., Mayho, M., Brown, J., Li, S., Swanson, J., Rayner, J. C., Jiang, R. H. Y., \& Adams, J. H. (2018). Uncovering the essential genes of the human malaria parasite Plasmodium falciparum by saturation mutagenesis. Science (New York, N. Y.), 360(6388). 